4 nordon 



\section{Digital applications and movement tracking forms according to EG-legislation 1013/2006}


Digital applications and movement tracking forms according to EG-legislation 1013/2006

TemaNord 2010:560

(C) Nordic Council of Ministers, Copenhagen 2010

ISBN 978-92-893-2111-2

Print: Kailow Express ApS

Cover photo: Volvo

Copies: 0

Printed on environmentally friendly paper

This publication can be ordered on www.norden.org/order. Other Nordic publications are available at www.norden.org/publications

Printed in Denmark

Nordic Council of Ministers

Ved Stranden 18

DK-1061 København K

Phone (+45) 33960200

Fax (+45) 33960202

www.norden.org

\author{
Nordic Council \\ Ved Stranden 18 \\ DK-1061 København K \\ Phone (+45) 33960400 \\ Fax (+45) 33111870
}

\section{Nordic co-operation}

Nordic co-operation is one of the world's most extensive forms of regional collaboration, involving Denmark, Finland, Iceland, Norway, Sweden, and three autonomous areas: the Faroe Islands, Greenland, and Åland.

Nordic co-operation has firm traditions in politics, the economy, and culture. It plays an important role in European and international collaboration, and aims at creating a strong Nordic community in c strong Europe.

Nordic co-operation seeks to safeguard Nordic and regional interests and principles in the global community. Common Nordic values help the region solidify its position as one of the world's most innovative and competitive. 


\section{Content}

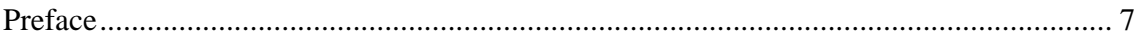

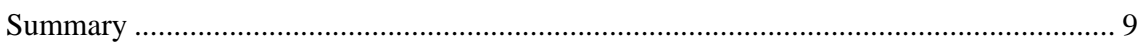

Digital reporting for transboundary movements of waste ........................................ 9

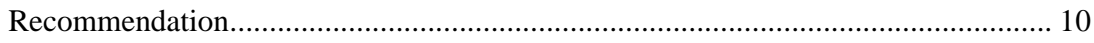

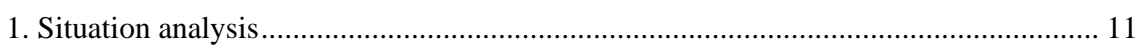

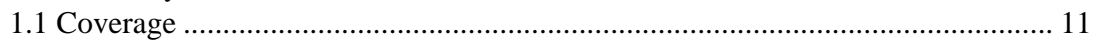

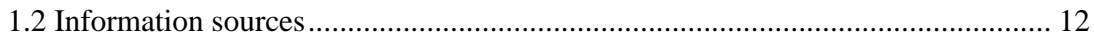

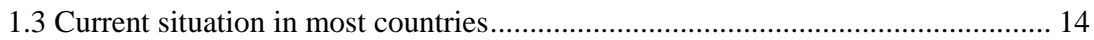

1.4 National and International projects.............................................................. 17

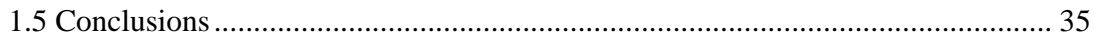

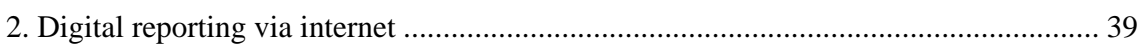

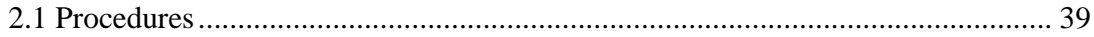

2.2 Notification Procedure …........................................................................... 40

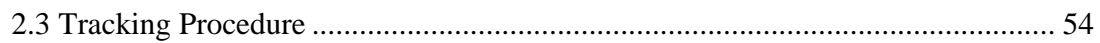

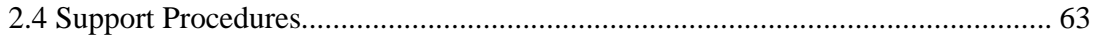

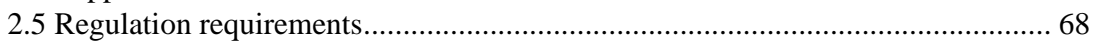

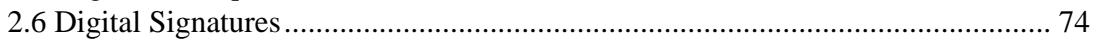

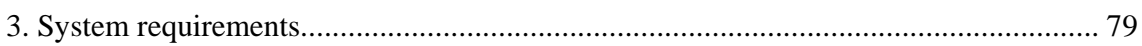

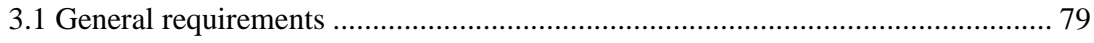

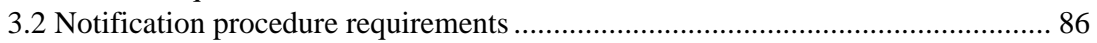

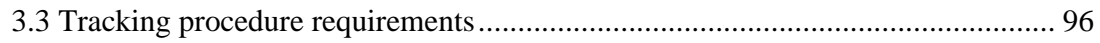

3.4 Support procedures requirements ..................................................................... 104

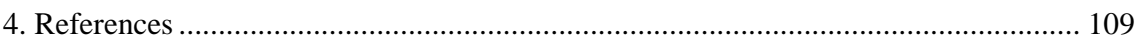

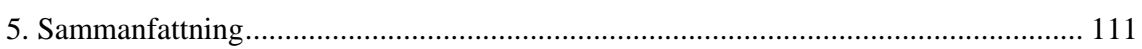

5.1 Digital rapportering för gränsöverskridande transporter av avfall....................... 111

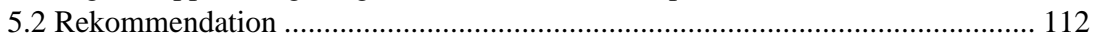

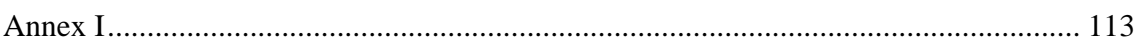

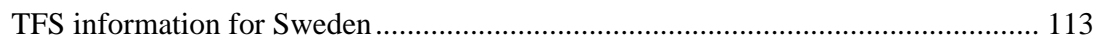

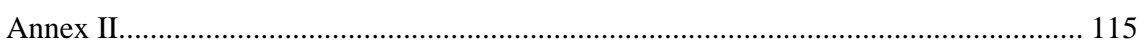

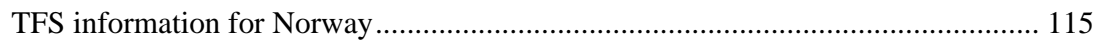

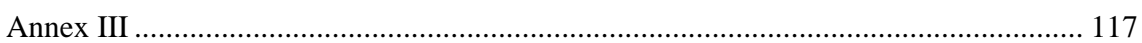

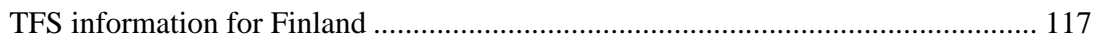

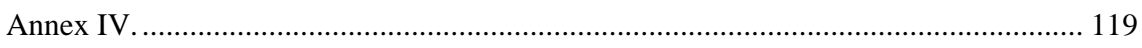

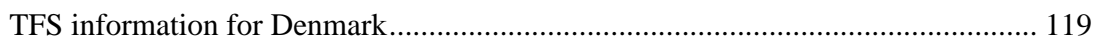

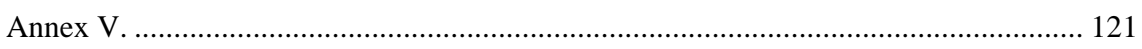

Other examined countries WebPages on transboundary movements of waste .......... 121 



\section{Preface}

Regulatory framework surrounding transboundary movements of waste are common to EU member countries. It is a comprehensive regulatory framework that governs how the process to make a notification of transboundary movements of waste should be conducted. The current process is mainly paper based and requires considerable amount of resources and most of the work involved in the process is also repeated by each of the involved participants which makes the process unnecessarily slow and cumbersome making it difficult to adhere to the regulatory framework. The Nordic Waste Group therefore sees great potential for the Nordic countries to establish a common digital process for digital applications and movement tracking forms according to EG-legislation 1013/2006. This project aims to make a situation analysis to see what systems exist for this kind of reporting in other countries and also make a study with the specifications for how a Nordic system can be devised.

The Nordic Waste Group had appointed a steering committee which followed the progress of the project. The committee had the following representatives:

- Ulrika Hagelin, Naturvårdsverket, Sweden

- Noman Ahmed and Magdalena Kwarta, Klima- og forurensningsdirektoratet, Norway

- Dorte Skjøtt Jakobsen, Miljøstyrelsen, Denmark

- Hannele Nikander, SYKE, Finland

The project has been carried out by the consultant firm Devoteam Quaint. Jörgen Karlsson has been responsible from Devoteam Quaint.

The steering committee wants to thank all participants for all their work in this project.

Östersund in February 2010

Ingela Hiltula

Committee Chairman 



\section{Summary}

\section{Digital reporting for transboundary movements of waste}

This report contain a situation analysis and a proposed solution for the Nordic countries to manage the notification and tracking procedures with digital reporting instead of the paper based procedures used today. The situation analysis covered all of the $27 \mathrm{EU}$-member states as well as three other countries.

As far as this report have been able to conclude none of the examined countries has a digital solution for all of procedures involved and only three of the countries have a national or regional solution for the digital reporting within the tracking procedure. However several of the countries seem to have implemented or are in the process of implementing digital reporting as a concept for other types of procedures (e.g. national waste reporting).

The majority of the examined countries still use the paper based process and are expected to continue doing this in the coming years due to the low number of ongoing projects with the aim of digital reporting within the TFSprocedure ${ }^{1} \mathrm{~s}$.

Digital reporting within the TFS-procedures can reduce administrative work, increase quality and speed up the information exchange between the involved stakeholders as well as save valuable time and resources that could be allocated to further inspection and control measures instead of using them on administrative work. The solution for digital reporting in this report suggest a Nordic TFS-system which cover both the notification and the tracking procedures and even if it is suggested to be limited to the Nordic countries at the initial stage it is designed to easily allow additional participating countries. The main components of the solution encompass the following activities

- Registration of stakeholders

- Digital registration of export notifications

- Digital registration of non-Nordic import notifications

- Export/Import of Notification data by XML to National TFS-systems

- Automatic acknowledgements by e-mail

- Registration of decision data

- Digital reporting of shipment

- Automated annual Basel-reporting

The solution design is based on the assumption that not all countries will participate and that certain key documents (e.g. original notification, move-

\footnotetext{
${ }^{1} \mathrm{TFS}=$ transfrontier shipments of waste
} 
ment documents and financial guarantee etc.) remain in paper while replacing "copies" with electronic copies, digital reporting and e-mail.

This approach of the solution allows for a gradual implementation, making the addition of additional countries relatively easy and reaps many of the benefits without requiring large investments in IT-infrastructure for the involved stakeholders.

\section{Recommendation}

Based on the findings of this report, the author recommends the competent authorities of the Nordic countries (Denmark, Norway, Finland and Sweden) to design and build a Nordic TFS-system for digital reporting based on the proposed solution and with the functionality and features described in chapter 2 and chapter 3 of this report.

This could be done as a continuous project with design, detailed requirements, development, test and implementation or it could be separated into two projects where the first deliver a complete solution with system specifications etc. followed by another which construct, test and implement the Nordic TFS-system.

The projects should be a joint operation between representatives from the Nordic competent authorities, representatives from the private sector and ITconsultants specialized in the design and construction of internet applications. Financing and ownership of the Nordic TFS-system could be solved in several ways with one approach being a joint financed and co-owned system with a one-time payment followed by a joint responsibility for maintenance and annual maintenance costs. An alternative to this could be to keep national ownership of the stored data while purchasing annual licenses for the use of a TFS-system owned and maintained by a private company.

The Nordic TFS-system is recommended to be completed as a complete package covering both the notification and tracking procedures according to the requirements of chapter 2 and chapter 3 of this report. If this is considered too expensive or time-consuming the alternative recommendation is to build a system that covers the tracking procedure with the addition of the registration of decision data.

Further addition of participating countries should be done after the system have been completed and tested by the Nordic countries and should be concentrated on non-Nordic countries ${ }^{2}$ with as large number of annual notifications regarding waste movements to or from a Nordic country for maximization of the benefits.

\footnotetext{
${ }^{2}$ See Annex I, II, III and IV for waste flow information to and from the Nordic countries.
} 


\section{Situation analysis}

\subsection{Coverage}

The focus of the situation analysis chapter for this report have been to investigate which (if any) of the (primarily EU) countries have established or are in the process of launching electronic applications in support of the specific processes involved in the transboundary movements of waste in accordance to the EG-legislation 1013/2006

Primary focus of the situation analysis have been to identify projects or applications that can replace the paper based processing of applications and/or movement tracking forms between waste operators and the competent authorities in the involved countries with an electronic solution in appliance with the current EG-legislation.

This report cover all of the 27 EU-members including three of the OECD members that are not members of EU (Iceland, Norway and Canada) as well as the country of Taiwan (which were included based on the knowledge that they use internet based system for reporting of transboundary movements of waste).

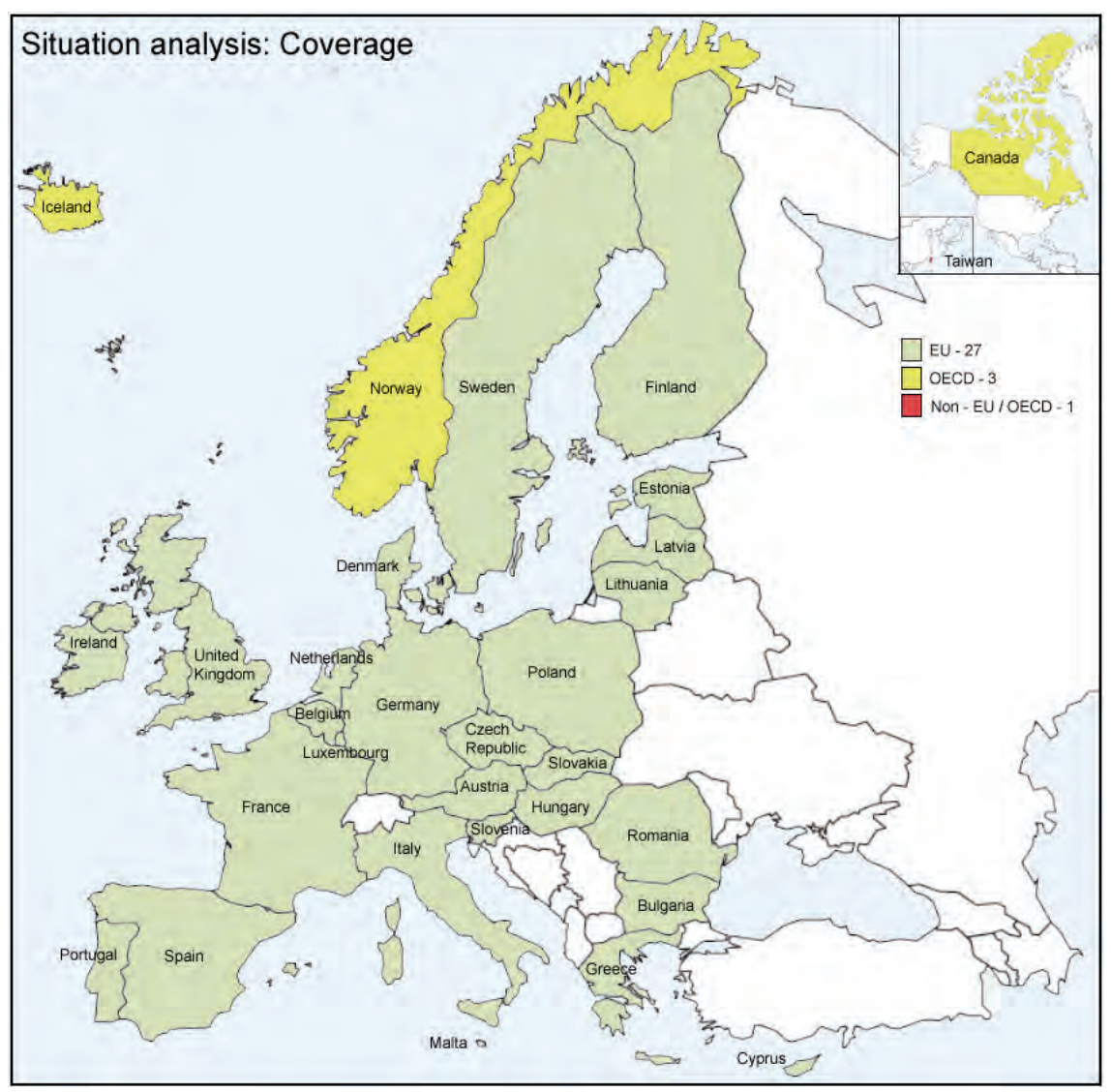




\subsection{Information sources}

The data and information contained in the situation analysis is based almost entirely upon public sources. The primary sources of information on each country or project have been:

- Ministry of Environment WebPages

- Environmental protection agency WebPages

- Specific project WebPages and reports

- IMPEL ${ }^{3}$ reports

- Workgroup meetings (documentation and presentations)

Since most (with the exception of three or four member states ${ }^{4}$ ) present only cursory information about transboundary movements of waste in other than their native language this pre-study were forced to examine the WebPages in each of the countries native language.

While this have been essential and given a better understanding of the publicly available information it has also been slightly more timeconsuming (due to the need of translation) than if the information had been available in one of the major languages. One problem however is the possibility that information might have been lost or misinterpreted during translation from a native non-English language.

\subsubsection{Several competent authorities in a single country}

In 7 out of the $27 \mathrm{EU}$-member countries the responsibilities of authorizing transboundary movements is divided. In those countries there are several competent authorities involved in the process. Each competent authority often has responsibilities based on import or export for a specific geographic region, waste type (e.g. manure) or all transit applications.

\footnotetext{
${ }^{3}$ IMPEL - Implementation and Enforcement of Environmental Law.

${ }^{4}$ Finland, Bulgaria and Hungary are amongst the countries that to some extent provide multilanguage support on transboundary movement of waste process.
} 


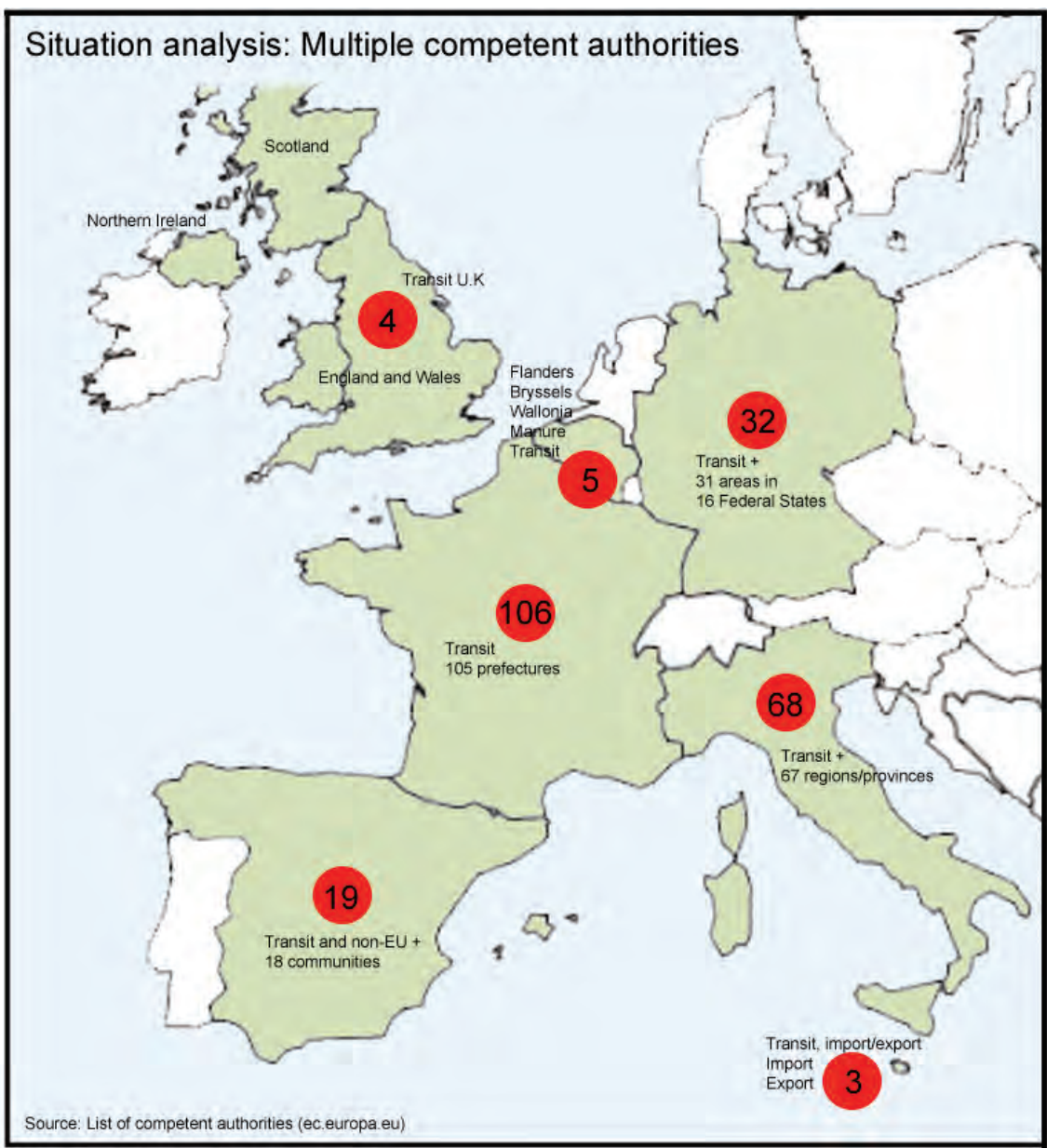

Source: list of competent authorities (ec.europa.eu). Overview of countries with more than one competent authority.

In the cases of France, Italy and Germany (the countries with the most number of competent authorities) the pre-study have not had the necessary time to cover all of the departments, regions and areas due to the large amount of WebPages involved.

Instead of trying to cover all competent authorities, coverage in the cases of multiple competent authorities were concentrated to each of those countries competent authority on transit as well as selected local competent authorities. Those covered are the ones which have been involved in the IM$\mathrm{PEL}^{5}$ meetings or is participating in a relevant project.

The author do not believe that the exclusion of several local authorities in this pre-study have affected the findings of the report in a major way. The case being that most local competent authorities have limited resources (both human and financial) to invest in the kind of electronic applications and infrastructure that is needed to enable notifiers and the authorities to handle the transboundary movements of waste in accordance to ECregulation.

\footnotetext{
${ }^{5}$ IMPEL - Implementation and Enforcement of Environmental Law.
} 


\subsubsection{Transboundary movement of waste information on internet}

Most of the EU-member (and OECD) countries publish specific information (e.g. regulations, forms and useful links) on the transboundary movement of waste on their WebPages. Each country has a different collection of documents, facts, links, services and applications made available to the involved stakeholders ${ }^{6}$.

For six out of the 27 EU-member countries the pre-study were unable to find any public information regarding transboundary movements of waste on the competent authorities' WebPages as well as on the Ministry of Environment WebPages. For all other countries links that have been found to the specific pages on transboundary movements of waste have been included in the appendix for further reference.

Please observe that most of those links refer to WebPages in the native language of the member country except in cases where the exact same page was available in English.

\subsection{Current situation in most countries}

After reviewing the WebPages published by the competent authorities on transboundary movements of waste, reading the reports of IMPEL and numerous reports from different workgroups it seems that a majority of the EU (and OECD) member states share the same situation on the subject of managing and controlling transboundary movements of waste.

Instead of listing each of the $27 \mathrm{EU}$ members and the 3 OECD countries with descriptions that in most cases are almost identical, this pre-study will present the most common situation for a competent authority in regard of managing the transboundary movements of waste. For more detailed information on each country visit the competent authority webpage provided in the appendix.

In addition to this typical situation there will be presentations of countries and projects which have progressed further than this typical situation by offering a more automated way of handling the transboundary movement of waste process (see 1.4 National and International projects).

\footnotetext{
${ }^{6}$ E.g. Wasteproducers, wastebrokers, waste carriers, recovery- and disposal facilities.
} 


\subsubsection{Typical situation in the majority of the examined countries}

The most common situation is described below and applies in most parts to 22 of the 31 countries examined during this pre-study.

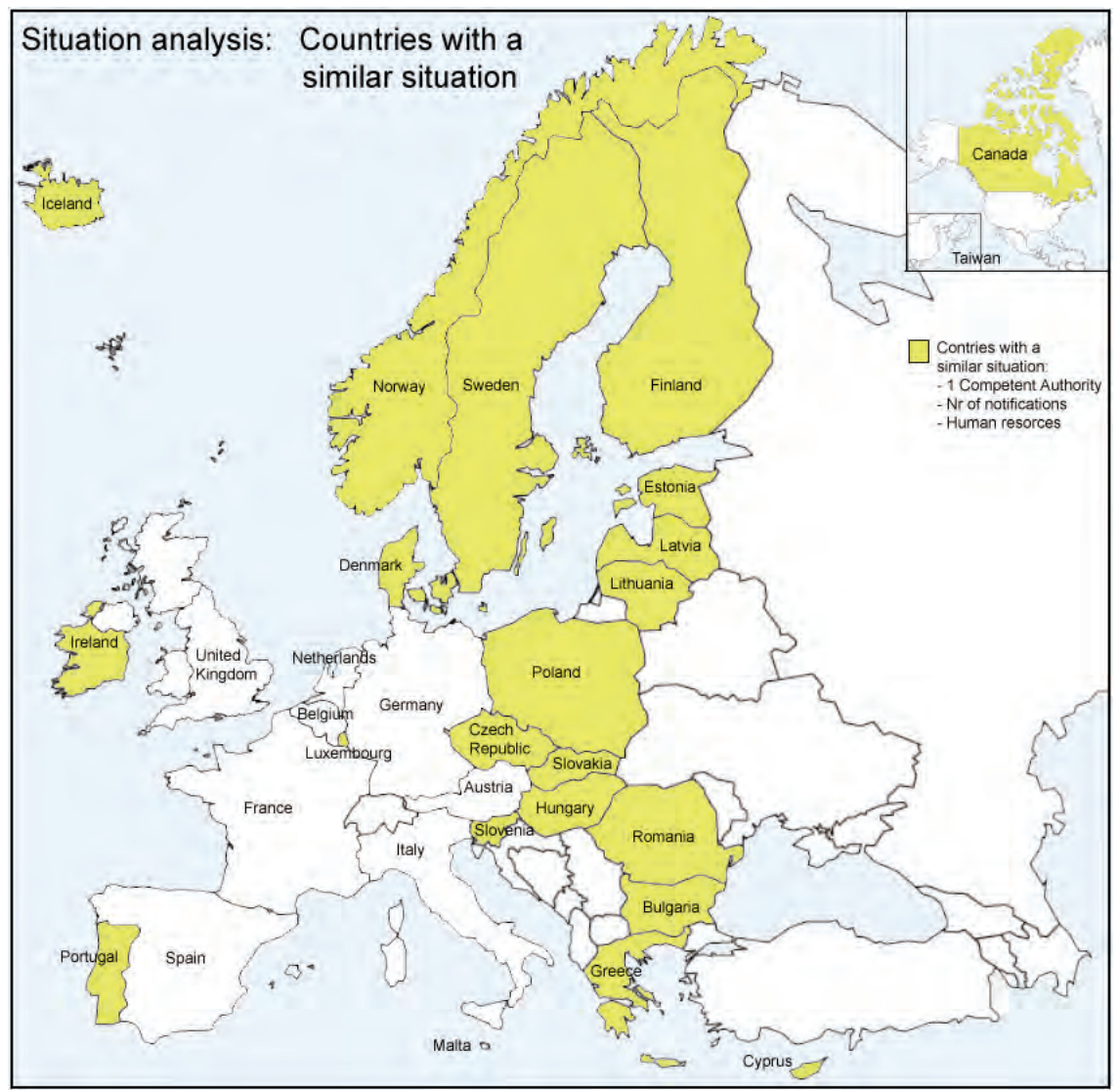

- 1 Competent authority on a national level is responsible for granting permits for transboundary movements of waste

- Customs and police authorities responsible for enforcement actions

- Low and/or infrequent cooperation and information exchange between the different authorities involved (national as well as international). Information exchange is often limited to paper based copies of approved notifications

- The competent authority have 3-6 TFS experts that handle notification and movement documents

- Handle approximately 130-600 notification applications annually

- Have a paper based process for notification and movement documents

- Have one or more internal IT-systems for the registration of notification and movement documents. Access to these systems is limited to the competent authority only.

- Hosts a webpage (in the native language) with the following information mainly targeted at native stakeholders in their roles as waste producers, waste carriers and waste receivers 
- News (transboundary movements of waste area)

- Guidelines (e.g. when and how to apply, how to complete forms)

- Legislation and regulations (e.g. EG 1013/2006, National legislation)

- FAQ (Frequently Asked Questions within the subject)

- Waste lists

- Examples of forms for Notification and Movement documents

- Links to useful external sources (e.g. Basel Convention, OECD)

- Do not publish the approved notifications on the internet (some countries ${ }^{7}$ however publish decisions on notification documents on the Internet)

- Do not offer any e-services or applications within the area of transboundary movements of waste

- Lacks the human and financial resources to develop an efficient and automated digital process between notifiers and the competent authority as well as the IT-infrastructure needed

- Lack of electronic exchange of notification documents between involved authorities complicates the meeting of deadlines of the ECregulation

- Have trouble with the use of foreign languages in import notification documents

- Express the need of an EU wide electronic notification system before concurrent and incompatible systems have been established

- Hosted or participated in one or more "Information Exchange and Awareness Raising Events on SHIPMENT of Waste" ${ }^{8}$ and have established contact with respective competent authorities in neighbouring countries

\footnotetext{
${ }^{7}$ Netherlands, Belgium, Finland, Malta, Poland, Slovakia and Taiwan.

${ }^{8}$ Source: http://www.bipro.de/waste-events.
} 


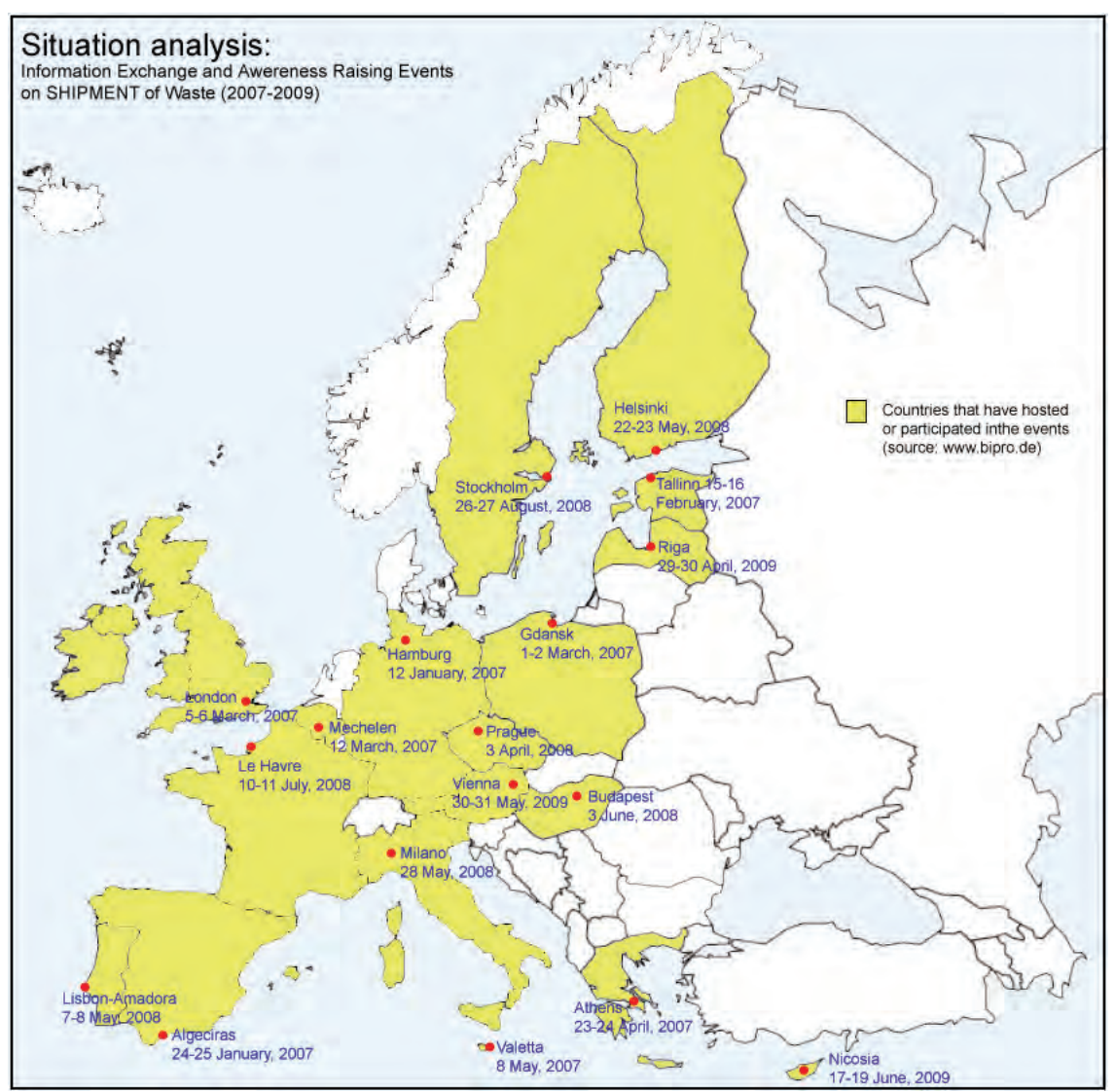

Information Exchange and Awareness Raising Events on SHIPMENT of Waste in 2007-2009.

\subsection{National and International projects}

This chapter contains national and international projects that this pre-study have found to have the goal of automating the processes of movement of waste in one or more ways. The projects are mostly national initiatives and differ widely in size, choice of solution and coverage of the different processes within the movement of waste area.

After examining all of the $27 \mathrm{EU}$ member states and the selected OECD countries this study found that there seem to be a relatively low number of initiatives with the specific goal of enhancing the notification process within the transboundary movements of waste area.

In several of the IMPEL reports that address the movements of waste, as well as in many of reports from national workgroup meetings between 2007-2009, member states seem to express the need of an EU wide electronic notification system.

So why is it that there aren't more initiatives addressing the automation of the processes involved in transboundary movement of waste? There are probably several reasons for this, but some explanations for the lack of more initiatives in this area might be due to the following reasons: 
- Legislation up until recently demanded signed paper copies throughout the process of transboundary movement of waste

- Difficulties in developing and managing projects involving several countries (e.g. language barriers, funding, legislation)

- Developing and deploying a solution that can be accepted and fits all countries are expensive and consumes large amounts of time and funding

- The technical possibilities within the IT-infrastructure have been limited and have in some cases been available only for the last couple of years (e.g. secure digital signatures, GPS tracking devices etc)

- Many of the competent authorities are short-staffed and lack the necessary funding to participate or start these kind of initiatives

During this pre-study 14 projects/system was found related in some way to the movement of waste area or used technology that include use of digital signatures, smart cards or chip-technology. Most of the projects found are related to national waste management and do not specifically cover the transboundary movement of waste process. The four most relevant and interesting projects/systems that this pre-study found have been covered in detail below and the remaining nine have only been briefly covered since they do not directly affect the transboundary movement of waste process.

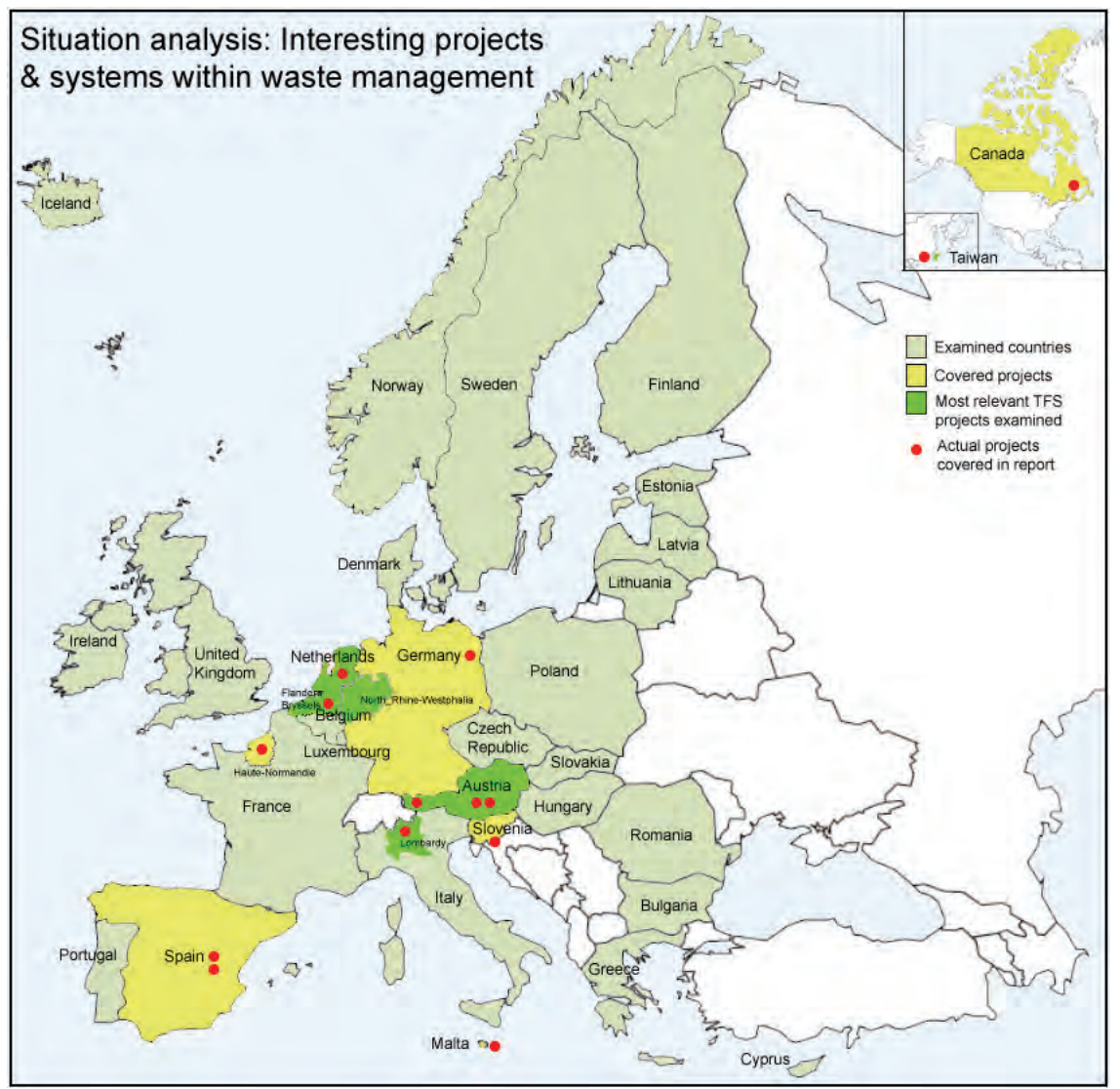

Countries and projects covered with relevance to the transboundary movement of waste process. 
1.4.1 S.I.T.T (Lombardy, Italy)

\begin{tabular}{ll}
\hline Type of project/system: & In use \\
Scope: & Lombardy, Italy \\
Relevance to TFS: & Export shipments \\
Involves private companies: & Yes \\
Involves enforcement authorities: & Yes \\
Make use of digital signatures: & Yes \\
\hline
\end{tabular}

The IREALP ${ }^{9}$ organisation have been conducting an experiment since 2006 on the behalf of the Directorate General Networks, Utilities and Sustainable Development of the Lombardy Region in managing and monitoring the transportation of special waste

The project has two main objectives:

- Simplify management practices relating to the transport of waste across borders, through their complete dematerialisation

- Allow verification in real time of waste movement for disposal in the territory of Lombardy

The project that has involved various institutional bodies (regional and provincial authorities designated for verification as well as NOE and ARPA) and private companies engaged in the process as waste producers (notifiers) and waste carriers has now reached the final stage in which test and deployment is in progress.

Export notifications that earlier were to be delivered in paper form to designated offices, is now fully computerized and through the use of CRS ${ }^{10}$ protocol submitted online. In this way the necessary information is transmitted digitally to the regional offices making immediate exchange of documents between offices and operators possible.

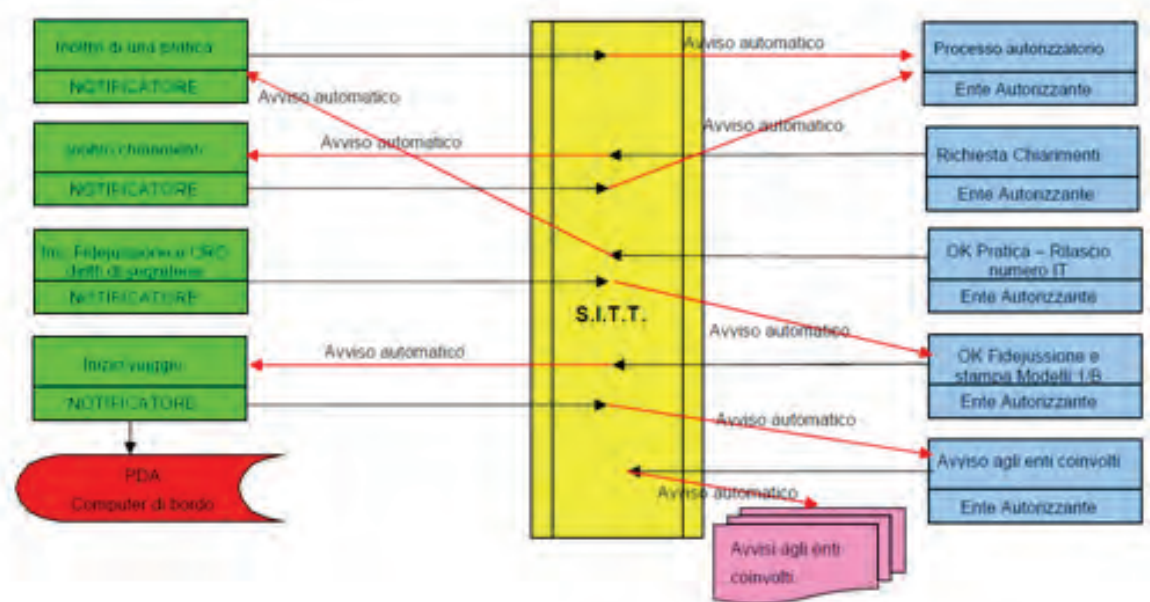

Slide of workflow covered from presentation "IREALP Istituto di Ricerca per l'Ecologia e l'Economia Applicate alle Aree Alpine” at workshop meeting in Milano 28 May 2008.

\footnotetext{
${ }^{9}$ IREALP - Research Institute for Ecology and Economy Applied to Alpine Areas.

${ }^{10}$ CRS - Map Regional Services.
} 
Vehicles of companies subject to testing (within the project) have installed equipment consisting of a GPS receiver, a GPRS module and a wireless module. Observations of the satellites are sent to central control which processes the position information using data from permanent stations of the network-IREALP GPSLombardia (www.gpslombardia.it).

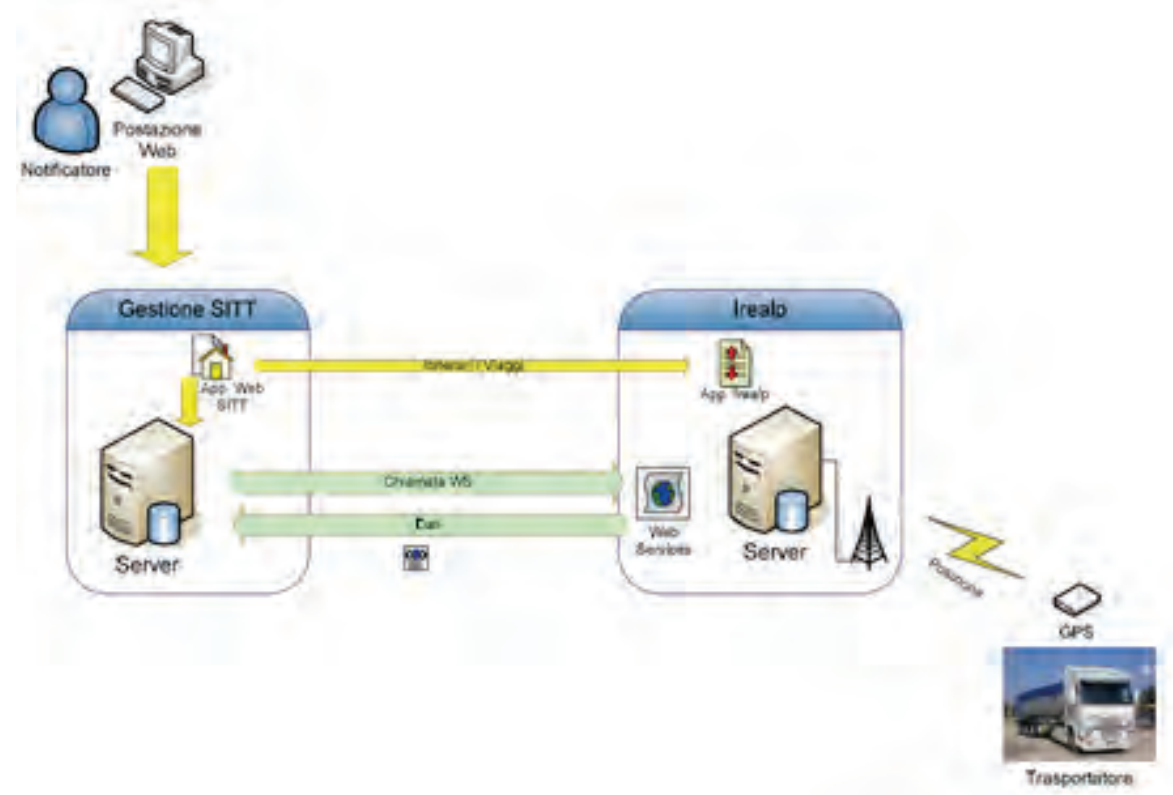

Slide of interaction between components from presentation "IREALP Istituto di Ricerca per l'Ecologia e l'Economia Applicate alle Aree Alpine" at workshop meeting in Milano 28 May 2008.

The new information system of Region of Lombardy is now active and stakeholders and public authorities may use the online information system S.I.T.T for managing the transboundary movement of waste (originating from the Lombardy region) through internet.

The centralized system offers quicker management practices to transport operators of waste across borders, but also a range of online services to streamline communications with public authorities and verification by the aviation control. 


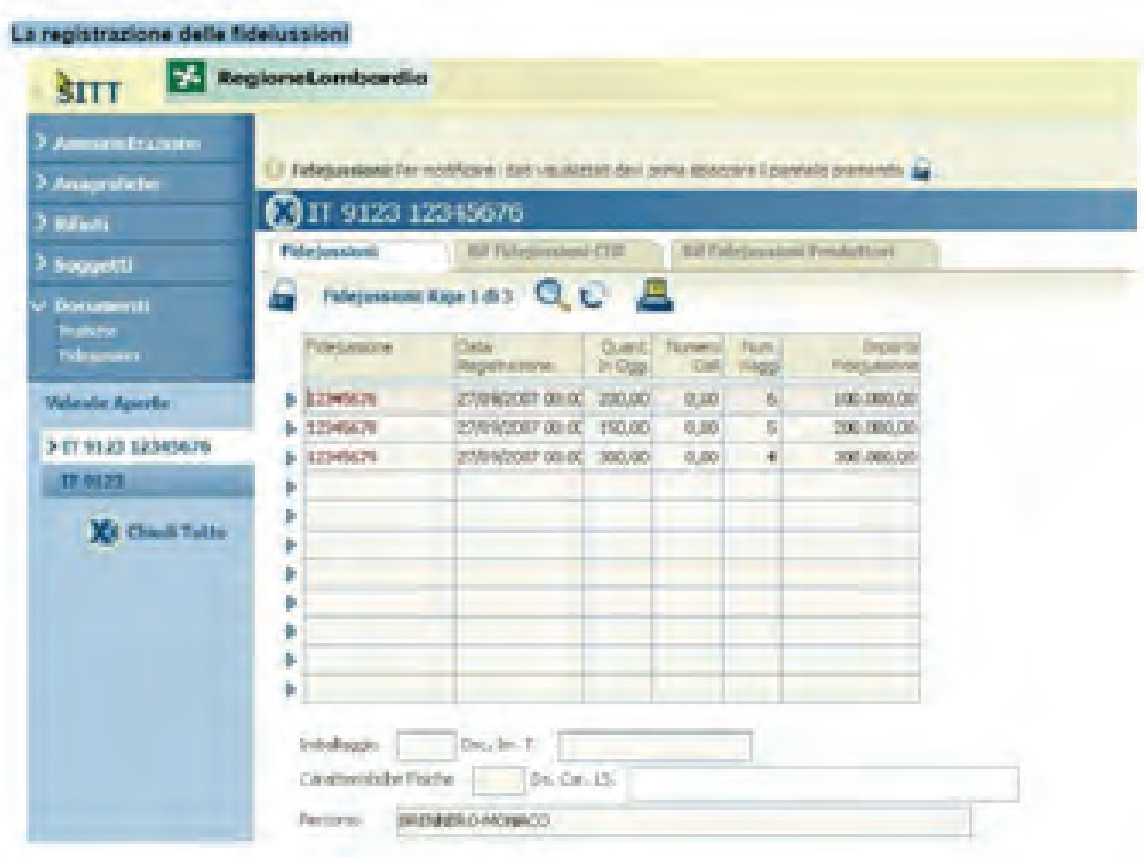

Slide of registration of bonds in S.I.T.T from presentation "IREALP Istituto di Ricerca per l'Ecologia e l'Economia Applicate alle Aree Alpine" at workshop meeting in Milano 28 May 2008.

The system also track waste movements and automatic checks are made against the actual notification documentation between the paths taken and those planned in order to detect any abnormalities of travel. In case of deviations from the planned route of travel or anomalies, the system raises alarms that are sent to the competent authorities.

The system S.I.T.T can also be used by ARPA ${ }^{11}$ and Noe Carabinieri ${ }^{12}$ to run smoother inspections of waste movements and facilitate exchanges of digitally signed documents between regional offices, provincial and operators.

${ }^{11}$ ARPA - Agenzia Regionale per la Protezione dell’Ambiente (Regional Environment Protection Agency).

${ }^{12}$ Environmental Police. 


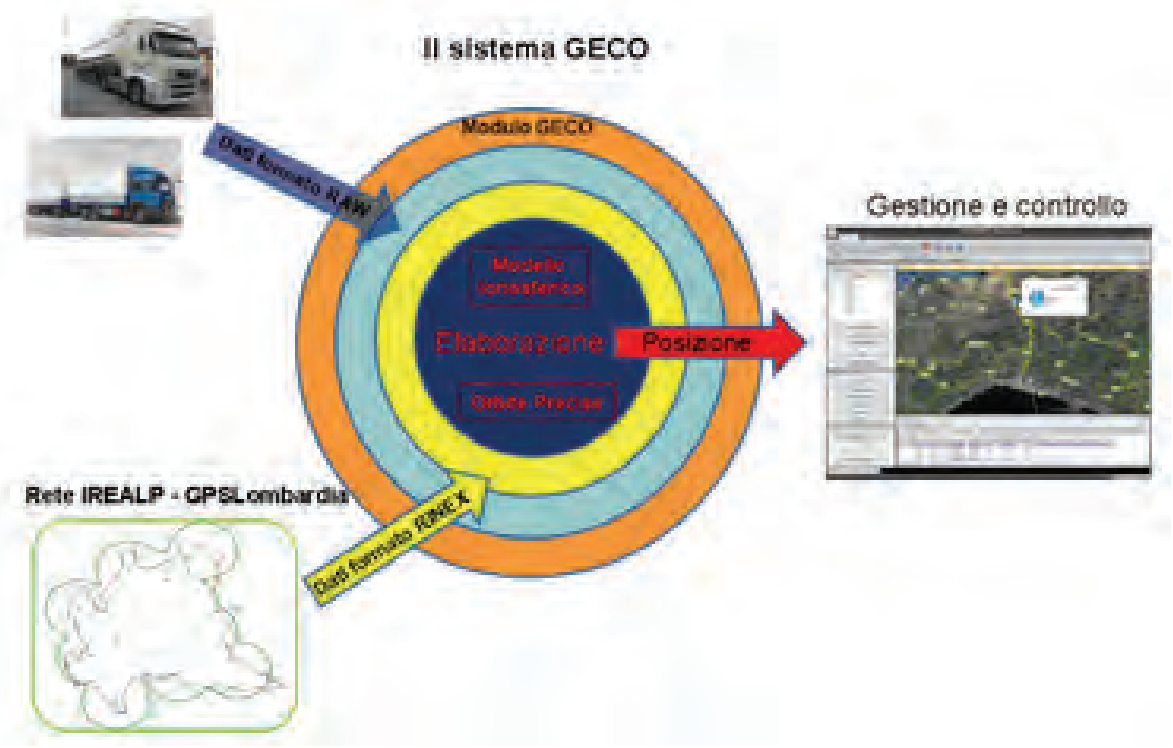

Overview of tracking system from Stazioni GNSS permanenti a supporto del monitoraggio di veicoli e persone.pdf on www.irealp.it.

In addition to the S.I.T.T system used in the Lombardy region, companies such as Computer Solutions group ${ }^{13}$ provide software to companies engaged in import and export of waste and support administrative and regulatory practices of transboundary movement of waste.

In the case of Computer Solutions group, the software ${ }^{14}$ offers functionality such as

- Traceability of movements (GPS tracking, route planning)

- Forms and documents (digital documents)

- Digital Signatures

- Workflow management

- Access via web

- Online payments

- Integration with S.I.T.T

For more information on the software visit the webpage http://www. csgroup.itcontents/modulo_sitt.htm

\subsubsection{SWERS (China, Taiwan)}

\begin{tabular}{ll}
\hline Type of project/system: & In use \\
Scope: & International \\
Relevance to TFS: & Notification of shipments \\
Involves private companies: & Yes \\
Involves enforcement authorities: & Yes \\
Make use of digital signatures: & - \\
\hline
\end{tabular}

\footnotetext{
${ }^{13}$ Computer Solutions group - www.csgroup.it.

${ }^{14}$ Software called - progetto WinSm@R.T modula Transfrontalieri.
} 
Taiwan have in order to properly manage the import and export of domestic wastes, as well as to fully comply with the Basel Convention ratified the "Waste Import and Export Management and Basel Convention Implementation Plan" in 2000. The main measures implemented through this plan are outlined in the chart below. Through continual effort, Taiwan has made significant achievements in controlling waste export and import.

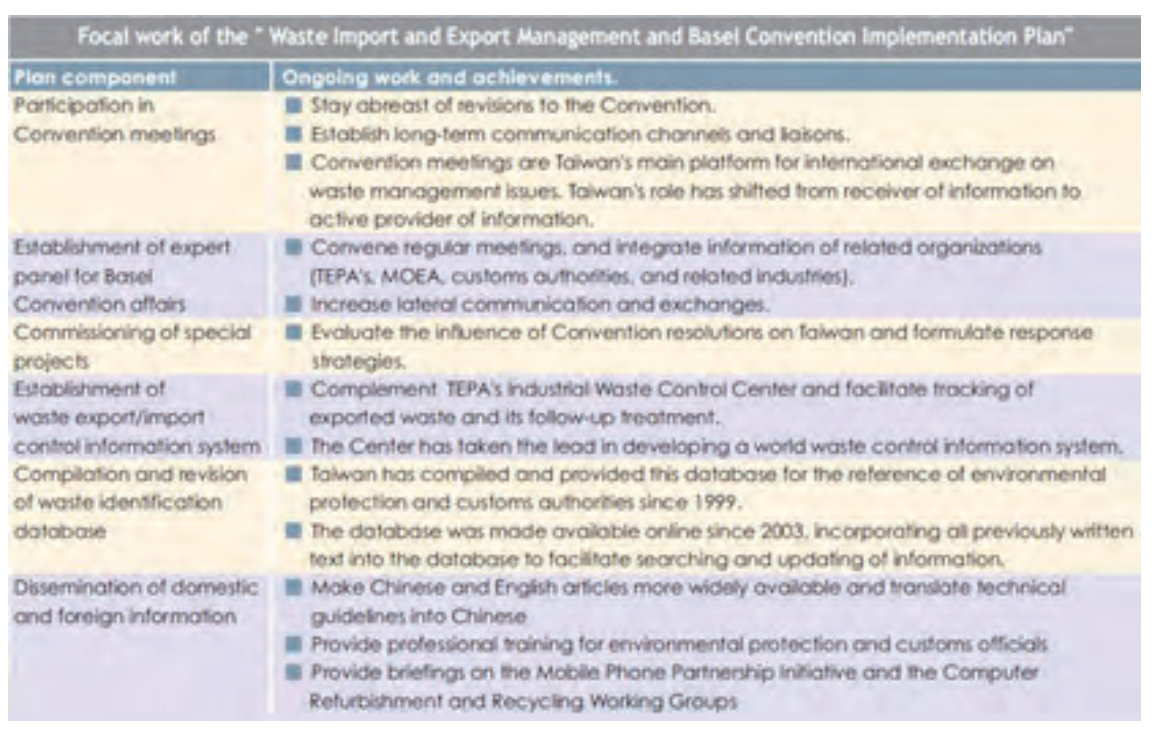

Overview of main measures implemented in Taiwan, China.

To ensure effective management of domestic industrial wastes, TEPA ${ }^{15}$ established the Industrial Waste Control Center in year 2000, and adopted an online reporting system for designated industries to track the movement of wastes generated from these designated industries. Since 2001, TEPA has successively installed GPS instant tracking technology on designated waste transport vehicles to monitor their routes. This system now provides realtime monitoring of around 1,500 waste clearance vehicles, ensuring strict control over the transport of all Taiwan's hazardous industrial waste.

In 2005, over 15,000 firms now use the online reporting system. 12.4 million Tonnes of wastes are reported through this system, accounting for $96 \%$ of all industrial wastes. Each day an average of over 10,000 firms send in their wastes clearance manifests online, and an average of over 800,000 manifests are received per month.

\footnotetext{
${ }^{15}$ TEPA - Taiwan Environmental Protection Administration.
} 


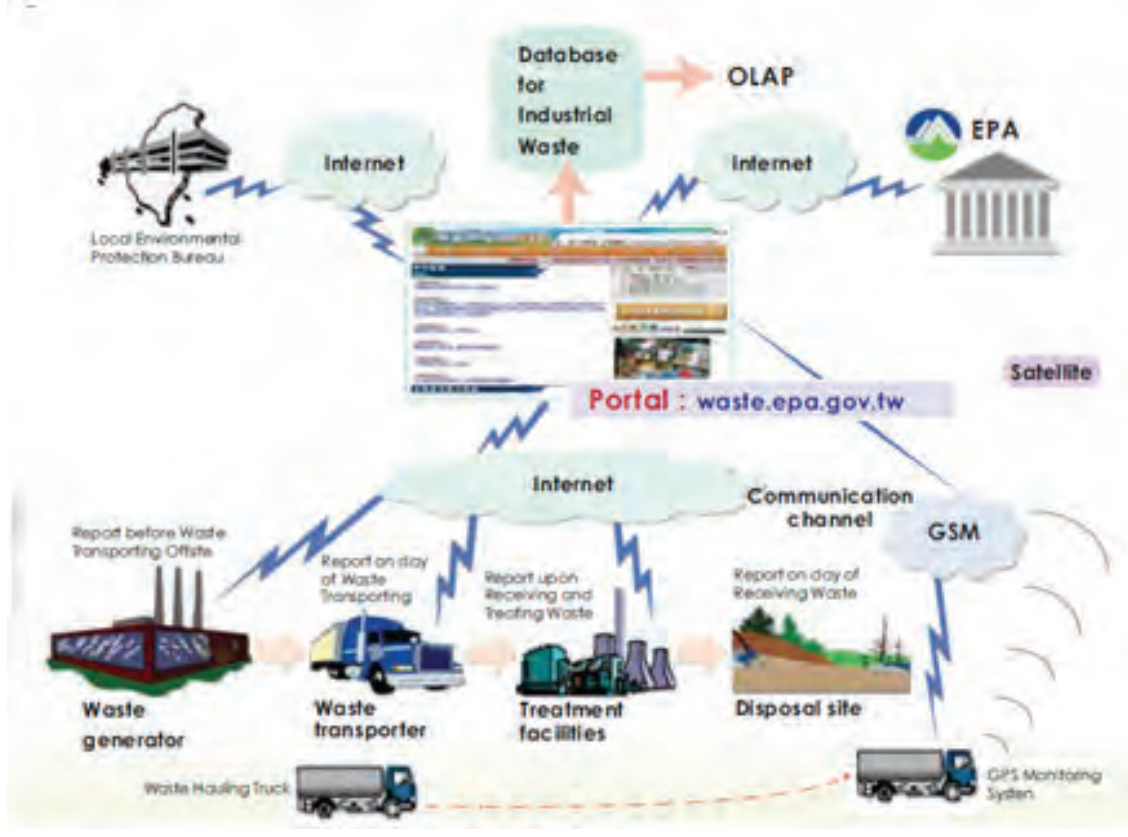

Systematic diagram for the operation of the Industrial Waste Control Center.

To properly manage the transboundary movement and treatment of waste, TEPA has integrated the existing Industrial Waste Control Center system and the online Solid Waste Export Reporting System (SWERS). All domestic firms have already made the switch from using a paper based system to reporting this information online. Foreign recovery- and disposal facilities ${ }^{16}$ that receive wastes from Taiwan have already registered and are complying with the online reporting system.

This change has increased the efficiency of waste export controls. Currently over 50 companies use this system to submit triple manifests for transboundary movement of waste every year. In 2004, over 2,500 sets of manifest data are reported, ensuring adequate control over the flow of waste treated abroad.

The Solid Waste Export Report System can be accessed at: http://waste. epa.gov.tw/export/main.asp

\footnotetext{
${ }^{16}$ Companies in EU member states that import waste from Taiwan.
} 


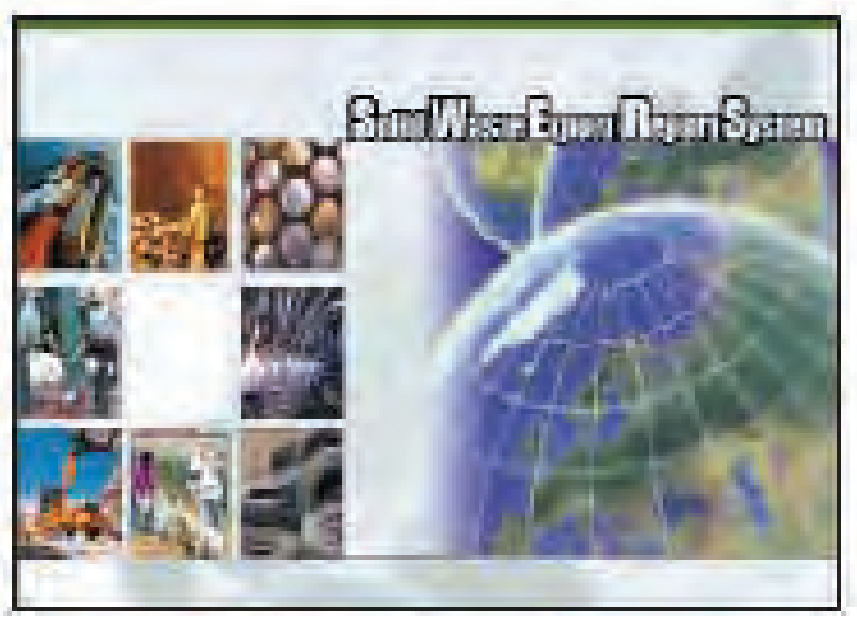

The Solid Waste Export Report System

Records on the import and export of wastes show that no hazardous industrial wastes have been approved for import to Taiwan for several years. The main types of wastes approved for export are electroplating sludges, mixed waste metals, wastes containing PCBs, and dusts and ash. The export volume of these wastes has remained the same since 2002.

The Industrial Waste Control Center database now contains over 40,000 waste generators and more than 30 million records on national and international waste. This is the first and largest system to date to use Internet reporting to manage transboundary waste movement. There are more than three million visitors to the web site annually and is the one most visited site among Taiwan's government web sites.

The EPA and local enforcement authorities have more than 300,000 visitors who log into the management system annually. This system offers the environmental competent authority a sound basis for inspecting illegal activities and also offers businesses a chance to conduct self-service within the waste management area. The system achieves the dual goals of convenient service and environmental management. For more information visit the EPA website and read the extended abstract \#333 on e-Revolution and Mobilization of Waste Management in Taiwan.

\subsubsection{EUDIN (Netherlands, Belgium, Austria and Germany)}

\begin{tabular}{ll}
\hline Type of project/system: & In progress/test activities \\
Scope: & International \\
Relevance to TFS: & Notification of shipments/ Exchange authority- \\
& authority \\
Involves private companies: & Yes \\
Involves enforcement authorities: & No \\
Make use of digital signatures: & - \\
\hline
\end{tabular}


EUDIN (European Data Interchange for Waste Notifications) is a project started by Netherlands ${ }^{17}$ and Belgium ${ }^{18}$ in early 2000, Germany ${ }^{19}$ and Austria $^{20}$ joined in 2001. The aim of the EUDIN-project is to set up an electronic system that enables an electronic exchange of the data of the notification form and the movement/tracking form.

EUDIN is targeted at both the competent authorities of participating states as well as all parties involved in the cross-border transport of waste, primarily waste producers, carriers and recovery/disposal companies. Because of the much higher amount of movement documents compared to the amount of notification forms, the EUDIN project have focused primarily on the electronic exchange of the movement documents.

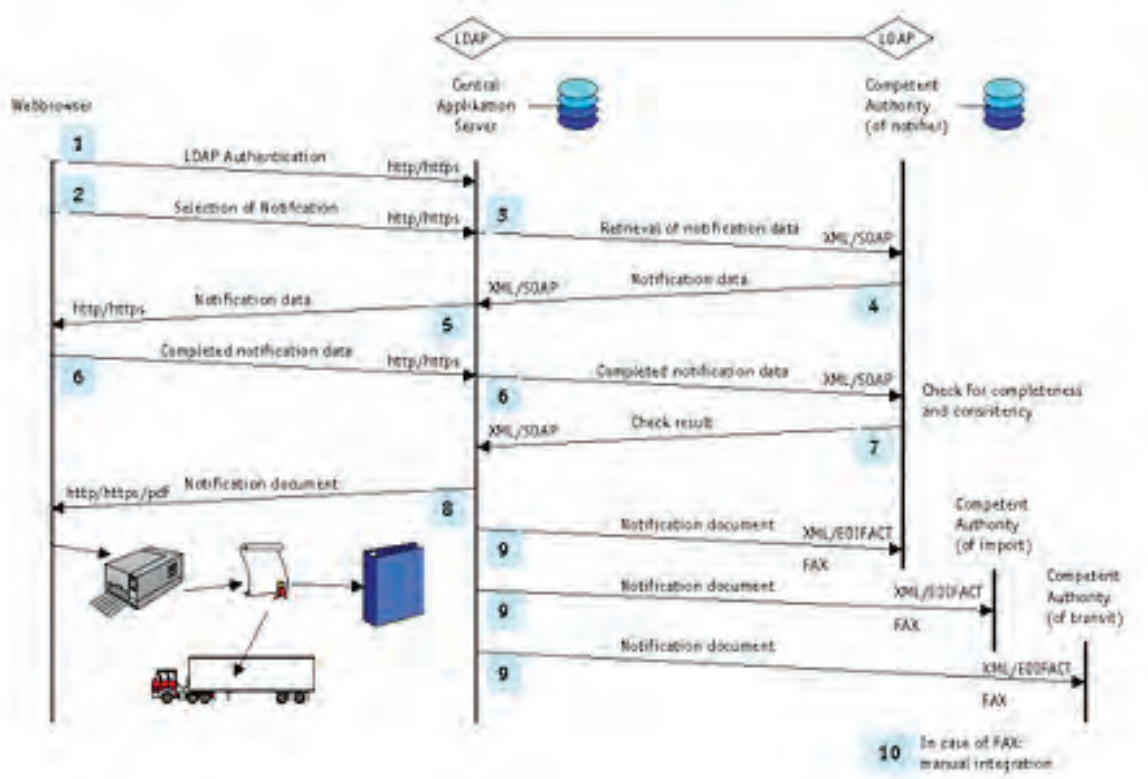

Overview of the notification process supported by Eudin (source presentation Condat).

The electronic distribution of the notification of shipments, receipts and confirmation of recovery/disposal will enhance the monitoring process. The reports will be better legible, less fault sensitive and the handling will be less time consuming for all parties involved in addition to the environmental aspect of replacing the current paper based process with a digital process of notification of movement documents.

The data of a specific movement document will be put into the electronic data processing system by the exporting company. The data of the confirmation of receipt and of the confirmation of recovery/disposal will be put in by the importing company.

\footnotetext{
${ }^{17}$ by the Ministry of Housing, Spatial Planning and the Environment, (VROM).

${ }^{18}$ by Openbare Afvalstoffenmaatschappij Voor Het Vlaamse Gewest OVAM for the region of Flanders.

${ }^{19}$ by the State Office of the Environment, North Rhine-Westphalia (LUA NRW) of the Land North Rhine-Westphalia, and the Federal Office of the Environment (UBA).

${ }^{20}$ by the Ministry of Agriculture, Forestry, Environment and Water Management (BMLFUW).
} 
The company will submit these data to "its" competent authority either by the use of a web-application (HTML over HTTP(S) is used for a webclient solution) or by using direct system-to-system communication via structured (XML-) messages. Competent authorities will be provided with the opportunity to transfer these data directly in their back-office systems without any manual intervention.

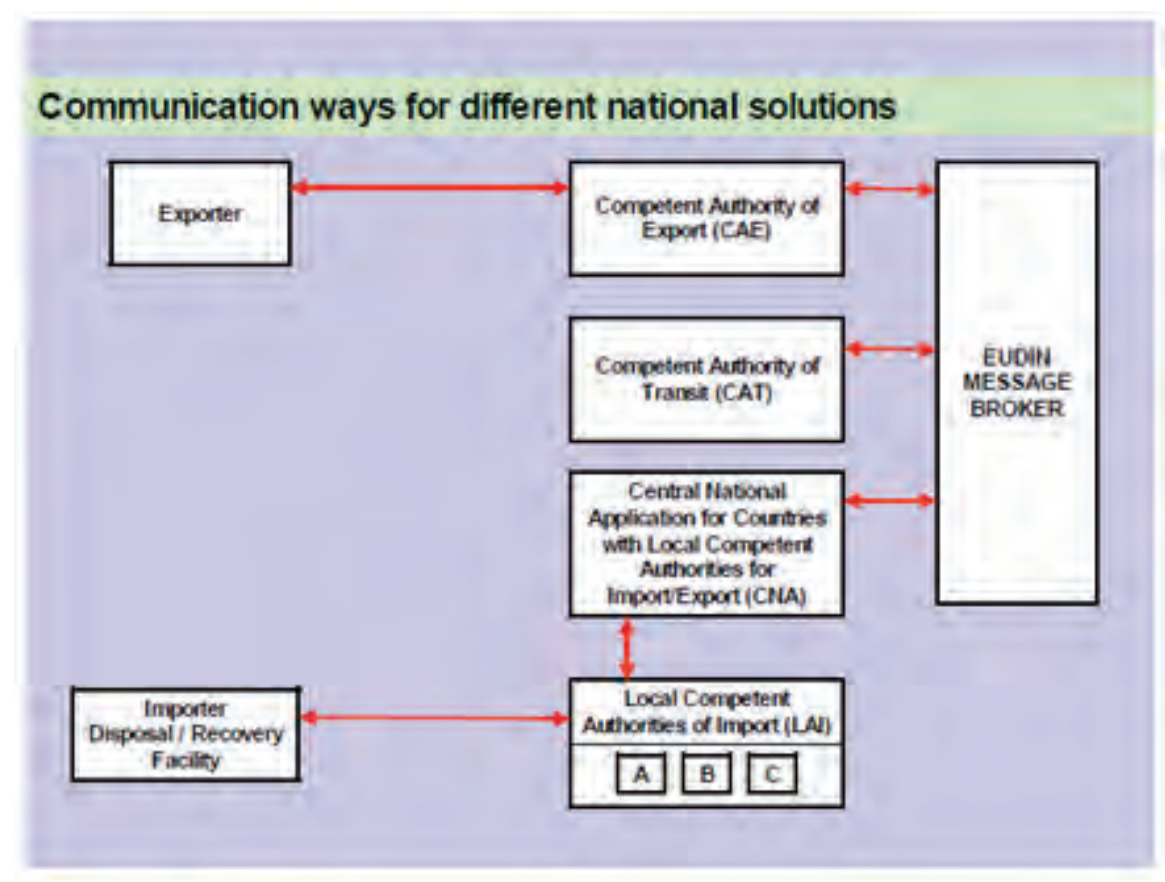

Overview of information flow between participants

Source: www.eudin.org.

This implies that two different front-office solutions can be implemented:

- A web browser solution for companies that do not have a sufficiently automated back-office system

- Direct communication of messages between back-office systems for companies with existing IT-infrastructure. 


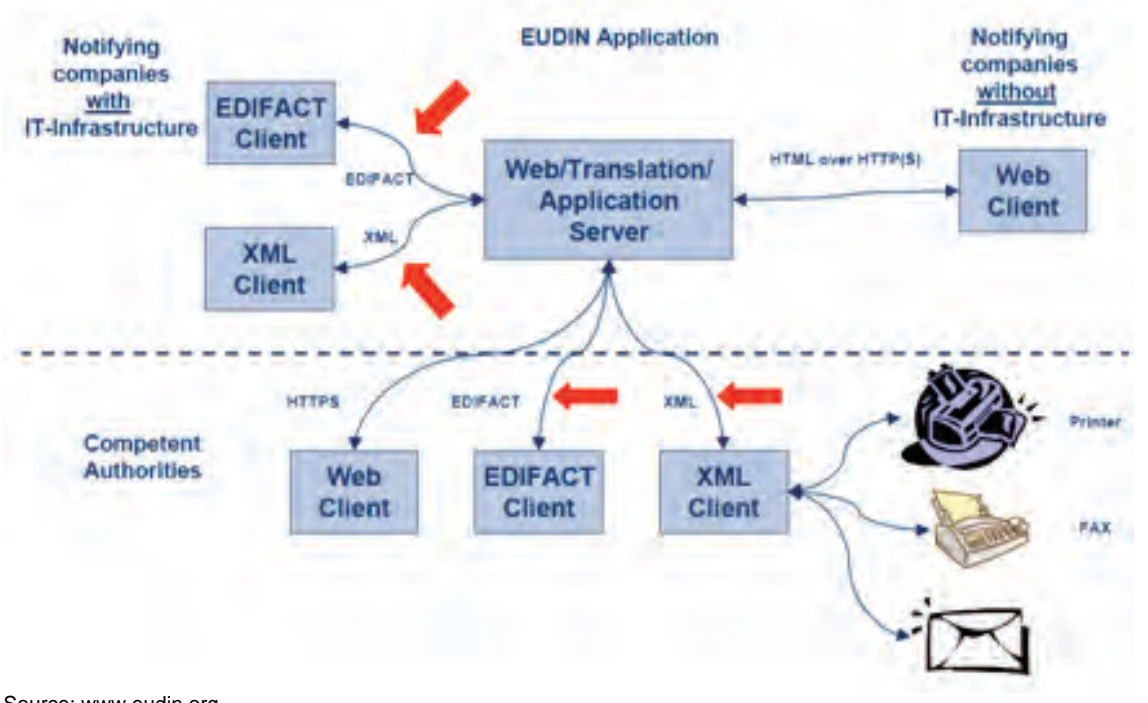

Current situation in EUDIN

It has been somewhat difficult to find current information on the EUDINproject as the latest newsletter on the project website is from December 2002 but through individuals and other reports some information have been found about the progress within the project.

A coordinator at SenterNovem in the Netherlands coordinates the continued work in EUDIN and the project have completed the work on building a message broker (server) and the specifications have been tested.

Another round of testing will take place soon ${ }^{21}$, during which Belgium and Austria will try to send and receive all movement documents digitally. Germany is still involved although their participation is somewhat hampered by the fact that not Federal authorities are represented in the EUDIN project, and so it is difficult to achieve common ground with the different parts of Germany. Austria has come far with all their ICT developments and are ready to start using the message broker (hence the near-live testing) and are also testing digital notification.

The Netherlands are building a new database for internal processing of the Notifications. The Netherlands plan to connect to the EUDIN server in 2010 at the earliest. The Netherlands have an up-and-running application for Dutch notifiers, in which they can enter their movement documents online. For the moment this is only accessible for Dutch notifiers, but plans have been made for the expansion outside the Netherlands with German and Belgian waste receivers being first in line.

\footnotetext{
${ }^{21}$ According to information given in December 2008.
} 


\subsubsection{TERRA (Netherlands)}

\begin{tabular}{ll}
\hline Type of project/system: & In use \\
Scope: & National \\
Relevance to TFS: & Notification of shipments \\
Involves private companies: & Yes \\
Involves enforcement authorities: & - \\
Make use of digital signatures: & No \\
\hline
\end{tabular}

SenterNovem is an agency of the Dutch Ministry of Economic Affairs and their goal is to convert government policy into reality. On behalf of the Dutch government they implement policy regarding:

- Innovation

- Energy and Climate Change

- Environment and Spatial Planning

SenterNovem handles receives approximately 2,000 general notifications and over 75,000 faxes annually. They have been developing and testing a system for online notification of transboundary movements of waste (TERRA). These test activities seem to have just been completed and the system is now in full production. Dutch notifiers can apply and receive an account, giving them access to the system and enables digital notification of shipments and exchange with the Dutch competent authority.

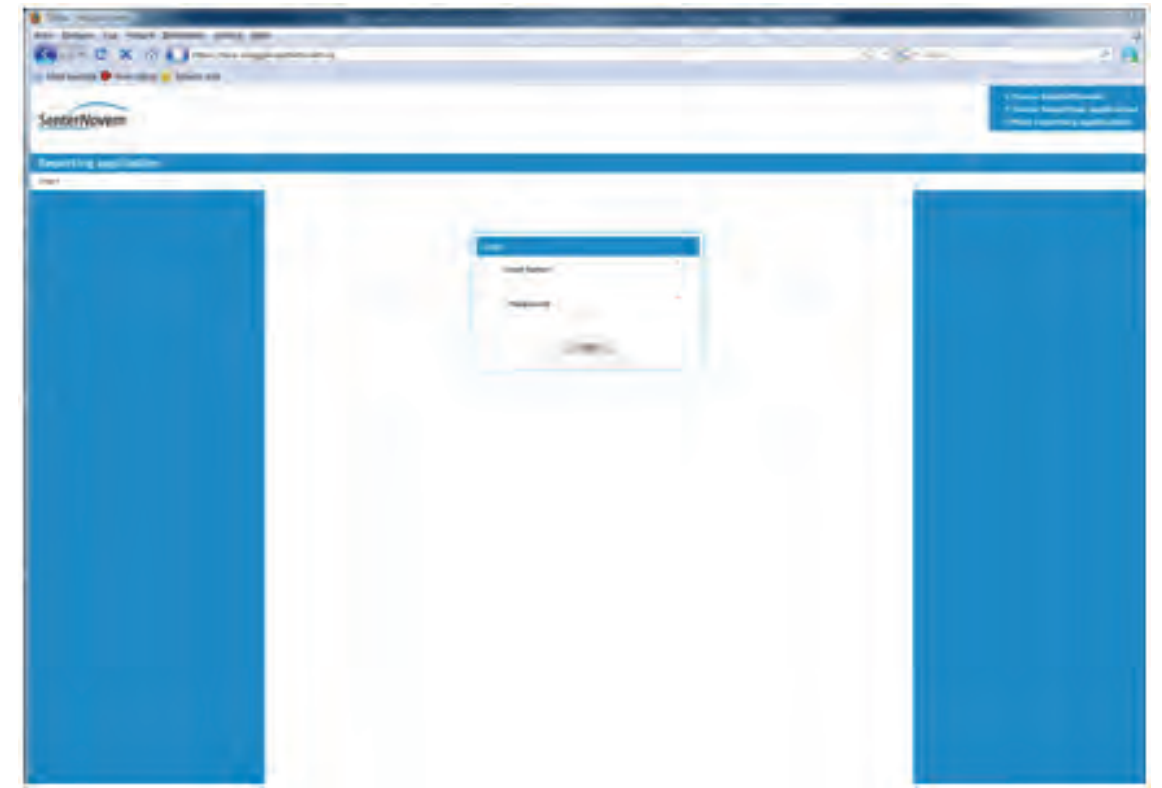

Portal to the Dutch notification system at https://terra-inloggen.senternovem.nl/.

While the system is currently limited to Dutch waste notifiers, the system itself is developed using English as the main language making it possible to include carriers and recovery/disposal facilities from the import countries as well. 
The system supports the following four processes within the notification of transboundary movement of waste

- Notification (AM) of the actual shipment (based on an approved general notification document). Called Shipment Announcement

- Receipt notification (OM) which is the receipt of the facility receiving the waste. Called Confirmation Receipt

- Processing statement (VV) which is confirmation the recovery/disposal facility gives when the recovery or disposal of waste have been completed. Called Confirmation of Treatment

- Withdrawal (IN) in which the notifier can withdraw a previously announced shipment. Called Cancellation

The different functions available within the system depend on the type of actor involved in the notification process. That means that only the waste producer (which have applied for the general notification) can make a notification of a shipment, and only the destination facility can report a processing statement as is shown in the chart below.

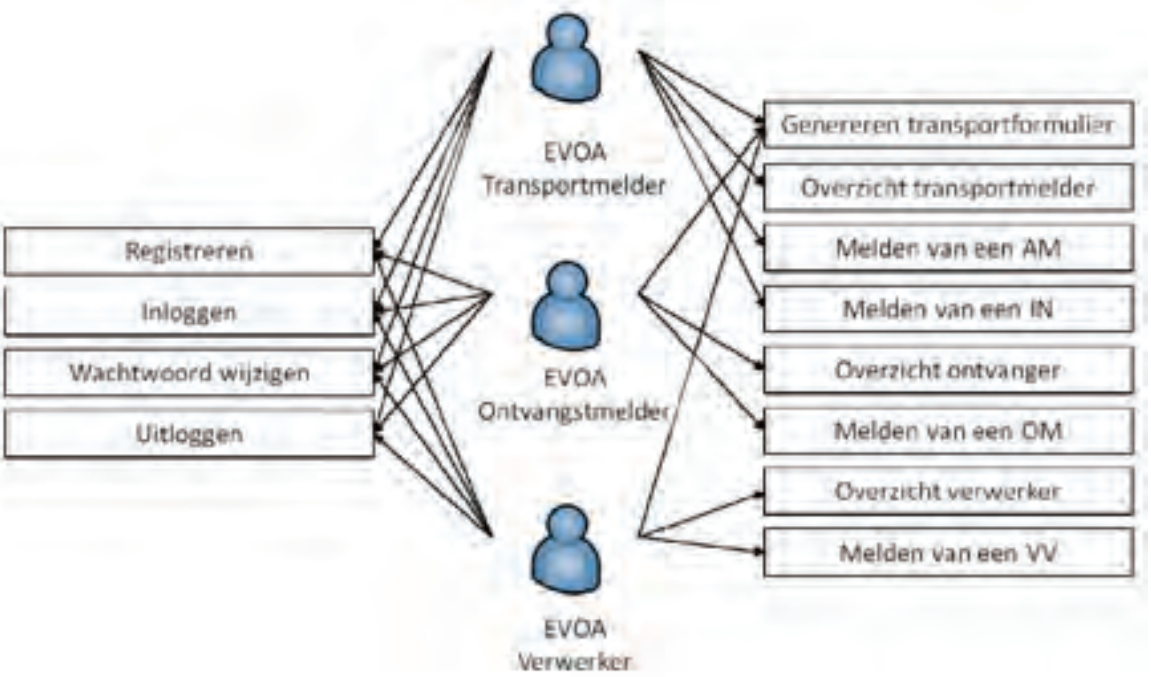

Available functionalit.y

Source: Gebruikersinstructie Elektronische Meldapplicatie, September 2009.

The system contains functionality to automatically control that a notification of a shipment can be made, this includes checks that the following is true:

- Duration of the general notification is still valid

- Capacity limit of the general notification is not yet fully reported

- Number of allowed transports are not yet received and/or processed

Notifications of shipments for which the above is true is underlined and marked in green (while unavailable ones are shown in gray), allowing the 
user to report a notification of shipment based on the chosen general notification. Archive functionality is available to the company for "old" general notifications that were approved, period has expired or all shipments are received and processed.

Each of the general notifications shown has the following information presented

- Notification number (with link to related notified transports)

- Receiver

- Validity dates (from - until)

- Total Quantity and Total Shipments

- Used Quantity and Available Shipments

- Available Quantity

It is also possible to see a list of notified shipments for each of the general notifications. This list contains information on

- Transport number

- Type

- Shipment date

- Weight

- PDF-document

- Cancellation

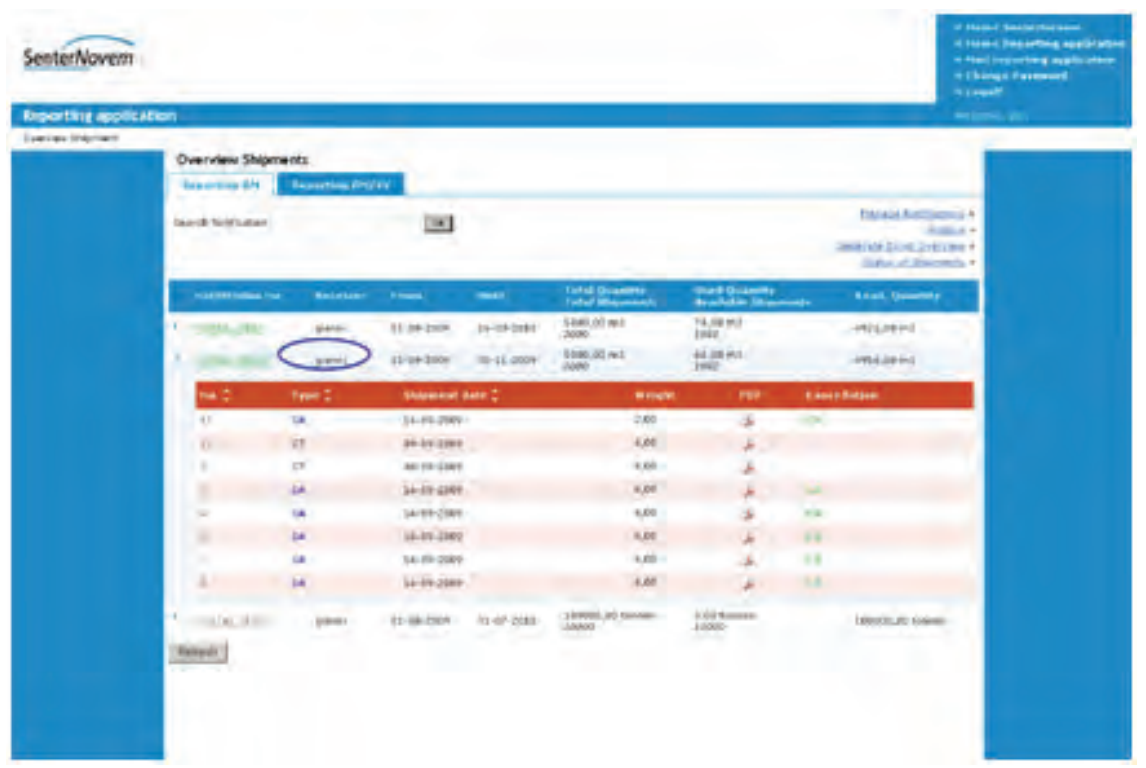


In addition to the examples given above, the system also offers the following functionality according to the user manual ${ }^{22}$

- Create Excel-overview of shown notifications

- Notification of shipment (AM)

- Cancellation of notified shipment (IN)

- Confirmation of receiving a shipment (OM)

- Confirmation of processing statement (VV)

- Bulk reporting for multiple identical shipments

- Create movement document (latest version in PDF)

Overall this system offers good support to the notification of shipments that originate from The Netherlands or notification of shipments with a destination facility within the Netherlands. However since no exchange of information is made with other competent authorities the full potential of the solution is not yet reached, involved waste producers and facilities will still have to send paper based copies to the other involved authorities.

\subsubsection{Other examined projects and systems}

\section{SEEMSEED (Spain)}

The SEEMSEED (Study, Evaluate and Explore in the domain of the Single Electronic European Market) project contained a pilot case covering the transboundary movements of waste process between Spain and Germany. The project was active from January 2004 to June 2006 and concluded among many things that with an international system in place the cost savings for personnel alone would be $€ 6,000$ per complete transboundary movement.

\section{ETER (Spain)}

The objective of the project is to enable stakeholders ${ }^{23}$ to download, complete and return PDF forms that facilitate Notifications of hazardous waste, instead of using the paper based documents that are currently in use. Five (out of 18) communities currently accept the intelligent pdf-forms via e-mail and one of the communities (Comunidad Autónoma de Valencia) provide some web services for direct exchange of this information between businesses and the local authority.

\section{DRIRE HN (Haute-Normandie, France)}

During the Information Exchange and Awareness Raising Event that took place in Le Havre in July 2008 the region of Haute-Normandie presented a new online application for managing general notifications through internet.

\footnotetext{
${ }^{22}$ User manual - Gebruikersinstructie EM versie September 2009.

${ }^{23}$ Waste producers and waste carriers.
} 
This application is used by the competent authority to enter and maintain general notifications as well as to produce statistical information.

\section{Hazardous waste inventory (Malta)}

The "Hazardous waste inventory and technical assistance in regulatory aspects of hazardous waste management" project was a part of the twinning project Transition Facility 2004 (2004/16762.07.01). The project developed two data management and monitoring systems. One system would handle the applications and hazardous waste consignment notes while the other system would manage general notification forms and movement/tracking forms in accordance with EC-regulation on transboundary movement of waste.

\section{Pfändertunnel (Austria)}

The project uses chip-technology for the electronic registration of shipments and receipt for recovery/disposal movements passing through the Pfändertunnel. The project has documented 18,224 transport registrations and 16,727 receipt and recovery registrations (between September 2008 and March 2009). The Pfändertunnel, situated close to the Swiss and German border of western Austria is the most travelled overland tunnel used in Austria, with more than 30,000 vehicles passing each day.

\section{E-TFS pilot A action (Austria and min. 5 other countries)}

This planned (not yet started) project was presented on the same awareness raising event as project Pfändertunnel (see above). Facts from presentation are presented below:

- Electronic system between participant states to exchange important notification data and transport data

- Facilitation of the annual reporting to the secretary of the Basel Convention and the European Commission

- Project budget: max. 10 Million $€$

- EU pays $50 \%$ of project costs

- Minimum: 6 Partners (Member states)

- Project time 2011-2013

\section{EDM - Electronic Data Management (Austria)}

The aim of this system called EDM (Electronic data management in the Environment and Waste Management) is the gradual transition from traditional "paper systems" into a collection of efficient, electronic collection and reporting systems. Several of the EDM sub-projects (e.g. eConsignment Note or waybills, eBalance Sheets, eLandfill, ePermit, eAudits, eIncineration) have planned or ongoing tests where involved companies will be able to transmit information and documents electronically instead of sending papers to the competent authority. 
Austrian producers of hazardous waste are required to register by electronic means only (no paper applications). This can be done through the EDM portal (www.edm.gv.at). Waste owners also have the option of an electronic data transfer of consignment notes to the competent authority.

More than 100,000 waste producers and 6 million consignment notes are currently stored within the EDM-system and almost 450,000 consignment notes ${ }^{24}$ are registered annually.

The EDM-project also houses the testing activities involving information exchange between Belgium and Austria competent authorities (within the EUDIN-project) as well as tests of digital notification (within the eShipment subproject).

\section{ARSO-IS Odpadki (Slovenia)}

The Environmental Agency of Republic of Slovenia (ARSO) has developed a system called IS-Odpadki ${ }^{25}$. The system manages national waste shipments and the different stakeholders ${ }^{26}$ can access the system through internet.

The system makes use of digital signatures to verify the exchange of information between the user and the system which allows the stakeholders to transmit documents and notifications through data entry via a web browser instead of sending papers to the competent authority.

The project is currently in a testing phase and involved companies have to use the paper based process concurrently with the digital process.

The project have also produced XML-schemas and a developer guide for those companies that wish to enable communication without the manual data entry through a web browser. More information on the project can be found here (in Slovenian): http://okolje.arso.gov.si/odpadki/

\section{ESTMHW (Canada)}

The competent authority Environment Canada started a project in 2001 that would enable parties involved in the movement of hazardous wastes to enter and transmit electronically all the information pertaining to the movement of a particular shipment, particularly when the shipment crosses a Canadian border.

In the evaluation of the project it is concluded that the need for monitoring and enhancing of the processes involved still remain and that this in a sense is due to the fact that the project has not been able to reach the goals. The following facts are given to explain why the project was not able to reach the goals:

- The implementation of a system with smart cards was not realistic as it did not include necessary external partners (CBSA and industry).

\footnotetext{
${ }^{24}$ Source: Austrian National Plan.

${ }^{25}$ IS-Odpakdi - IS Waste.

${ }^{26}$ Waste producers, waste carriers and recovery- and disposal facilities.
} 
The fact that a IT-solution was proposed to a business problem without a pre-study led to a solution that did not fit the problem

- The alternative plan that were presented after the smart card system is hampered by a legal dispute still in progress

- The re-organisation of IT and management resources in combination with unclear budget and budget responsibilities have affected the strategy work in a negative way

\section{GADSYS (Germany)}

The ASYS is a monitoring system for waste shipments. The system is used by all Federal States (through the Central Office for Waste Record Procedures) and is installed at more than 1,000 workplaces over Germany. The system can exchange information with other national authorities as well as private companies involved in the waste management business.

A new system called GADSYS ${ }^{27}$ (Gemeinsamen Abfall DV-Systeme) expanded (in August 2004) the co-operation between the Federal States and with the 2007-2009 implementation of the program eGovernment 2.0, the German government has given particular focus to electronic records procedure for the environmentally sound disposal of waste as there are still about 3 million consignment notes created and used in a costly paper form format every year.

According to the Ordinance on Waste Recovery and Disposal Records (NachwV) as of April 1, 2010 all parties involved in the process of disposal of hazardous waste will be required to maintain electronic records - this applies to waste producers, disposers, and transporters, as well as the responsible government agencies.

It is anticipated that some 50,000 companies will be affected in the process of making a transition from the current paper based process to a complete digital process. The system make large scale use of electronic signature (within eGovernment) and future plans include access by federal state police forces as well as the Federal Office for Goods Transport (BAG). Transport companies will then no longer need to carry the numerous consignment notes in paper format.

\subsection{Conclusions}

After examining hundreds of national WebPages and reading available reports on the subject of transboundary movements of waste as well as international and national reports on projects aiming for the improvement of government efficiency within the waste management area, there are some conclusions to be made on the countries that were examined during this prestudy:

\footnotetext{
${ }^{27}$ More information on www.gadsys.de.
} 
- None of the countries (27 EU, 3 OECD, 1 other) has a digital solution for all of the main processes involved in transboundary movements of waste

- None of the examined countries have a digital solution for the general notification application process

- Only Netherlands has a nationwide implementation of digital reporting for the use of private companies (recently implemented)

- 8 of the countries ${ }^{28}$ have either implemented digital reporting as a concept $^{29}$ in a selected region or is in the process of testing digital reporting with a limited amount of companies at a national level

- Only Taiwan, China currently allows digital notification of shipments from foreign stakeholders

- The focus and solutions differ among the countries with ongoing or completed projects

- One project with the scope of international cooperation (EUDIN)

- Germany, Netherlands, Belgium ${ }^{30}$, Austria, Italy ${ }^{31}$, Taiwan/China are the countries/regions which have the most experiences with digital reporting within the area of waste management

- The majority of the examined countries still use the paper based process and are expected to continue doing this in the coming years due to the fact that they lack ongoing projects with the aim of digital reporting

This study has found only four systems/projects that directly address the specific processes within the transboundary movements of waste and are in use or are in the proximity of live testing. These systems have been covered in detail above and are

- S.I.T.T in Lombardy, Italy which manages notification of movement documents and allows real-time monitoring of movements through GPS-technology. This is only possible at a local level within the Lombardy region

- SWERS in Taiwan, China which requires national and international companies involved in the export of waste from Taiwan to report the movement documents through a web portal

- EUDIN, the joint project of Netherlands, Austria, Germany and Belgium where Belgian and Austrian authorities have progressed far in the exchange of notification data between the competent authorities

- TERRA in Netherlands which recently allows Dutch notifiers to digitally report export notifications of shipments and import receipt and disposal/recovery confirmations of shipments

\footnotetext{
${ }^{28}$ Spain - Valencia, Italy - Lombardy, Netherlands, Austria, China - Taiwan, Belgium, Slovenia, Germany.

${ }^{29}$ Not necessarily transboundary movements, but instead applied in notification of national waste.

${ }^{30}$ Applies to OVAM.

${ }^{31}$ Applies to Lombardy region only.
} 
The need for an international solution for digital reporting of transboundary movements of waste differs between the countries as the countries have to handle different amounts of general notifications and notification of movements. This pre-study have found no official statistics on the number of general notifications managed by each country but have been able to gather approximates through the use of the IMPEL TFS Seaport II report, information given by different countries in the BiPRO-events ${ }^{32}$ and a questionnaire sent by e-mail to the different countries. Not surprisingly this shows that the countries with the largest need of such a system also are the ones where most of the initiatives have been found.

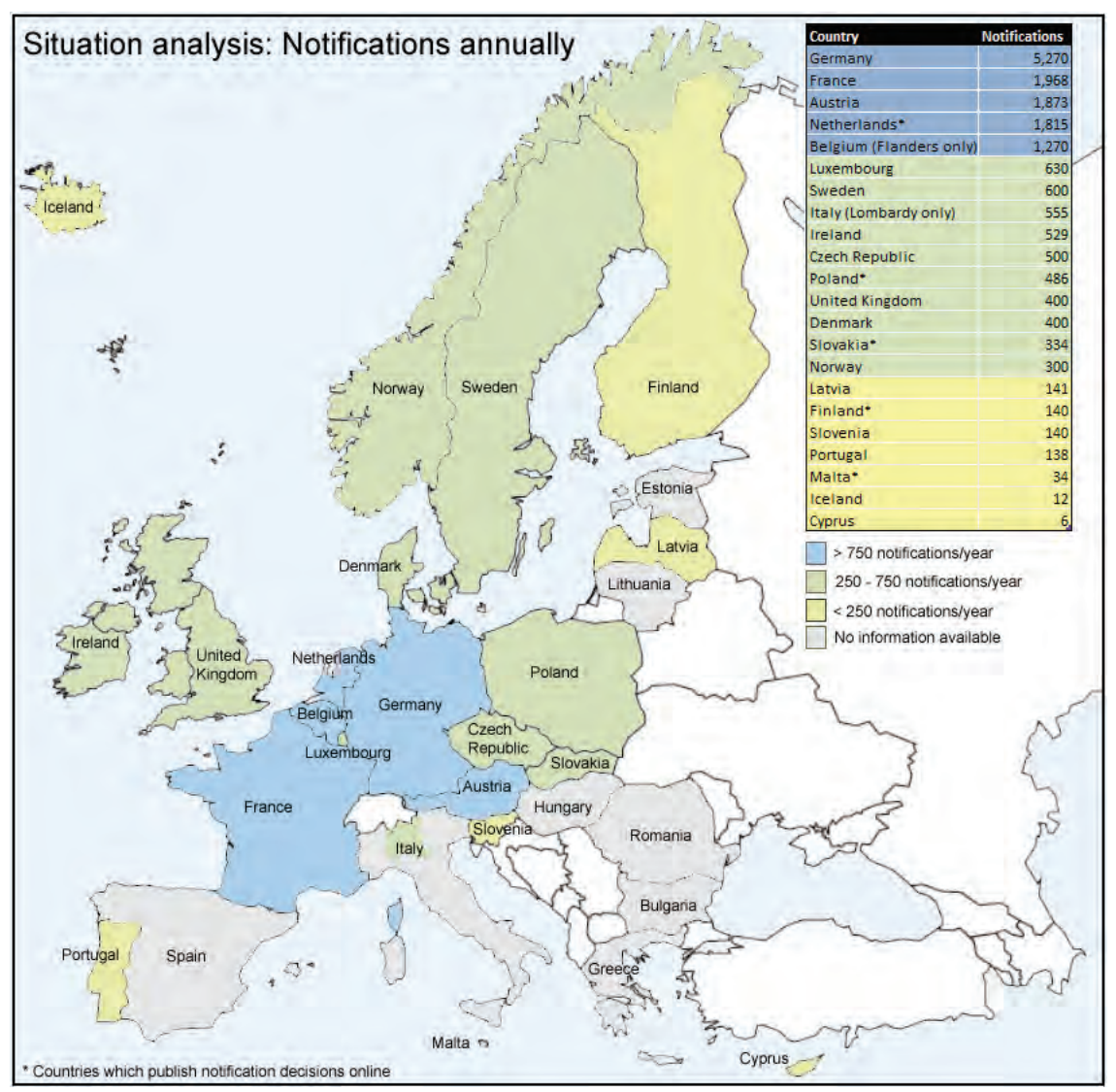

Approximate of the number of general notifications handled annually by each of the examined countries

${ }^{32}$ BiPRO events - Information Exchange and Awareness Raising Events on SHIPMENT of Waste. 



\section{Digital reporting via internet}

\subsection{Procedures}

There are two main procedures involved when managing a transboundary movement of waste. The first is the Notification procedure in which the exporter applies for permission to make one or more shipments of waste and it also include the decision activities of the competent authorities involved. The other one is the Tracking procedure where the exporter and the receiving facility report the actual shipments of waste.

Each Notification procedure often involves several parallel repeating tracking procedures

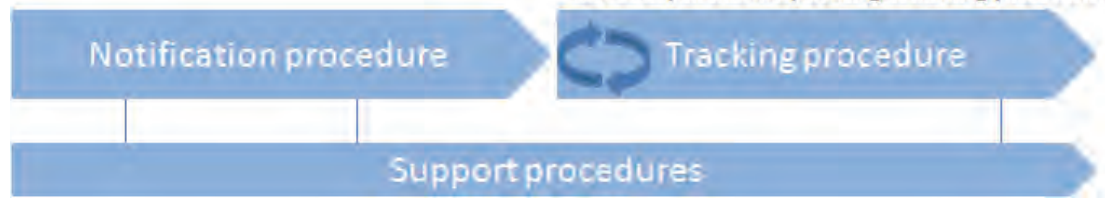

The chapter "Notification procedure" includes proposed solutions for

- Digital registration of the Notification document

- Digital exchange of notification data between Nordic countries

- Automated acknowledgements by e-mail

- Registration of decision data for all countries importing from or exporting to a Nordic country

The chapter "Tracking procedure" contains information on solutions for

- Digital registration of

a) Notification of shipment

b) Receipt of shipment

c) Processing statement

- Digital registration of non-Nordic import and export shipments which involve one or more Nordic countries

- Automated acknowledgements by e-mail

In addition to the two main procedures there are support procedures which support one or both of the main procedures and it provides information on

- Digital registration of stakeholders

- Digital registration of non-Nordic import notifications

- Automated annual Basel reporting 
The main procedures as well as the support procedures have been examined with the intention of suggesting a solution that would make use of a more automated way of managing the procedures. The work has mainly been focused on the use of digital reporting and digital exchange of documentation through internet to reduce administrative work and to enable electronic processing of the information currently available on paper.

\subsection{Notification Procedure}

Waste encompassed by the EC-regulation 1013/2006 which is destined for disposal- or recovery operations and are originating from or, destined to an EU member state are subjected to the notification procedure described in the EC-regulation and can take place only upon prior written notification to the competent authorities of the country of export, import and transit, if any, and after receiving consent from these authorities.

The notification contain among other things detailed information about

- Unique identification number of the notification (country code and a number, e.g. SE 123456)

- Stakeholders involved in the movement

- Waste (classification, weight etc)

- Type of operation (recovery, disposal) 
ANNEX IA

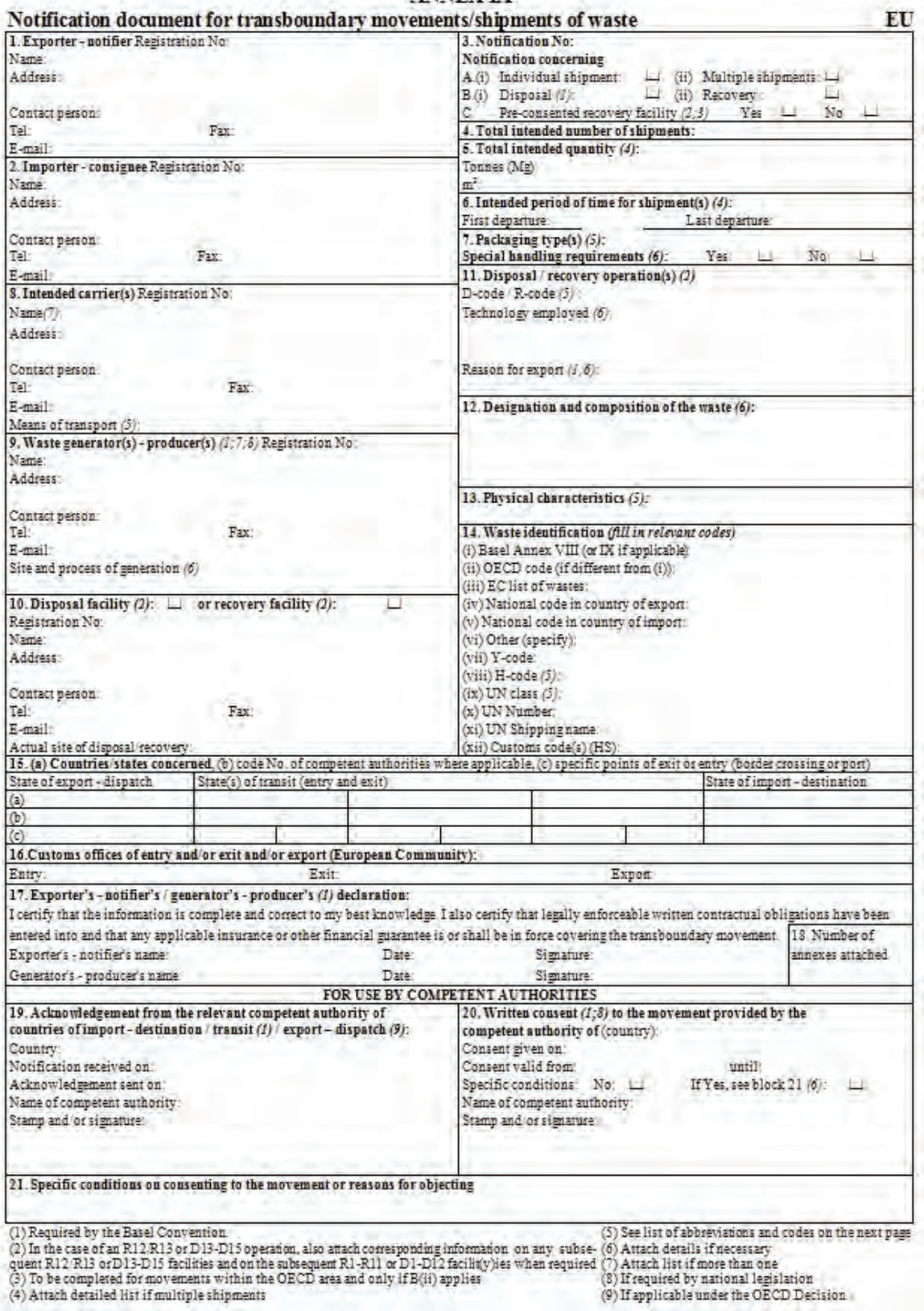

Example of an English Notification Document Form (page 1).

The notification allows the competent authorities to decide whether to object or consent to the transboundary movement. The "notification document" can cover a single shipment (single notification) or multiple shipments of waste (general notification).

An approved notification is 
- Valid for a certain type of waste

- Valid for a certain amount of time (usually one year or three years in some cases)

- A total amount of waste (in weight) that can be shipped

- A total number of transports allowed

The exporter (usually a waste producer or a broker) initiates the transboundary movement from the export country and upon receipt of a notification, the competent authority shall transmit an acknowledgement to the exporter with a copy to the competent authorities of all other countries involved within three (3) working days of receipt of the notification. All involved countries must consent to the movement for it to take place. The notification may be provided by post, e-mail with digital signature, email followed by post, or fax followed by post.

The above description of the process is a simplification and for a more supportive and explanatory document on the procedures involved please consult the Guidance Manual for the Control of Transboundary Movements of Recoverable Wastes, OECD 2009 
CASE 1

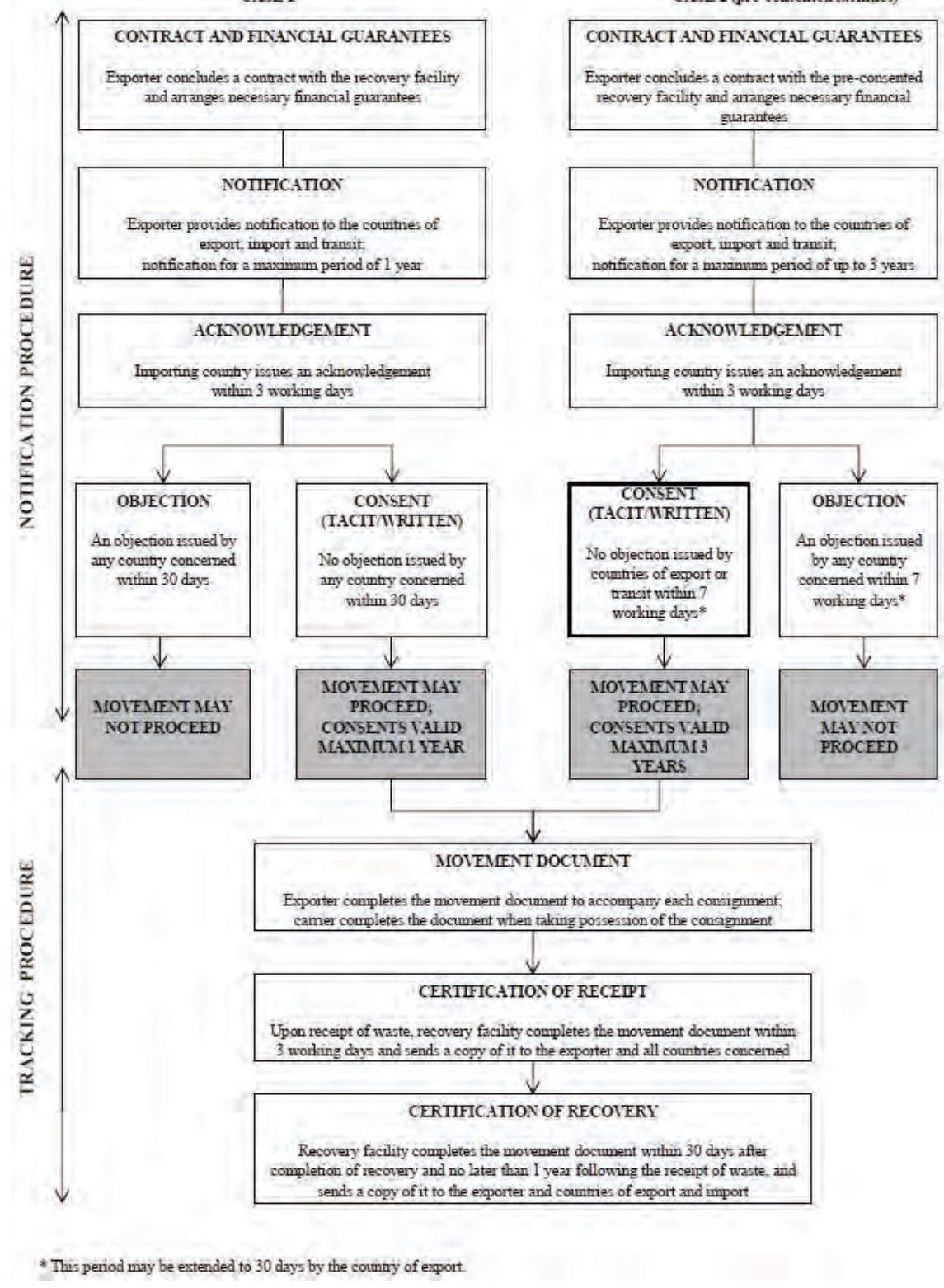

Main Stages of the Amber Control Case 1 and Case 2 procedures

Source: Guidance Manual for the Control of Transboundary Movements of Recoverable Wastes, OECD 2009

\subsubsection{Digital reporting of an export notification}

The digital reporting of export notifications from one of the Nordic countries assume that all exporters are registered as such. The number of unique companies involved as exporters varies between the Nordic countries but is in the range of 35-120 per Nordic country.

Registration of stakeholders is described detail within the chapter support procedures, registration of stakeholder procedure. The suggested procedure for managing export notifications are described in text and in a series of flowcharts below. 


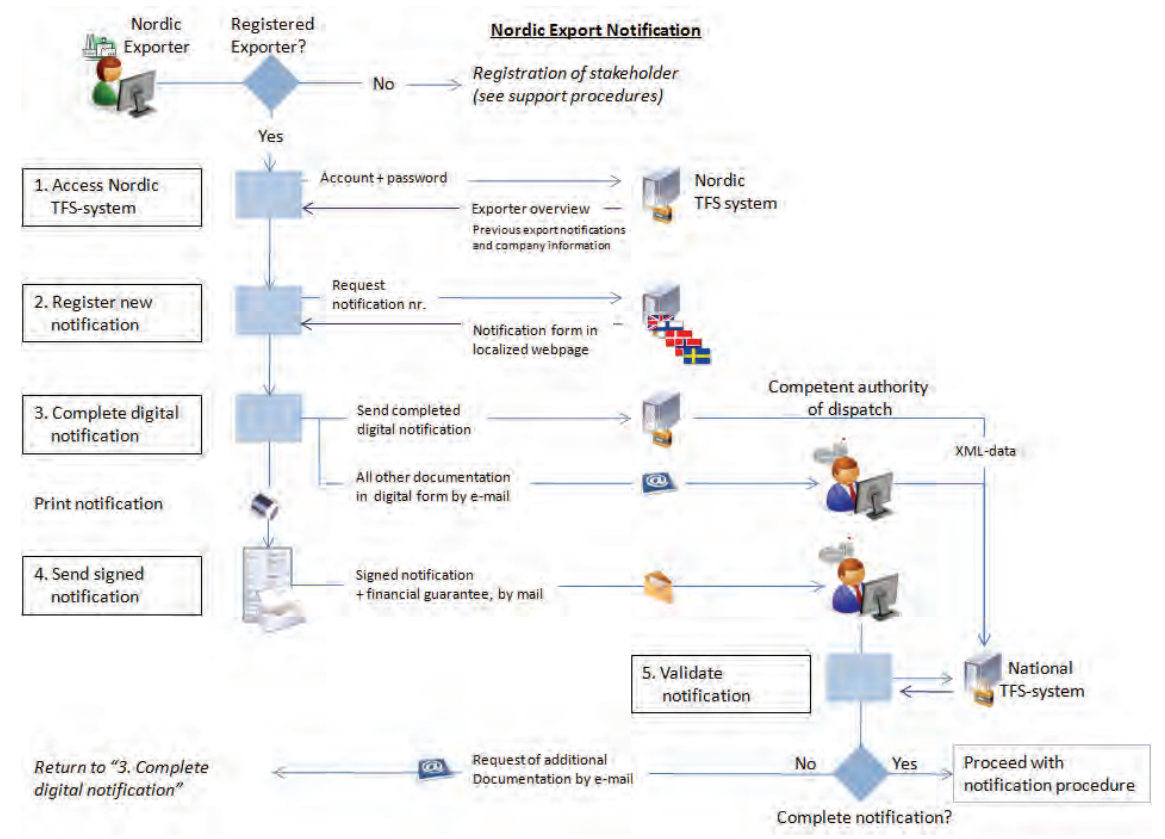

\section{Access Nordic TFS-system}

To access the Nordic TFS-system the representative for the exporting company uses the account and password given ${ }^{33}$ to them by the competent authority of dispatch. The system then provides an overview of any previous notifications registered ${ }^{34}$ as well as the company information provided in the registration of stakeholder procedure.

\section{Register new notification}

The exporter chooses to register a new notification within the system and is then given the next available unique notification number from the system. The presentation of the new notification is very similar to the current notification document and it is presented in any of the following languages English, Finnish, Danish, Norwegian or Swedish. The registration form contains several helpful features (e.g. waste lists, validity checks, registered facilities etc) to help the exporter fill in the notification document correctly. The exporter can save the notification form without sending it to the competent authority thus enable the continued registration another day. Please consult the chapter Technical requirements for more information on the features provided within the notification document.

\section{Complete digital notification}

When the representative of the exporting company have completed the notification document form the system checks the completed form for any errors (e.g. empty mandatory fields etc). When the notification document form is correct and completed it is saved and it receives a new status within the sys-

\footnotetext{
${ }^{33}$ See chapter Support procedures - Registration of stakeholder procedure for details

${ }^{34}$ Only notifications registered after the implementation of the system will be shown
} 
tem. The Nordic TFS-system then transmits a XML ${ }^{35}$-file of the completed notification document form that is imported into the National TFS-system of the competent authority of dispatch.

The system provides the representative with a pre-formatted e-mail in which the representative shall provide attachments of all other required documentation (e.g. scan of the financial guarantee etc) in digital form. The e-mail is then sent to the competent authority of dispatch.

\section{Send signed notification}

The representative of the exporting company then prints the notification document form (from the Nordic TFS-system) and signs the printed document. The representative puts the signed notification and the financial guarantee in an envelope and mail the envelope to the competent authority of dispatch.

\section{Validate notification (dispatch)}

When the signed notification document and the financial guarantee have been received by the competent authority of dispatch an officer check that the

- Timestamp of signed notification is the same as in the system

- Notification is signed and dated

- Financial guarantee is correct and present

- E-mail with the appropriate notification number contains all required documentation in digital form

- Above contains all information required for a decision on the transboundary movement to be made

If additional information is needed the request is made to the exporter by email. If changes have been made or have to be made on the signed notification form compared to the digital version registered a new signed notification have to be sent by the exporter. Minor changes can at the discretion of the competent authority of dispatch be made as long as the signed notification document contains the exact same information as the digital version stored in the Nordic TFS-system. Validation of the notification shall be made within three working days after receiving the signed notification and should result in a request for additional information, a transmission or acknowledgement of the notification.

\footnotetext{
${ }^{35}$ XML - eXtensible Markup Language
} 


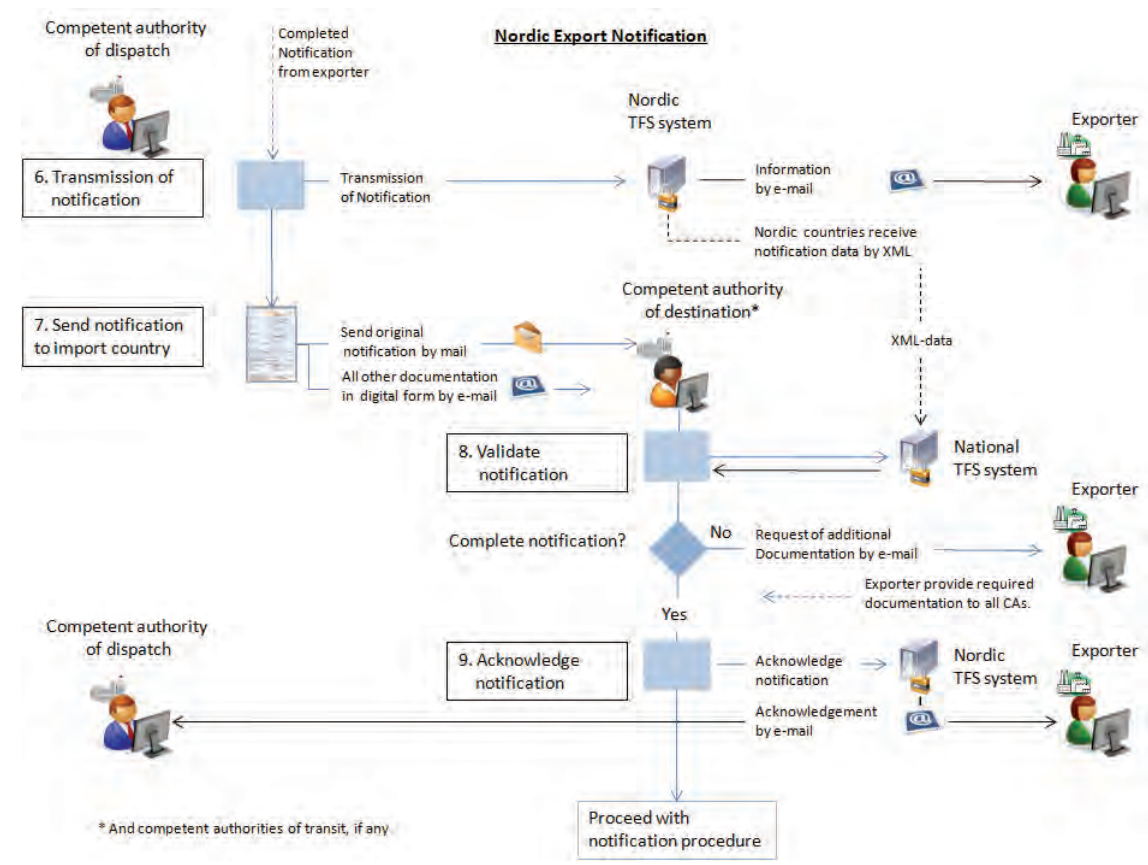

6. Transmission of notification (dispatch)

When the officer of the competent authority of dispatch decides that the notification is complete he or she access the TFS-system and change the status of the digital notification to "transmitted by dispatch". This triggers an automatic e-mail to the exporter ${ }^{36}$ with information of the transmission of a complete notification.

At the same time the Nordic TFS-system then transmits a XML ${ }^{37}$-file of the completed notification document to the National TFS-system of the competent authority of destination provided that the competent authority of destination is participating in this solution. The system also makes sure that no changes can be made by the exporter to the digital notification data. Changes can however be made by an officer of either the competent authority of dispatch or destination.

\section{Send notification to import country}

The officer of the competent authority of dispatch sends the original notification document by mail to the competent authority of destination. The email containing the digital versions of all other required documentation is then sent to the competent authority of destination.

If the competent authority of destination doesn't accept digital documentation these documents are then printed and put in the same mail as the original notification document. The above also applies to any transit countries involved except that the notification document is a copy instead of the original notification document.

\footnotetext{
${ }^{36}$ Other stakeholders could easily be included to receive the same e-mail if desirable.

${ }^{37}$ XML - eXtensible Markup Language.
} 


\section{Validate notification (destination)}

When the original notification document and the e-mail with the required documentation have been received by the competent authority of destination an officer check that the

- Timestamp of signed notification is the same as in the system

- Notification is signed and dated

- E-mail with the appropriate notification number contains all required documentation in digital form

- Above contains all information required for a decision on the transboundary movement to be made

If additional information is needed the request is made to the exporter by email. If changes have been made or have to be made on the signed notification form compared to the digital version registered a new signed notification have to be sent by the exporter. Minor changes can at the discretion of the competent authority of dispatch be made as long as the signed notification document contains the exact same information as the digital version stored in the Nordic TFS-system. Requests for additional information and responses associated with these should be sent to all other involved competent authorities as well. Validation of the notification shall be made within three working days after receiving the signed notification and should result in either a request for additional information or an acknowledgement of the notification.

\section{Acknowledge notification (destination)}

When the officer of the competent authority of destination decides that the notification is complete he or she access the TFS-system and change the status of the digital notification to "acknowledged by destination". This triggers an automatic e-mail to the competent authority of dispatch and the exporter $^{38}$ acknowledging the receipt of a complete notification.

\footnotetext{
${ }^{38}$ Other stakeholders could easily be included to receive the same e-mail if desirable.
} 


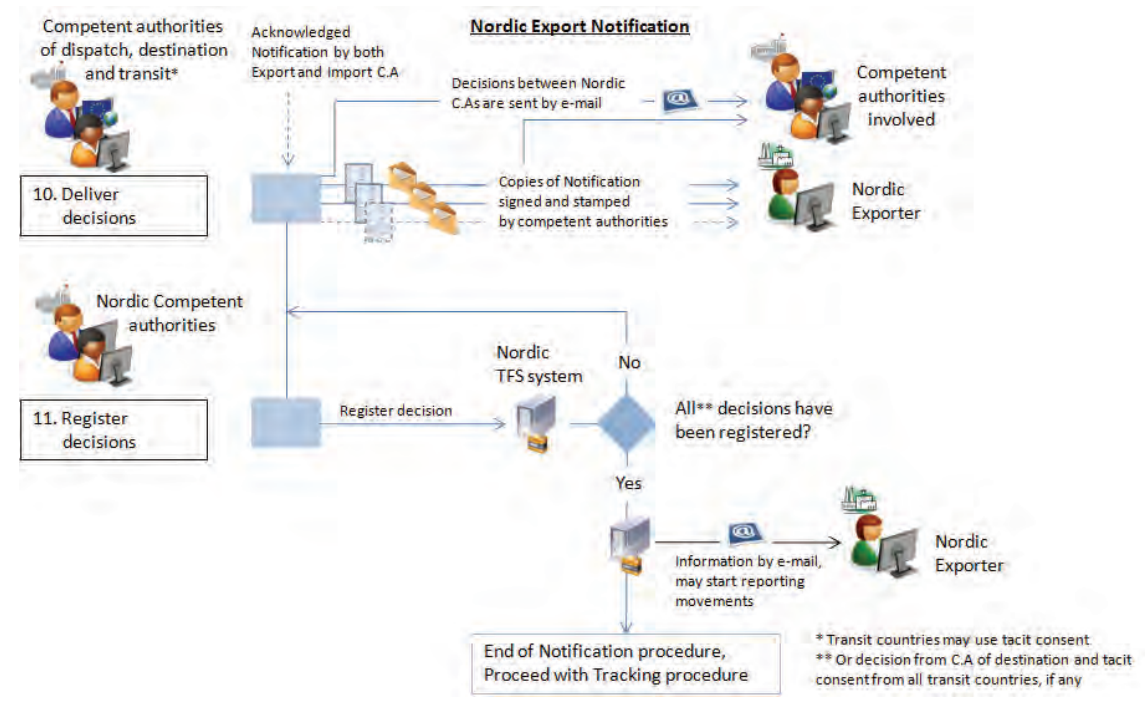

\section{Deliver decisions}

The competent authorities of destination, dispatch and transit have 30 days following the date of the acknowledgement by the competent authority of destination in which to take one of the following decisions in writing as regards the notified shipment:

- Consent without conditions

- Consent with conditions

- Objections

Tacit consent by the competent authority of transit may be assumed if no objection is lodged within the said 30-day time limit. The competent authorities shall transmit their decision and the reasons therefore to the exporter in writing with copies to the other competent authorities concerned. The competent authorities shall signify their written consent by appropriately stamping, signing and dating the notification document or their copies thereof. The decisions made by Nordic competent authorities may be transmitted to other Nordic competent authorities ${ }^{39}$ by a pre-formatted e-mail instead of mail by post.

\section{Register decisions}

When a Nordic competent authority has delivered their decision, an officer of the competent authority register their decision into the Nordic TFSsystem. The information registered is to be used as a basis for the digital reporting of movement documents and should at minimum include the following information

\footnotetext{
${ }^{39}$ May also include other countries accepting e-mail instead of mail by post.
} 
- Notification number

- Number of transports allowed

- Maximum amount of waste allowed

- Validity dates (from and to dates for each of the deciding competent authorities)

Information on exporter, importer, waste types etc is already available due to the earlier (see activity 2 and 3) registration of notification data. Additional registration of decision data may be included and may include complete digital versions of the decisions if the solution is to be expanded to provide customs, police and other authorities' detailed information on the actual decisions made by the involved competent authorities.

If the notification is concerning multiple shipments (general notification), it is possible (optional) to register the number of metric tonnes the financial guarantee covers and if the information is registered, the Nordic TFS-system will ensure that concurrent shipments of waste is kept within the limitation of the financial guarantee.

For cases where the competent authority of destination is a nonparticipating country the Nordic counterpart assumes responsibility and register the decision data based on the received written decision. Involved transit countries could either deliver a written decision or use tacit consent. Tacit consent is assumed if no written consent or objection has been received by a Nordic competent authority within 30 days of the notification acknowledgement by the competent authority of destination. When the all decision data has been registered the Nordic TFS-system sends an e-mail to the exporter that digital reporting of movement documents may begin. Note that the e-mail should point out that the exporter remains responsible for fulfilment of the requirements of the written consents and that the movements adhere to the conditions described in the written consents received by the competent authorities involved.

\subsubsection{Digital reporting of an import notification}

The procedure of managing import notifications differs between import notifications from one of the Nordic countries and import notifications from non-Nordic countries.

Import notifications from non-Nordic countries are handled according to the current procedure of each Nordic country with the additional support procedure of "Registration of import notifications from outside the Nordic countries". This is done to ensure that Nordic importers can register digital movement documents and to ensure that a complete set of data is available for statistical purposes as well as for the use of Nordic authorities involved in monitoring activities (e.g. Nordic customs, police and local authorities).

There are approximately between $40-100$ non-Nordic notifications and decisions that each Nordic country has to register in accordance with the 
description in the chapter of support processes. The rest however originate from other Nordic countries and are subject to a more automated process than the ones from the non-Nordic countries.

The suggested procedure for managing import notifications from other Nordic countries are described in text and in a flowchart below.

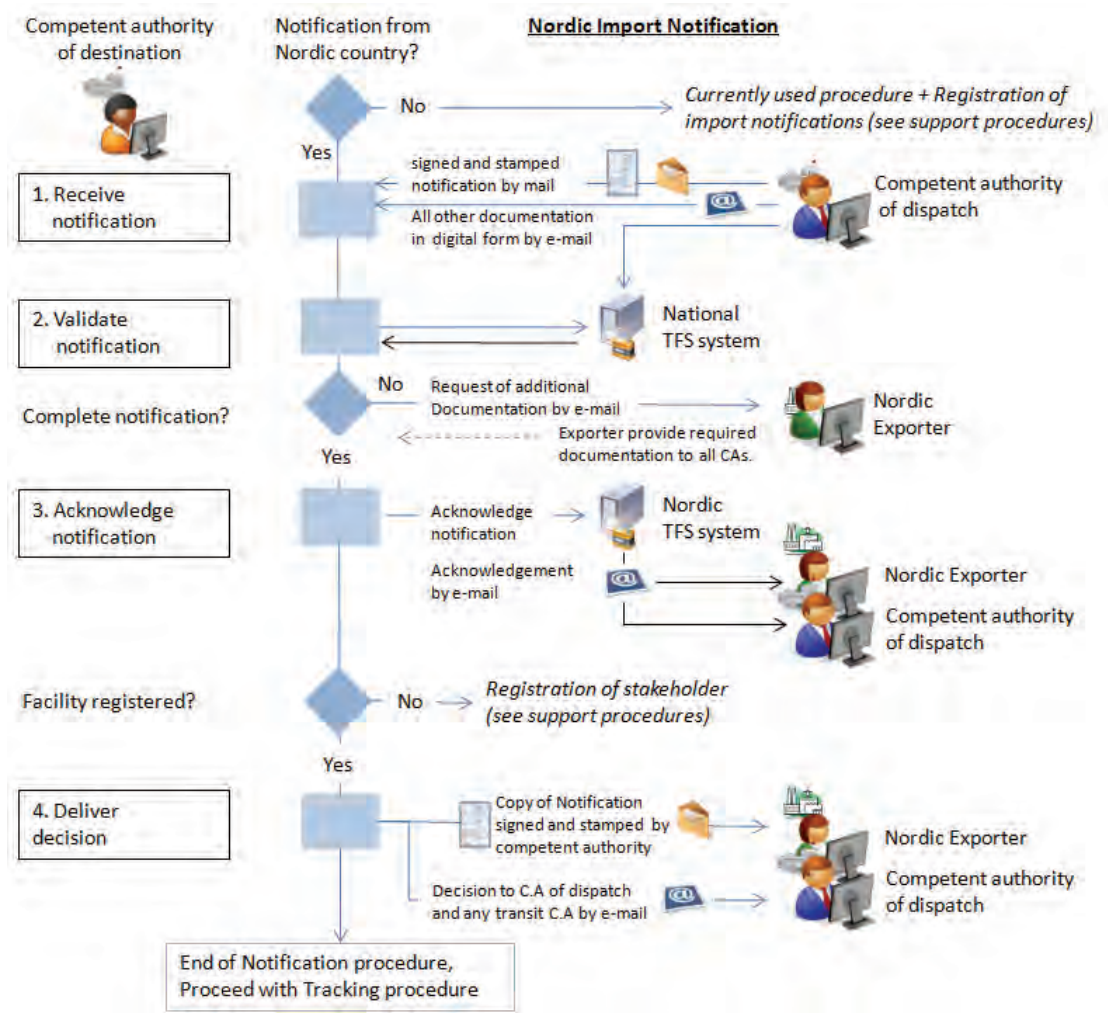

\section{Receive notification}

The digital notification data have already been received when the Nordic competent authority of dispatch acknowledged the transmission of the notification in the Nordic TFS-system. An e-mail containing all of the required documentation in digital form also arrived at that time leaving only the signed original notification document which arrives a somewhat later depending on postal services.

\section{Validate notification}

When the signed notification document and the e-mail with the required documentation have been received by the competent authority of destination an officer check that the

- Timestamp of signed notification is the same as in the system

- Notification is signed and dated 
- E-mail with the appropriate notification number contains all required documentation in digital form

- Above contains all information required for a decision on the transboundary movement to be made

If additional information is needed the request is made to the exporter by email. If changes have been made or have to be made on the signed notification form compared to the digital version registered a new signed notification have to be sent by the exporter. Minor changes can at the discretion of the competent authority of dispatch be made as long as the signed notification document contains the exact same information as the digital version stored in the Nordic TFS-system. Requests for additional information and responses associated with these should be sent to all other involved competent authorities as well. Validation of the notification shall be made within three working days after receiving the signed notification and should result in either a request for additional information or an acknowledgement of the notification.

\section{Acknowledge notification}

When the officer of the competent authority of destination decides that the notification is complete he or she access the TFS-system and change the status of the digital notification to "acknowledged by destination". This triggers an automatic e-mail to the competent authority of dispatch and the exporter ${ }^{40}$ acknowledging the receipt of a complete notification.

The officer also checks if the destination facility is registered in the Nordic TFS-system, if that is not the case (approximately less than 10 per year and country) the facility have to register, see the support process registration of stakeholder procedure for more information. The reason for this is to enable digital reporting of movement documents when they arrive at the importing recovery- or disposal facility.

\section{Deliver decision}

The competent authority of destination has 30 days following the date of the acknowledgement in which to take one of the following decisions in writing as regards the notified shipment:

- Consent without conditions

- Consent with conditions

- Objections

The competent authority of destination shall then transmit their decision and the reasons therefore to the exporter in writing with copies to the other competent authorities concerned. The competent authority shall signify their

\footnotetext{
${ }^{40}$ Other stakeholders could easily be included to receive the same e-mail if desirable.
} 
written consent by appropriately stamping, signing and dating the notification document or their copy thereof.

The decision is then transmitted to the Nordic competent authority of dispatch by a pre-formatted e-mail instead of mail by post while the exporter receives his decision by mail.

As soon as the competent authority of dispatch receives (and registers) the decisions made by the involved authorities the digital reporting of movement documents may begin in accordance with the all of the decisions involved.

\section{Conclusion notification procedure}

The solution described above is modular and it is possible to implement certain parts of the solution (e.g. activity 11 . Register decisions) and still be able to reap some of the benefits (e.g. digital reporting of movement documents and a tool for customs etc). However the solution proposed have been designed so that the solution

- Is in appliance with EC-legislation 1013/2006

- Not interfere with or replace national TFS-systems in use

- Is cost-effective and easy to use

- Enable digital reporting of movement documents

The solutions contain the following changes or additions to the notification procedure compared to the ones used today

- Registration of all Nordic exporters and importing facilities in a Nordic system

- Exporters ${ }^{41}$ registers a digital notification document and delivers all documentation in digital form ${ }^{42}$

- Acknowledgements and transmission of notifications is made through a common Nordic TFS-system

- Decision information is registered in a Nordic TFS-system by the Nordic competent authorities

The below chart shows the main activities of the notification procedure where the TFS-system is involved.

\footnotetext{
${ }^{41}$ Or in the case of import notifications from non-Nordic countries, the competent authority of destination.

${ }^{42}$ Some documents (e.g. Financial guarantee etc) is also provided in paper.
} 


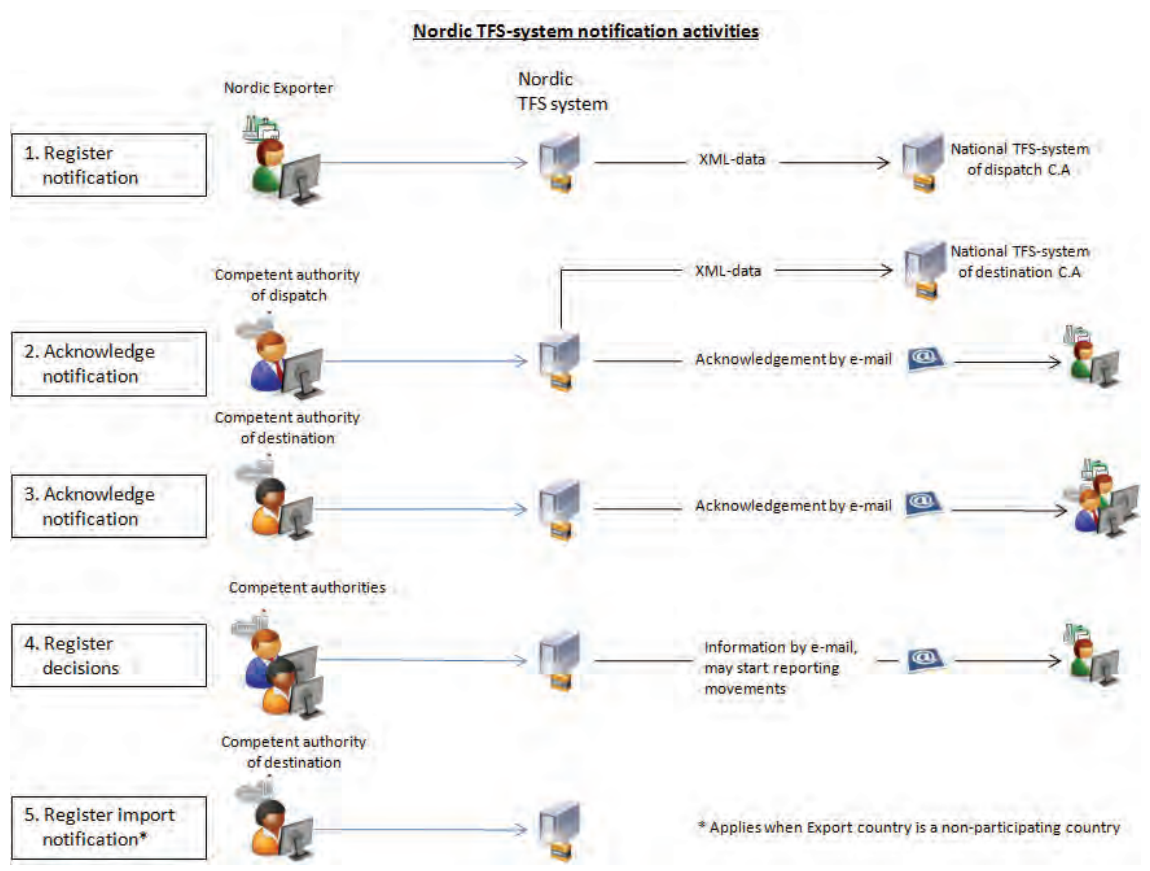

The proposed solution bring several advantages and as well as some disadvantages to the Notification procedure. Improvements brought by this solution is for example

- Superior support to exporting companies when completing the notification document

- Less errors in documentation and thus less time spent in the administrative procedures

- Faster exchange of information between stakeholders with the use of e-mail and the Nordic TFS-system instead of paper

- Less administrative work for the competent authorities as copying or printing of documentation is lessened or eliminated

- Platform for digital reporting of movements for all Nordic exporters and recover- and disposal facilities and international reporting of movements for all exporters, exporting to a Nordic country

- Data necessary to automate the annual Basel reporting

- A tool for customs, police and other involved authorities to more easily check the validity of notifications when dealing with transboundary movements of waste to or from a Nordic country

Disadvantages brought by this solution compared to the solution today is for example

- An additional system to manage (Nordic TFS-system)

- Different notification procedure for non-Nordic countries 
- Competent authority of destination have to register import notifications from non-participating countries, may lead to extra administrative work $^{43}$

\subsection{Tracking Procedure}

Once a notification has been approved by all the competent authorities involved, the exporter can start reporting shipment by sending a movement document (for each planned shipment within the relevant notification). The movement document contains all the relevant information of the waste shipment and a copy of the movement document shall always accompany the shipment (until received and disposed/recovered by facility).

The movement document contains information on

- Notification number (of the notification used for this particular shipment)

- Serial number of the transport (within the limit set by the notification)

- Exporter and Importer

- Carriers

- Waste

- Receiving facility

- Date of transport

- Actual amount of waste in shipment

\footnotetext{
${ }^{43}$ Depending on whether this registration is done today or not in any national system.
} 
ANNEX IB

Movement document for transhoundary movements/shipments of waste

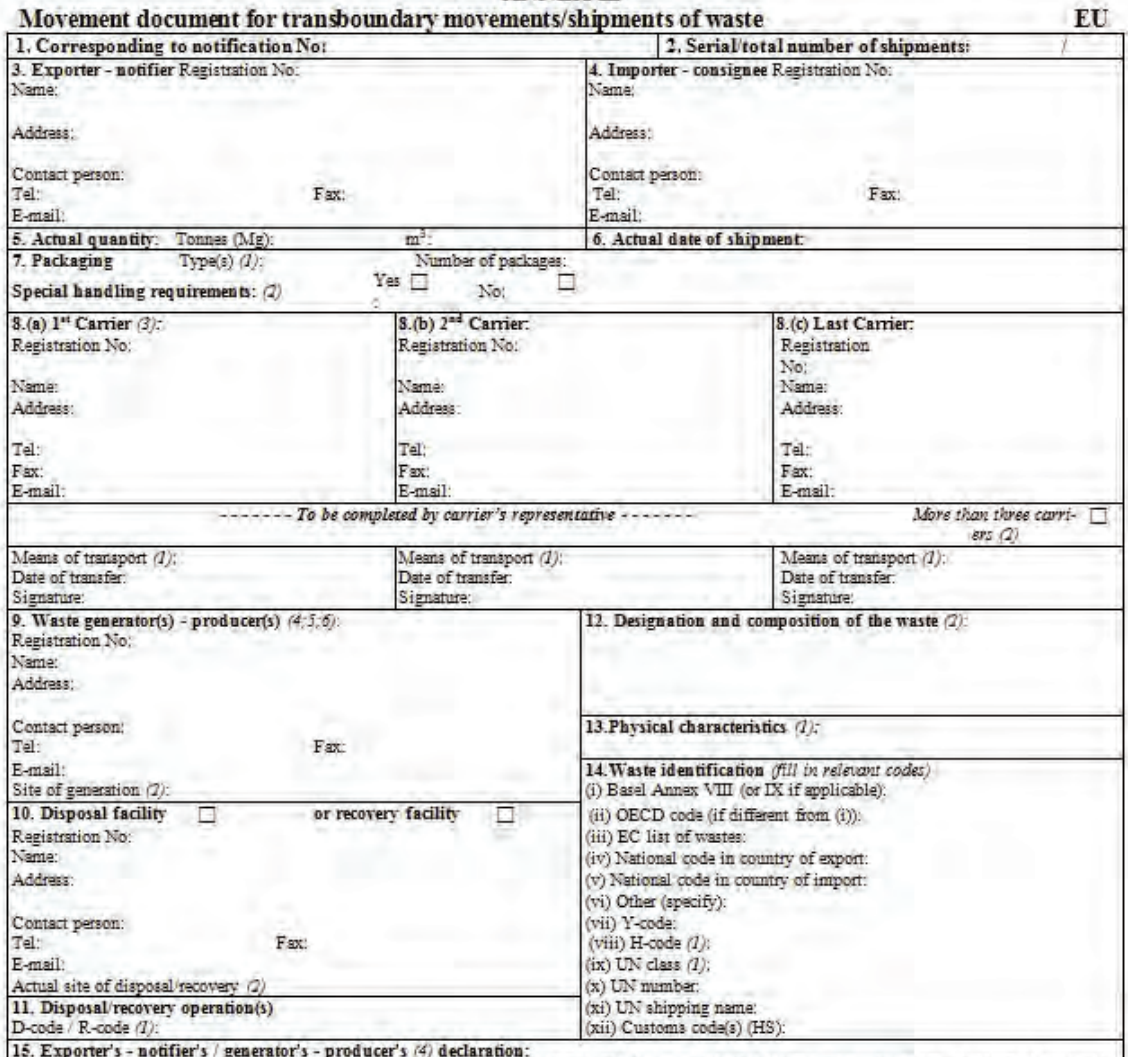

15. Exporter's - notifier's / generator's - producer's (4) declaration:

dige. I also certify that legally enforcesble written contractual obligation

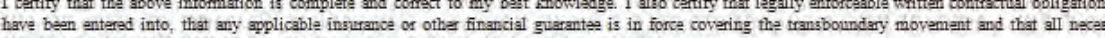

sary consents have been received from the competent suthorities of the countries concemed.
Name
Date

Signature

16. For use by any person involved in the transboundary movenent in case additional information is required

17. Shipment received by importer - consignee (if not facility): Date:
TO BE COMIPLETED BY DISPOSAL / RECOVERY FACILITY Signath

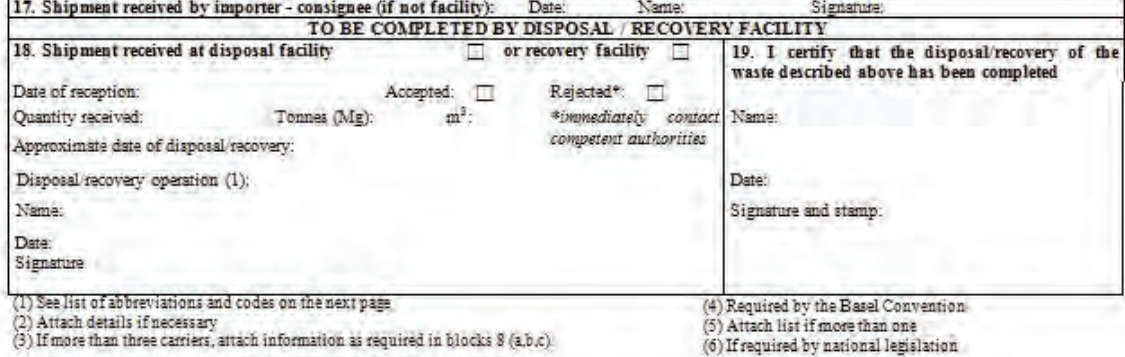

Example of English Movement Document Form (page 1).

The movement document accompanies the shipment and when the shipment is received at the destination facility, the facility send copies (receipt) of the movement document to the competent authorities in all involved countries as well as to the exporter. When the facility has recovered or disposed the waste (must be within one year of receiving the waste), the facility confirms the recovery- or disposal of the waste by sending signed copies of the completed movement document to all competent authorities and the exporter. 


\subsubsection{Digital reporting of export shipments}

The digital reporting of shipments of waste from one of the Nordic countries assumes that exporters involved in these shipments are registered as such. The number of unique companies involved as exporters varies between the Nordic countries but is in the range of 35-115 per Nordic country.

The registration process of Nordic exporters is carried out by the Nordic competent authority of dispatch. Registration of stakeholders is described detail within the chapter support procedures, registration of stakeholder procedure. The suggested procedure for reporting export movement documents and shipments are described in text and in a flowchart below.

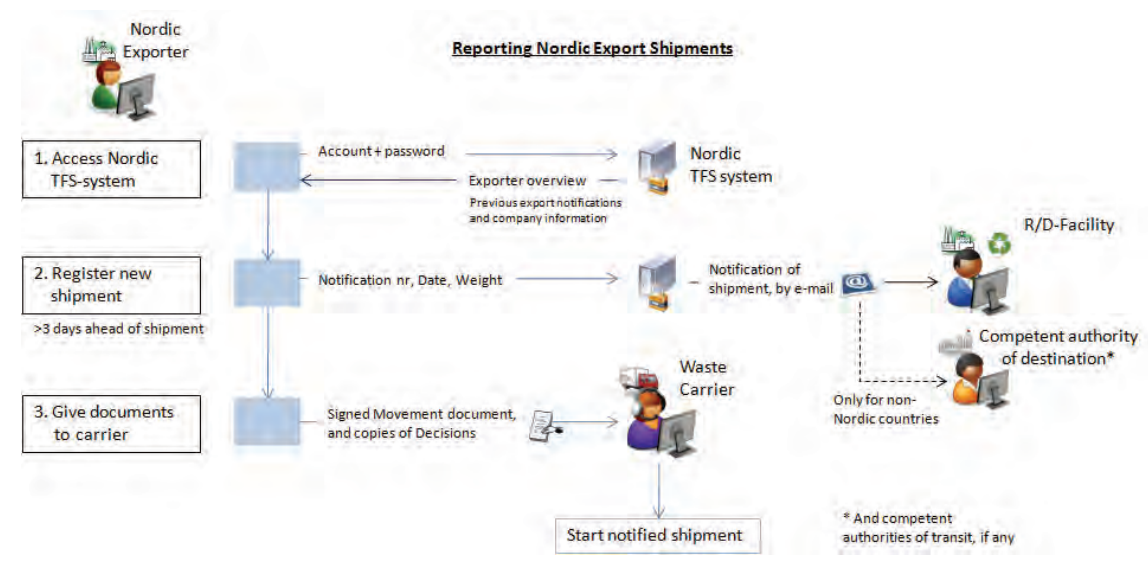

\section{Access Nordic TFS-system}

To access the Nordic TFS-system the representative for the exporting company uses the account and password given ${ }^{44}$ to them by the competent authority of dispatch. The system then provides an overview of any previous notifications registered ${ }^{45}$ as well as the company information provided in the registration of stakeholder procedure.

\section{Register new shipment}

The exporter selects one of the notifications for which he or she wants to register a new shipment. Selection is only possible if the notification is still valid (e.g. number of transports not exceeded etc). The exporter can then register date (must be at least 3 working days from current date) and the estimated weight of the shipment ${ }^{46}$.

The shipment is given the next available serial number within the allowed number of transports given in the registered decisions and the system automatically sends notification of the expected shipment to the recovery- or

\footnotetext{
${ }^{44}$ See chapter Support procedures - Registration of stakeholder procedure for details.

${ }^{45}$ Only notifications registered after the implementation of the system will be shown.

${ }^{46}$ Weight must be within the remaining weight allowed in the decision as well as within the financial guarantee weight if this information have been registered in the decision data.
} 
disposal facility and to any non-Nordic competent authority of destination involved by e-mail.

After registration of the shipment is completed the exporter prints the movement document from the TFS-system for use in the actual movement of the waste.

\section{Give documents to carrier}

When the shipment is about to begin the exporter hand over a signed copy of the printed movement document as well as copies of the signed and stamped notification documents received ${ }^{47}$ by the involved competent authorities. The carrier can then begin the actual movement in accordance with the requirements given in the decisions and in accordance with national and ECregulations.

\subsubsection{Digital reporting of import shipments}

The digital reporting of shipments of waste to one of the Nordic countries assumes that the facilities receiving waste in these shipments are registered as such. The number of unique companies involved in import varies between the Nordic countries but is in the range of $15-80$ per Nordic country.

The registration process of Nordic R/D-facilities is carried out by the Nordic competent authority of destination. Registration of stakeholders is described detail within the chapter support procedures, registration of stakeholder procedure. The suggested procedure for reporting import movement documents and shipments are described in text and in several flowcharts below.

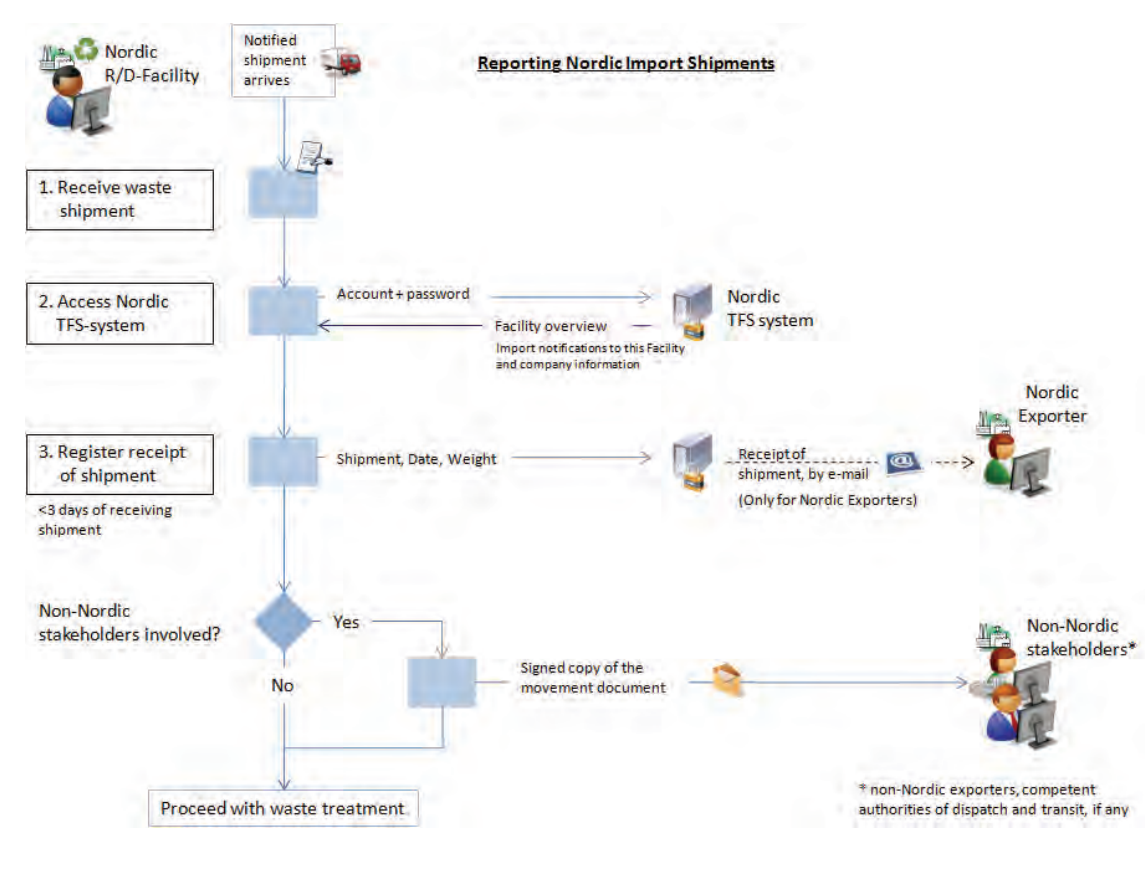

${ }^{47}$ Described in "Digital reporting of an export notification” - activity “10 Deliver decisions”. 


\section{Receive waste shipment}

When the Nordic R/D-facility receives the notified shipment, a representative for the facility receives, signs and note date and actual weight of the shipment on the movement document. The movement document is kept for documentation purposes and must be presentable upon request up to three years after the shipment started.

\section{Access Nordic TFS-system}

To access the Nordic TFS-system the representative for the receiving facility uses the account and password given ${ }^{48}$ to them by the competent authority of destination. The system then provides an overview of any previous notifications registered ${ }^{49}$ destined for their particular R/D-facility as well as the company information provided in the registration of stakeholder procedure.

\section{Register receipt of shipment}

The facility representative selects the notification and the correlating shipment number of the received shipment and registers date of receipt as well as the actual weight of the shipment. This registration must be done within three days of receipt of the waste. The Nordic TFS-system then automatical$1 y^{50}$ sends receipt of shipment with the registered information by e-mail to the Nordic exporter.

If the shipment involves non-Nordic stakeholders (e.g. non-Nordic exporter or competent authority of dispatch or transit outside the Nordic countries) the representative must also send signed copies of the movement document by mail, fax or other means depending on the competent authorities involved. After the registration of the receipt of shipment the facility may proceed with the treatment of the received waste.

\footnotetext{
${ }^{48}$ See chapter Support procedures - Registration of stakeholder procedure for details.

${ }^{49}$ Only notifications registered after the implementation of the system will be shown.

${ }^{50}$ This is only done for Nordic exporters but can be expanded to other registered stakeholders if desired.
} 


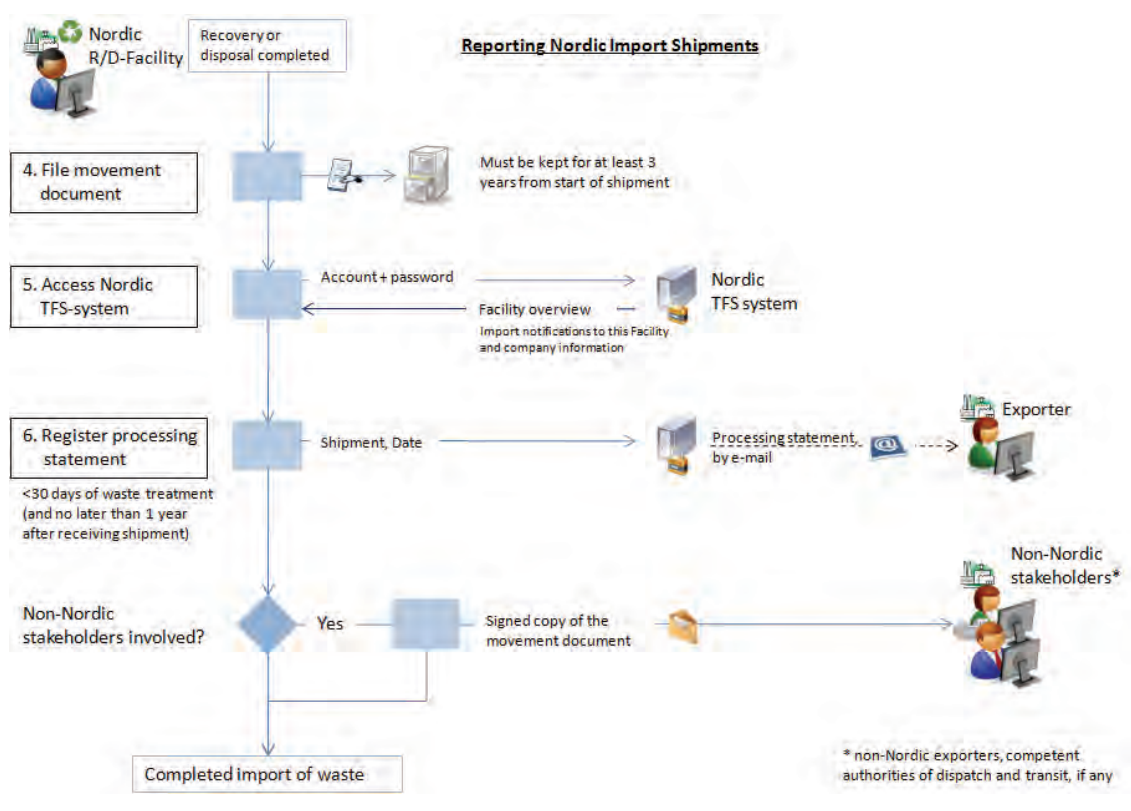

\section{File movement document}

When the Nordic R/D-facility has completed the recovery or disposal of the notified shipment of waste, a representative for the facility signs and records the date of recovery- or disposal on the original movement document. The movement document is then filed at the facility for documentation purposes and must be presentable upon request up to three years after the shipment started.

\section{Access Nordic TFS-system}

To access the Nordic TFS-system the representative for the receiving facility uses the account and password given ${ }^{51}$ to them by the competent authority of destination. The system then provides an overview of any previous notifications registered $^{52}$ destined for their particular R/D-facility as well as the company information provided in the registration of stakeholder procedure.

\section{Register processing statement}

The facility representative selects the notification and the correlating shipment number of the recovered or disposed shipment and registers the date of recovery- or disposal of the shipment. This registration must be done within 30 days of treatment and no later than one calendar year after receiving the waste. The Nordic TFS-system then automatically ${ }^{53}$ sends the processing statement with the registered information by e-mail to the Exporter.

If the shipment involves non-Nordic stakeholders (e.g. non-Nordic exporter or competent authority of dispatch or transit outside the Nordic coun-

\footnotetext{
${ }^{51}$ See chapter Support procedures - Registration of stakeholder procedure for details.

${ }^{52}$ Only notifications registered after the implementation of the system will be shown.

${ }^{53}$ This is only done for Nordic exporters but can be expanded to other registered stakeholders if desired.
} 
tries) the representative must also send signed copies of the movement document by mail, fax or other means depending on the competent authorities involved. The notified shipment has now been completed but other shipments concerning the same general notification may still be active or started later within the given requirements of the general notification.

\subsubsection{Digital reporting of non-Nordic shipments (export and import)}

Since the solution is built on the assumption that not all countries involved in waste shipments to or from the Nordic countries will participate in the suggested solution, this also means that some of the notified shipments will have a counterpart which is not part of the Nordic countries. In order to manage the shipment notifications, receipt of shipments and recovery confirmations involved in the tracking procedure a solution is provided for the digital reporting of non-Nordic shipments in the text and flowchart below.

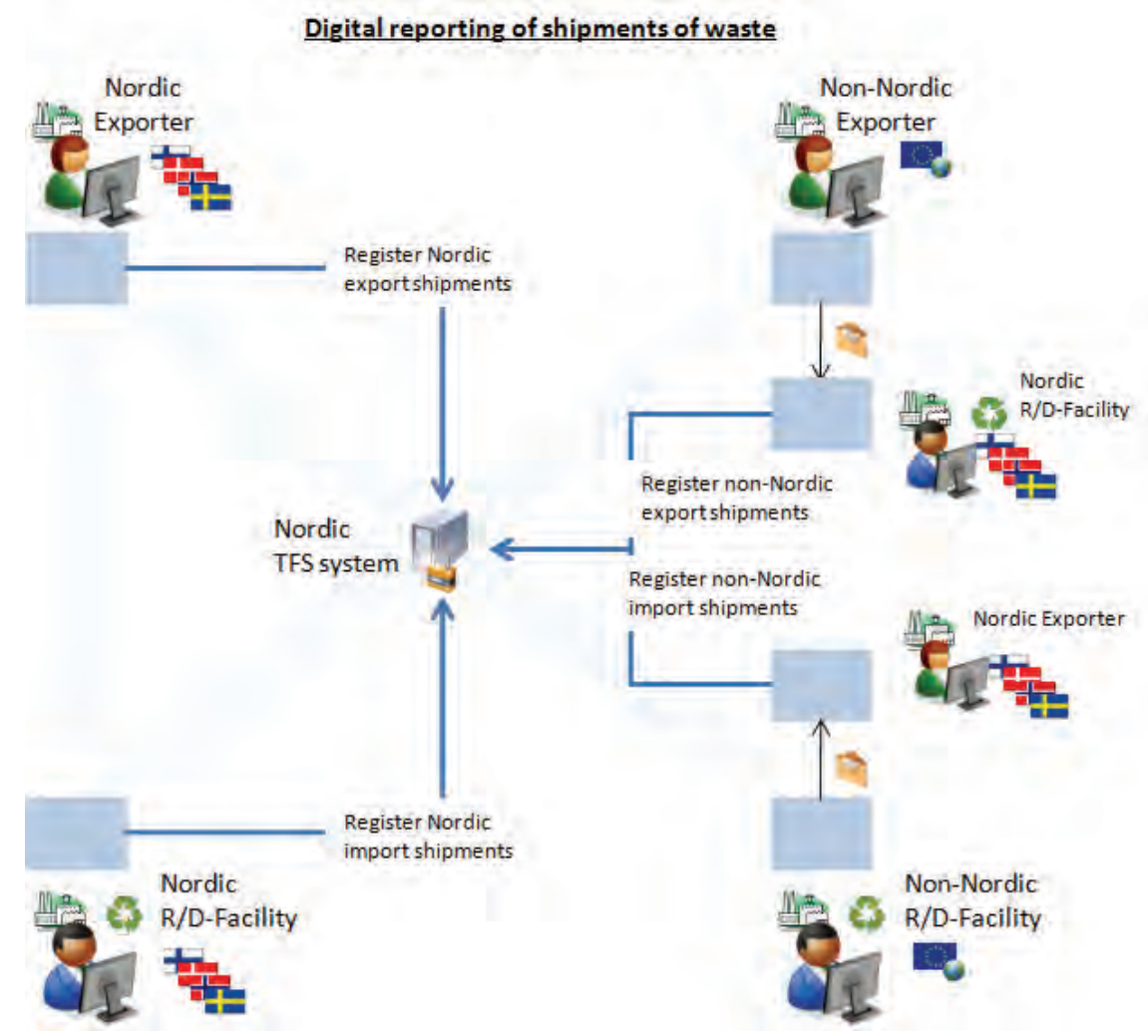

Digital reporting of non-Nordic shipment notifications will be reported by the receiving Nordic R/D-facility as they receive their signed copy of the movement document from the non-Nordic exporter. The reporting procedure is done in the same way a Nordic exporter notifies a shipment, but it is done by a representative for the receiving facility instead of a representative for the exporter. 
The digital reporting of non-Nordic receipt of shipment and recovery confirmation will be reported by the Nordic exporter as they receive their signed copy of the movement document from the non-Nordic R/D-facility. The reporting procedure is done in the same way a Nordic R/D-facility report receipt of shipment and the processing statement, but it is done by a representative for the Nordic exporter instead of a representative of the receiving R/D-facility.

\subsubsection{Conclusion tracking procedure}

The solution described within this report focus on the participation of the Nordic countries with the possible participation of a few other interested countries. By limiting the scope of the participating countries it is easier to reach common ground on the solution but it also raises a few issues that have to be resolved in order to reap some of the desirable benefits that the solution can provide. To ensure the automated reporting capabilities of the solution as well as a preferred more complete version of digital reporting of shipments, the issue of digital reporting for shipments involving non-Nordic exporters and non-Nordic recovery- or disposal facilities must be resolved. This is done by giving the responsibility of digital reporting to the relevant Nordic counterpart ${ }^{54}$.

As suggested in the chapter 2.2 Notification procedure the responsibility of registering of non-Nordic import notifications is to be managed by the Nordic competent authority of destination. In combination with the digital reporting of shipments (directly or indirectly) this would lead to a situation where all information regarding export from or import to a Nordic country is found within a common Nordic TFS-system which would reduce to number of paper based (or fax based) papers to a minimum. It would also give other stakeholders (e.g. customs, police, exporters, importers etc.) a way to track waste movements within their area of responsibility.

Provided that the solution can encompass all of the reporting involved in the tracking procedure this would also make it possible to relieve the stakeholders of the annual reporting requirement as that information would already be easily available to the competent authorities involved.

The solution proposed have been designed so that the solution

- Is in appliance with EC-legislation 1013/2006

- Not interfere with or replace national TFS-systems in use

- Is cost-effective and easy to use

- Enable digital reporting of movement documents

- Is complete and provide means for automated reporting capabilities

The solutions contain the following changes or additions to the tracking procedure compared to the ones used today

\footnotetext{
${ }^{54}$ Non-Nordic exporter - Nordic R/D facility, non-Nordic R/D facility - Nordic exporter.
} 
- Nordic exporters register a digital notification of shipment prior to the actual shipment instead of faxing the movement document to the Nordic competent authorities

- Nordic R/D-facilities register a digital receipt of shipment and a processing statement instead of faxing to the Nordic competent authorities

- Nordic exporters and R/D-facilities are relieved ${ }^{55}$ of the requirement to make annual reports to the Nordic competent authorities

- Nordic exporters and R/D-facilities take responsibility for the digital reporting of their respective non-participating counterparts (only applicable for non-Nordic stakeholders)

- Provide a platform for custom, police and other authorities to access relevant information on waste moments within their area of responsibility

- Elimination or reduction to a minimum of paper documents or fax based documents within the tracking procedure for involved authorities and stakeholders

The below chart shows the main activities of the notification procedure where the TFS-system is involved

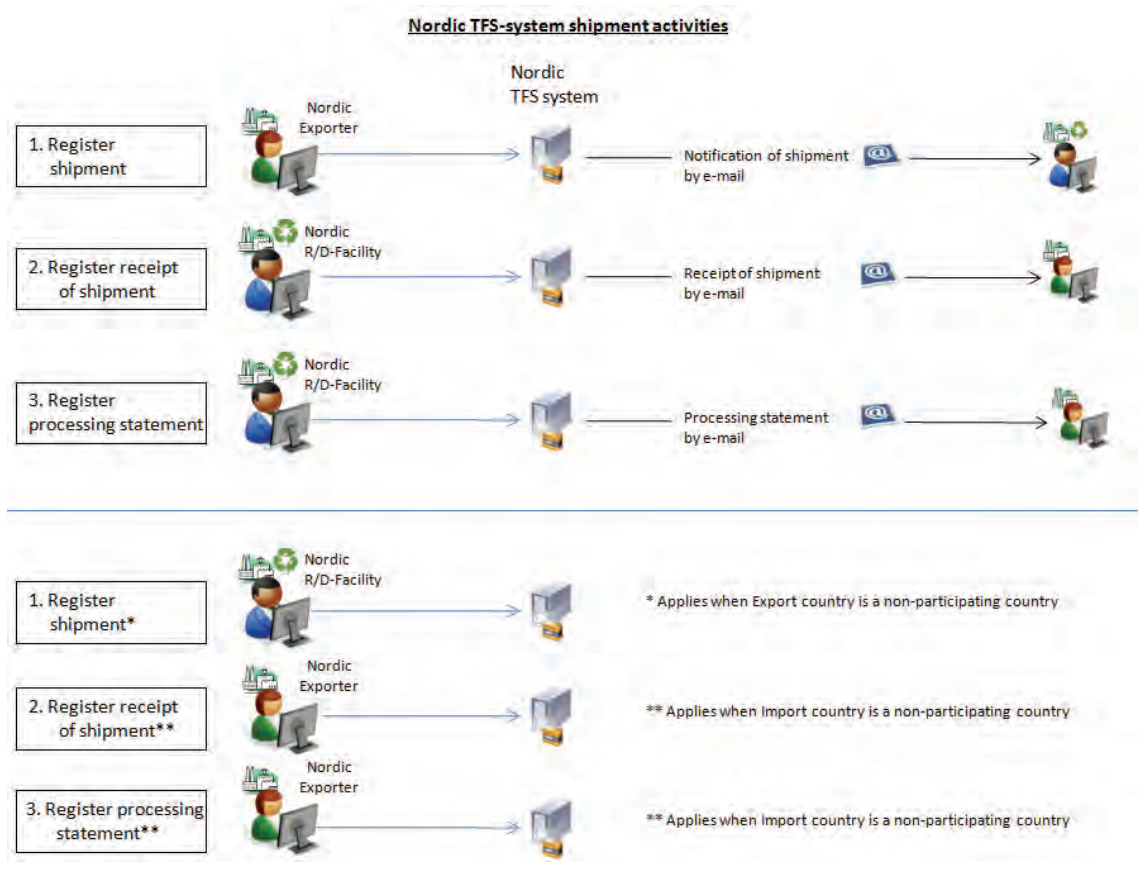

The proposed solution bring several advantages and as well as some disadvantages to the Notification procedure. Improvements brought by this solution is for example

\footnotetext{
${ }^{55}$ Provided that the solution encompass digital reporting for all movements to or from a Nordic country.
} 
- Faster exchange of information and less administrative work with the use of e-mail and the Nordic TFS-system instead of paper

- Less administrative work for the competent authorities as the digital reporting is done by the exporters and facilities

- Elimination of the annual reporting requirement for exporters and facilities and at the same time a platform for an automated annual Basel reporting procedure

- A tool for customs, police and other involved authorities to more easily check and prepare for the individual shipments of waste

- Allows for automatic control measures such as warnings when a notified shipment has not been received within a certain amount of time

Disadvantages brought by this solution compared to the solution today is for example

- An additional system to manage (Nordic TFS-system)

- Nordic exporters and facilities have to take responsibility of reporting their non-Nordic counterpart's shipment data.

\subsection{Support Procedures}

This chapter covers those procedures that support the core procedures (e.g. the notification procedure and the tracking procedure). These are important support procedures that help to improve the overall benefits of the solution and provide positive side-effects in the managing of general waste management. The procedures below are part of the core procedures but are detailed separately to avoid making the descriptions of the core procedures ${ }^{56}$ to complex but still provide detailed information of the recommended solution.

\subsubsection{Registration of stakeholder procedure}

In order to increase efficiency in the notification and movement procedures and to enable keeping accurate information about the different stakeholders this study recommend the registration of Nordic stakeholders ${ }^{57}$ involved in the import to a Nordic country or export from a Nordic country. Keeping such a register will provide

- More accurate information on stakeholders

- A basis for

a) Exporters to register notifications online

\footnotetext{
${ }^{56}$ Core procedures are the Notification procedure and the Tracking procedure.

${ }^{57}$ Importers, exporters, brokers, recovery- and disposal facilities involved in transboundary movements of waste.
} 
b) Faster registration of address and contact information (block 1, 2 and 6 in notification form)

c) Stakeholders to report movement documents online

- Better support when producing statistical information on waste

- More efficient managing of activities (e.g. information campaigns) directed at certain groups of stakeholders

Nordic Stakeholders register by accessing a registration form. The registration form contain information given in block ${ }^{58} 1-2$ and $8-10$ in the notification form, type of stakeholder (e.g. exporter, facility etc) as well as the registration number of the applying company.

The competent authority receives an e-mail with the newly registered stakeholder's information and approves the registration in the TFS-system which returns an e-mail containing account and password information to the registered stakeholder. The account and password information is bound to a certain representative of the stakeholder and it is possible to apply for several accounts, by listing the representatives and their respective e-mail addresses. Each user will be required to change the password given when they login for the first time.

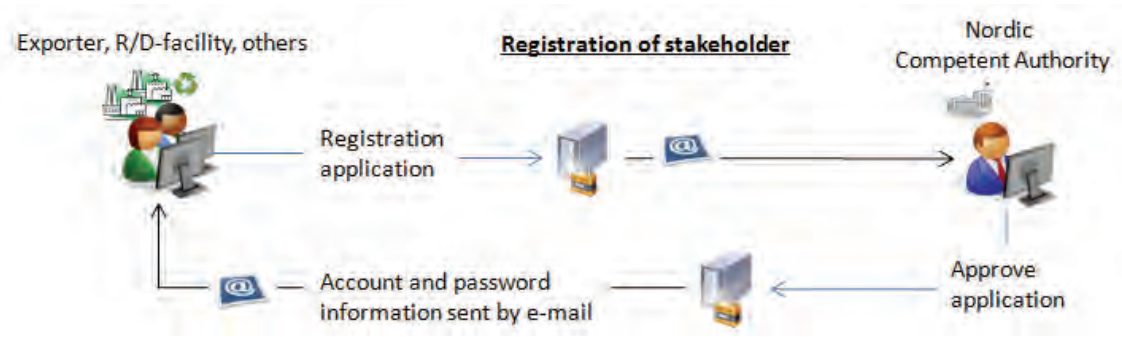

Overview of the Registration procedure of a stakeholder.

The registration procedure should be accompanied by an administrative fee to cover the competent authorities' costs of maintaining such a register. The registration (and its fee) should be limited in time (e.g. 1 year or 3 years) to help insure that the register is kept updated and that only active stakeholders remain in the register.

Based on import and export notifications from Sweden, Finland and Norway in 2008, the figures below show the approximate amount of stakeholders that such a register would hold ${ }^{59}$. A comparison between 2008 and 2009 show that approximately 85-90 percent of the stakeholders remain the same between two years.

- 220 Exporters - (Sweden 115, Finland 33, Norway 72)

- 120 Importers - (Sweden 79, Finland 15, Norway 23)

\footnotetext{
${ }^{58}$ The blocks contain Name, Address, Contact person, Tel, Fax, E-mail information.

${ }^{59}$ Not counting Denmark because the data is unavailable.
} 
The registration of stakeholders could be expanded to include non-Nordic exporters ${ }^{60}$ and non-Nordic importers ${ }^{61}$ involved in waste movements to or from a Nordic country as this would increase the efficiency of the tracking procedure. If these stakeholders were added to the solution that would increase the number of the registered companies by approximately

- 85 non-Nordic Exporters - (Sweden 50, Finland 20, Norway 15)

- 130 non-Nordic importers - (Sweden 60, Finland 30, Norway 40)

\subsubsection{Registration of import notifications from outside the Nordic countries}

The solution described in the notification procedure chapter expects all of the Nordic export notifications to be entered by the exporters in those countries, thus providing notification data to the import country whereas the exporting country is one of the Nordic countries. Since a major part of the Nordic waste import comes from other Nordic neighbours this solution provide notification data on all exports and between 44-81 percent of the import notifications depending on the Nordic country involved ${ }^{62}$.

The solution however does not cover import notifications from exporting countries outside the Nordic countries. While not entirely essential to the solution, there are major benefits that would be gained if all notification data regarding waste movements to and from the Nordic countries where gathered in the Nordic TFS system. Keeping a complete set of notification data for the Nordic countries would make it possible to develop or provide:

- Digital reporting of movements for all Nordic exporters and recoverand disposal facilities

- Data necessary to automate the annual Basel reporting

- International reporting of movements for all exporters, exporting to a Nordic country

- A tool for customs, police and other involved authorities to more easily check the validity of notifications when dealing with transboundary movements of waste to or from a Nordic country

To achieve the above benefits however, someone must register the notification data ${ }^{63}$. While the preferred solution would be to defer this responsibility to the exporter this is not realistic as that would require an international solution involving all competent authorities and all exporters. Instead this prestudy recommends that the competent authority of the importing Nordic country assumes the responsibility of registering the import notifications originating from non-Nordic countries. The competent authority register the

\footnotetext{
${ }^{60}$ Exporting waste from outside the Nordic countries to a Nordic country.

${ }^{61}$ Importing waste from a Nordic country.

${ }^{62}$ Coverage of import notifications is $63 \%$ for Sweden, 44 percent for Finland and 81 percent for Norway (2008 figures).

${ }^{63}$ Applies to import notifications from countries not being part of the solution.
} 
necessary notification data when the notification have been received and when a decision has been made regarding the notification and it also updates notification data when receiving decisions from a competent authority outside the Nordic countries.

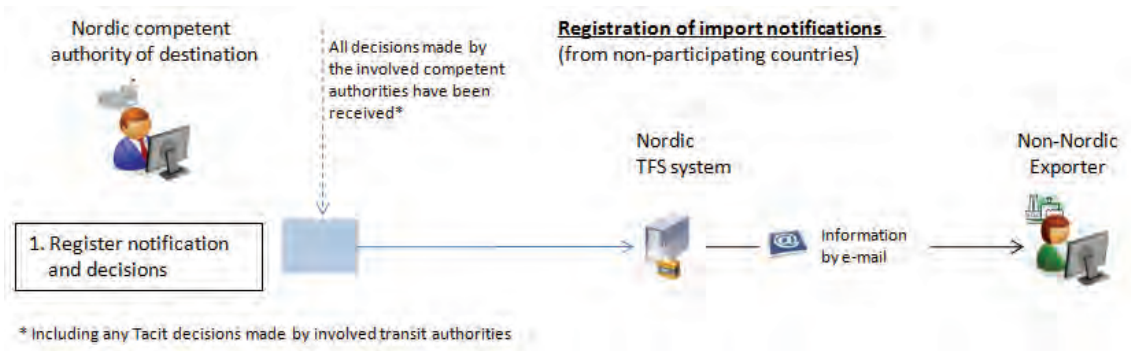

Overview of the import notification registration procedure for non-Nordic imports.

The extra work that ensues from this activity will amount to approximately 160 notifications annually (Sweden 100, Finland 40 and Norway 20) based on 2008 figures.

\subsubsection{Annual national Basel reporting}

Each country that is a Party to the Basel Convention is required to report information on the generation and movement of hazardous wastes. Every year, a questionnaire is sent out to member countries, requesting information on the generation, export and import of hazardous wastes covered by the Convention. This information is reviewed and compiled by the Secretariat and is presented in an annual report, which includes statistical tables and graphic representations of the data. These documents are available at www.basel.int/.

As described in the chapters of Notification procedure and Tracking procedure almost all of the information needed to produce the annual Basel report is already stored within the Nordic TFS system. The system can provide report data for Basel tables 6, 7 and part of table 8a which specifies totals and subtotals of exports and imports of waste for a particular country and year.

The information is gathered from the notification data provided by the exporters (sometime through the registration by a Nordic competent authority) as well as the corresponding notifications of shipment and receipts of shipment that the Nordic exporters and R/D-facilities report within the tracking procedure. 


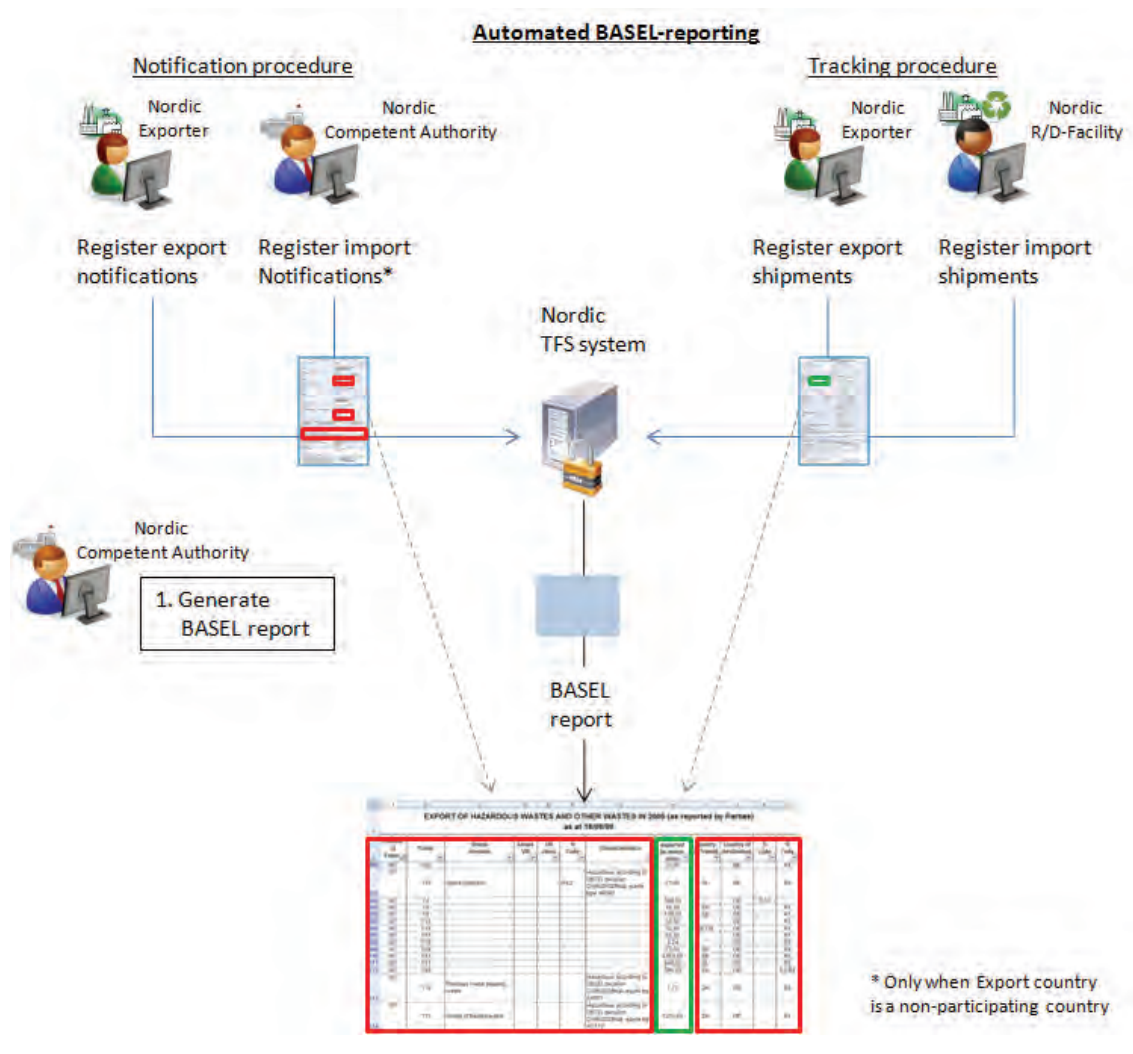

The information stored in the Nordic TFS-system could give different reports based on the parameters given. Reports could be grouped by country, year, waste types etc. as long as data for the given parameters exist within the system. Queries could only be made for information registered after the implementation of the Nordic TFS-system.

The Nordic TFS-system should include functionality to export reports in the form of Microsoft Excel sheets pre-formatted in accordance with the tables given in the blank Basel questionnaire (Part II, Section A). This will allow the Nordic competent authorities to produce the basis an almost complete annual Basel report and make it possible to complete the report with comments, remarks and other waste information not contained within the Nordic TFS-system.

To ensure that the information is trusted, the current procedure with an annual questionnaire to the stakeholders involved could be kept concurrently with the implementation of the Nordic TFS-system. However after verifying that the information provided through the Nordic TFS-system is correct and complete, the need for the stakeholders annual reporting should stop to exist and the requirement should be lifted to further lessen the administrative burden for stakeholders as well as involved competent authorities. 


\subsection{Regulation requirements}

The notification procedure and the procedure involving the reporting of transboundary movements of waste are subject to several regulations (e.g. 1013/2006, national regulations). Limitations of the scope of this pre-study have excluded national regulation and legislation as well as EC- regulation in general terms and have focused on the part of the EC-regulation that specify in which forms and media documents and information can be transferred between stakeholders and competent authorities, and in particular which documents that can be transmitted digitally and which that have to be sent as signed copies/originals on paper.

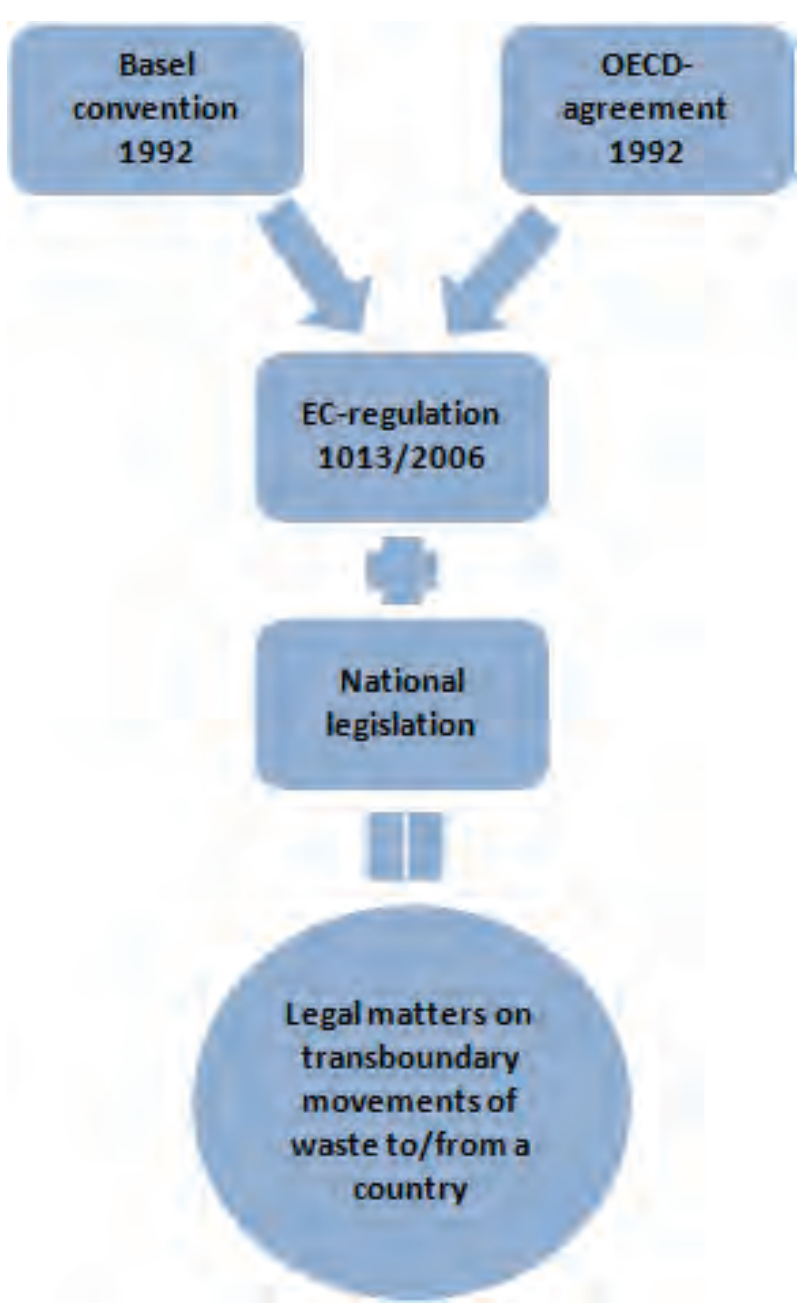

The regulation 1013/2006 have had a big impact on the proposed solutions of this pre-study since it play a major part in the effectiveness and beneficiary effects a digital reporting system might have on the procedures involved in transboundary movement of waste. If a regulation for example stipulates that a certain document has to be sent as a signed copy (e.g. movement document when received by facility) to stakeholders and competent authori- 
ties, this reduces the effectiveness and some of the benefits of using a system for digital reporting.

Described below are the most important documents and information within the Notification and Tracking procedures as well as an interpretation of the current legislation regarding the media used when transferring this information between stakeholders and competent authorities or between different competent authorities.

\subsubsection{Notification document}

Prior to commencement of each transboundary movement of wastes, the exporter shall provide written notification ("single notification") to the competent authority of dispatch. The notification document shall include all of the information listed regarding the notification document in the ECregulation ${ }^{64}$.

In cases where essentially similar wastes ${ }^{65}$ are to be sent periodically to the same recovery facility by the same exporter, the competent authorities of the countries concerned may elect to accept one "general notification" for such multiple shipments for a period of up to one year ${ }^{66}$.

The original notification document is to be signed and dated by the Exporter (and in the case of a recognised trader acting as an exporter, both the waste generator and the trader acting as exporter) before being forwarded on paper to the Competent Authority.

\subsubsection{Contract documents}

Transboundary movements of wastes which require notification may only occur under the terms of a valid written contract between the exporter and the recovery facility.

The contract shall:

- Clearly identify the generator of each type of waste and each person who shall have legal control of the wastes and the recovery facility

- Provide that relevant requirements of EC-regulation are taken into account and are binding on all parties to the contracts

- Specify which party to the contract shall assume responsibility for an alternative management of the wastes in compliance with applicable laws and regulations including, if necessary, the return of the wastes

A copy of the contract or such evidence to the satisfaction of the competent authority concerned shall be provided by the notifier or consignee upon request by the competent authority.

\footnotetext{
${ }^{64}$ Regulation(EC) No 1013/2006 of the European Parliament and of the Council of 14 June 2006 on shipments of waste.

${ }^{65}$ E.g. those having essentially similar physical and chemical characteristics.

${ }^{66} \mathrm{Up}$ to three (3) years in the case of pre-consented recovery facilities.
} 


\subsubsection{Financial Guarantee}

All transboundary movements of waste which require notification require the notifier (or someone on its behalf) to provide a financial guarantee. The financial guarantee should cover

- Costs of transport

- Costs of recovery or disposal

- Costs of storage for 90 days.

The financial guarantee or equivalent insurance is intended to cover costs arising in the context of cases where a shipment or the recovery/disposal cannot be completed as intended or cases where a shipment is considered illegal ${ }^{67}$

As the competent authority within the Community which has approved the financial guarantee (usually the competent authority of dispatch) also is the one which needs access of the financial guarantee in the cases described above it seems appropriate to require a signed financial guarantee accompanying the notification document for safekeeping at the relevant competent authority (and replacing paper copies thereof with digital copies), usually the original is kept by the competent authority of dispatch.

\subsubsection{Transmission and Acknowledgement of Notification}

Once the notification has been properly completed the competent authority of dispatch shall retain a copy of the notification and transmit the original notification to the competent authority of destination with copies to any competent authorities of transit, and shall inform the notifier of the transmission. This shall be done within three working days of receipt of the notification.

When the competent authority of destination considers that the notification has been properly completed, it shall send an acknowledgement to the notifier and copies to the other competent authorities concerned. This shall be done within three working days of receipt of the properly completed notification.

\subsubsection{Decision (Consent or Objection)}

The competent authorities of destination, dispatch and transit shall have 30 days following the date of transmission of the acknowledgement by the competent authority of destination in which to take a decision in writing regarding the notification. The competent authorities of destination dispatch and, where appropriate, transit shall transmit their decision and the reasons therefore to the notifier in writing within the 30-day time limit, with copies to the other competent authorities concerned.

Decisions shall be written and accompanied with the appropriate stamping, signing and dating of the notification document and the copies thereof.

\footnotetext{
${ }^{67}$ See article 22 of the Regulation(EC) No 1013/2006 of the European Parliament and of the Council of 14 June 2006 on shipments of waste for more information
} 


\subsubsection{Movement document}

The exporter shall complete and sign the movement document and shall send signed copies of the movement document to the competent authorities concerned and to the consignee at least three working days before the shipment starts. A copy of the signed movement document is to be retained by the exporter. Copies of the notification document containing the written consents of the competent authorities shall accompany each transport.

Each carrier shall complete and sign the movement document when taking possession of the waste. The recovery facility shall, by completing and signing the movement document, certify receipt and then recovery of the waste. Signed copies of the completed movement document (both when receiving and at the recovery/disposal of waste) must be sent to the exporter and the relevant competent authorities concerned.

\subsection{Format of the communications}

The format in which the communication of the above documents can be communicated is described in article 26 of the EC-regulation 1013/2006. The information and documents listed below may be submitted by post

- Notification (single shipment or general notification)

- The request and submission of additional documentation requested by competent authorities regarding the notification

- Written consent, conditions and/or objections to a notification

- Information on decisions to issue pre-consents to specific recovery facilities

- Prior information regarding actual start of the shipment

- Written confirmation of receipt of the waste pursuant

- Certificate for recovery or disposal of the waste pursuant

- Information on changes in the shipment after consent

- Written consents and movement documents to be sent regarding import/export/transit to and from third countries

Subject to the agreement of the competent authorities concerned and the notifier, the documents referred to in the above list may alternatively be submitted using any of the following methods of communication:

- Fax

- Fax followed by post

- E-mail with digital signature. In this case, any stamp or signature required shall be replaced by the digital signature

- E-mail without digital signature followed by post

The documents to accompany each transport (original movement document and copies of written consents of the competent authorities involved) may 
be in an electronic form with digital signatures if they can be made readable at any time during the transport and if this is acceptable to the competent authorities concerned.

Subject to the agreement of the competent authorities concerned and of the notifier, the information and documents in the list above may be submitted and exchanged by means of electronic data interchange with electronic signature or electronic authentication in accordance with the EC-Directive ${ }^{68}$, or a comparable electronic authentication system which provides the same level of security. In such cases, organisational arrangements concerning the flow of electronic data interchange may be made.

The Financial guarantee and contract documents however is not included in the above list and the format in which communication is carried out does not seem to be covered by article 26 in the EC-regulation 1013/2006. However information on the documentation itself can be found in article $5 \& 6$ of the EC-regulation 1013/2006.

\subsubsection{Conclusion}

As the article 26 in the EC-regulation stipulates, the basis of exchanging information is by post. This however can be replaced by several other means of communication subject to the agreement of the competent authorities concerned and the notifier.

The documents involved in the transboundary movement of waste is used for different purposes as described above and replacing all of them with digital versions would require large investments in IT-infrasture by stakeholders, customs, police as well as the involved competent authorities. In addition to the issue of investments there are national legislation issues that have to be addressed and the difficult task of bringing all of the countries involved to agree on a common solution.

Based on this, the pre-study recommends the Nordic countries to keep certain documents (e.g. financial guarantee, original notification etc.) in a paper based form, while replacing others with a digital form. As the Nordic countries main trading partners are other Nordic countries it should be possible to reach a common stance on which of these documents that could be replaced and also decide the means of exchanging this information between Nordic countries as well as any other country willing to agree to the solution decided.

The pre-study recommends the following on the exchange of information between the Nordic countries (and others willing to agree to this recommendation):

- To keep the financial guarantee and the original notification and movement documents in a paper based form

\footnotetext{
${ }^{68}$ Directive 1999/93/ EC of the European Parliament and of the Council of 13 December 1999 on a Community framework for electronic signatures.
} 
- Require (of the exporter) digital copies of all documentation involved in the notification

- Replace exchange of notification documents with the above digital set when dealing with other Nordic countries (exception signed Notification document)

- Use e-mail for acknowledgements of transmission and acknowledgement of notification to exporters and all competent authorities involved and ready to accept this solution

- Keep the decision document on paper while replacing the decision sent to other involved countries with a digital version of the signed and stamped original

- Registration of decisions in a common database where Nordic countries are involved as import/export or transit authorities for the use of digital reporting of movement documents by the stakeholders

The recommendations above are described in two flowcharts showing the important documents involved in the notification and movement procedure. The changes are mainly aimed at the Nordic countries but can be applied to all countries which accept the recommended solution (or part thereof).

Any of the digital documents and the digital exchange may be substituted for the current paper based procedure (e.g. when dealing with a country not accepting digital documents) but this will of course reduce some of the benefits gained by digitalizing the procedures.

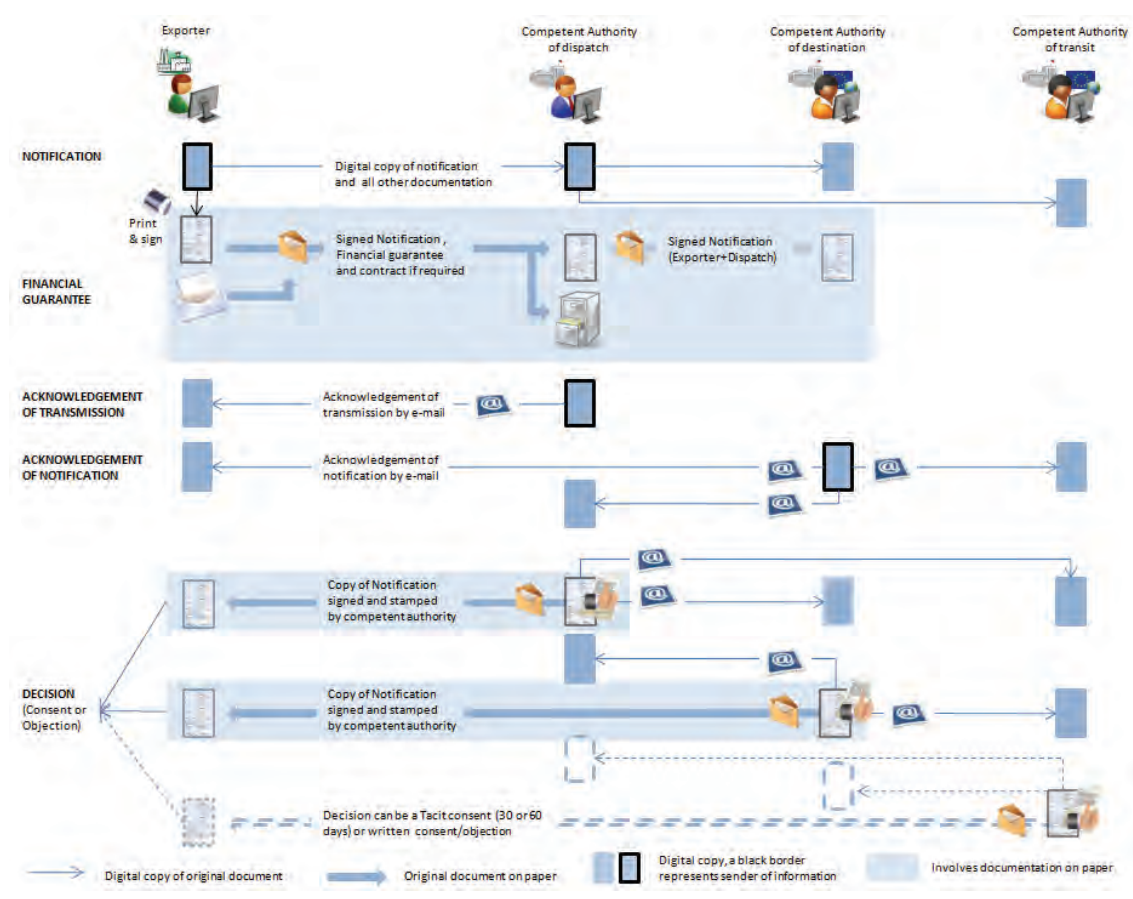

Flowchart of documents and stakeholders involved in the notification procedure with the recommended changes applied to the process. 


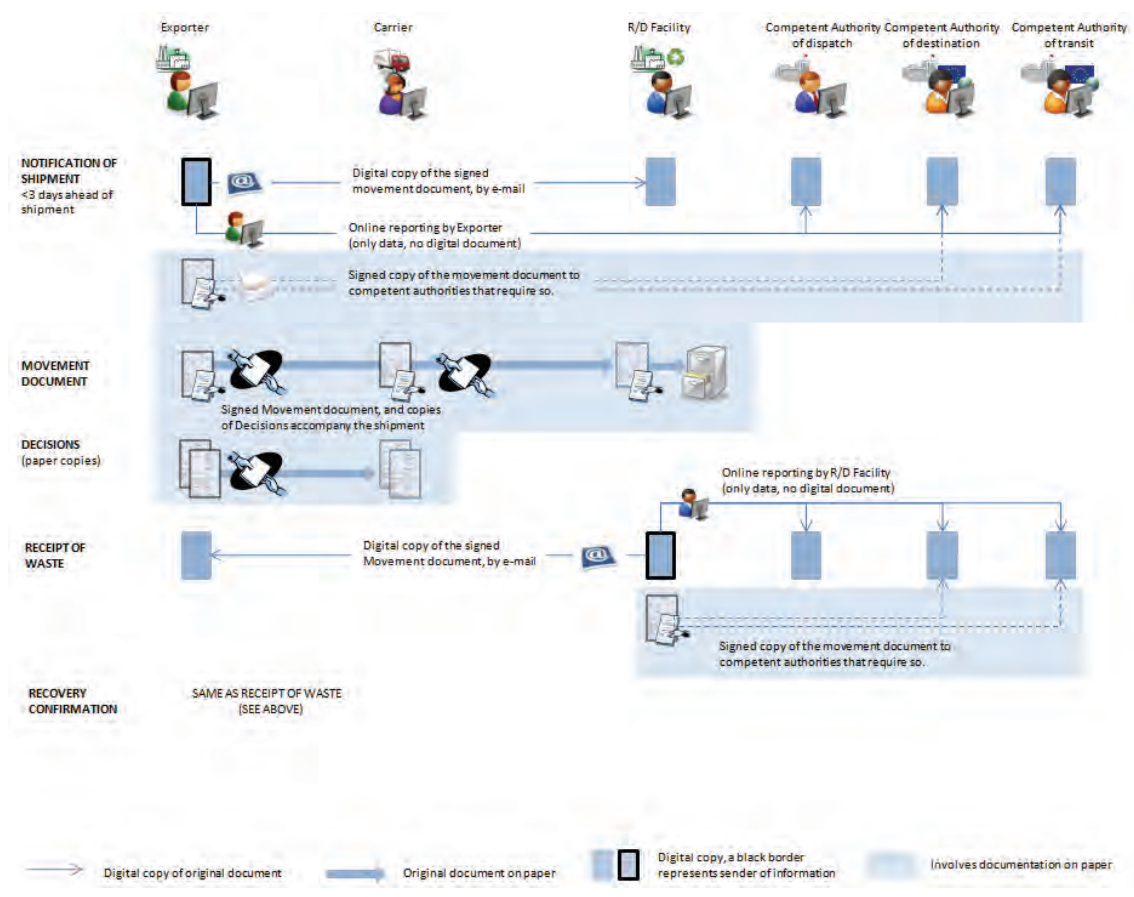

Flowchart of documents and stakeholders involved in the notification procedure with the recommended changes applied to the process.

\subsection{Digital Signatures}

Article 26 in the EC-regulation 1013/2006 makes it possible to replace almost all of the paper documents that are involved in the notification and tracking procedures with electronic versions of the paper documents. It even allows for the documents that accompany the transport to be replaced with electronic versions with digital signatures subject to the agreement of the notifier and the competent authorities concerned and provided that the documents can be made readable at any time during the transport and that this is acceptable to the competent authorities concerned.

Digital signatures are basically pieces of data which is attached to a message and which can be used to find out if the message was tampered with during the conversation (e.g. through the intervention of a malicious user). 


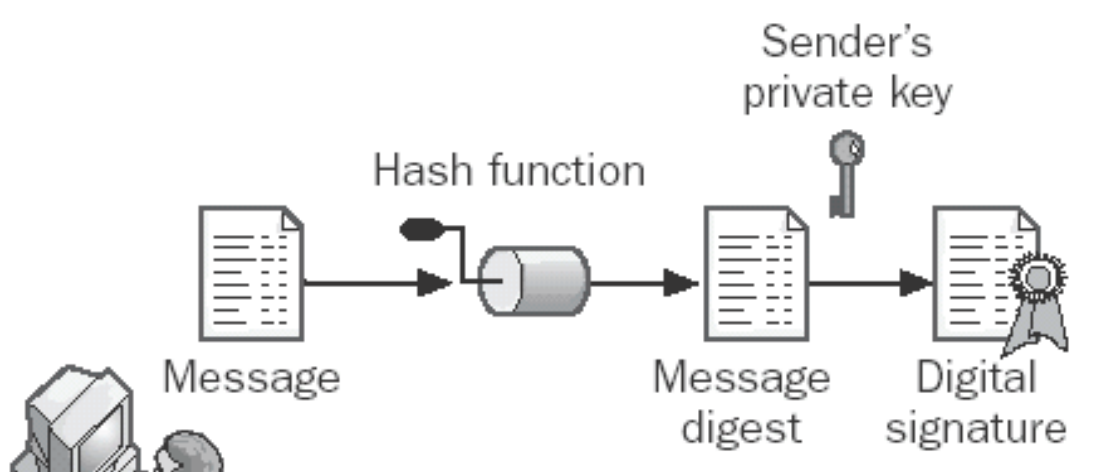

Sender

Creating a Digital Signature

Graphic from sample chapter of Microsoft Encyclopedia of Security.

Combined with a digital certificate, the data can be used to validate who you are. They can be used by different software to confirm your identity to any third party concerned. Digital signatures are commonly used by banks to validate the identity of their customers through their use of a digital certificate.

This could for example be used to ensure that a notification or a receipt of waste by e-mail is from the originating sender and that it has not been tampered with. Digital signatures are not to be confused with Electronic signatures which are scanned copies of a physical written signature.

The use of public-key cryptography can ensure secure conversations through internet and the use of digital signatures can ensure integrity of the conversation, but to ensure authenticity of the sender the digital signature will have to be combined with a digital certificate.

Digital signatures combined with a digital certificate can provide the following effects

- Insure by means of verification and validation that the user is whom he/she claims to be

- Insure data integrity and proves that the message or transaction has not been accidentally or maliciously altered

- Provide confidentiality and ensure that messages can only be read by authorized intended recipients.

- Verify date and time so that senders or recipients can not dispute if the message was actually sent or received.

There are several ways that digital signatures and the use of public and private keys can be used when communicating with digital documents. The different ways provide different benefits and they can be combined to achieve one or more desirable effects. 
In order to be able to communicate with digital signatures and at the same time ensure the authenticity of the sender each of the involved stakeholders would need the following

- A public key

- A private key

- A digital certificate from a third party

The public key is known to everyone (it is a public) it can be used to encrypt or decrypt messages. The private key must be known only by its owner and can be used by the owner to encrypt or decrypt messages. The digital certificate certifies that the public key is owned by this particular stakeholder. This is signed by a third party called the certificate authority.

\subsubsection{Using digital signatures in document exchange}

A digital signature can be added in all document exchange between stakeholders involved in the transboundary movement of waste procedures. The document exchange between an exporter and a competent authority which uses digital signatures can be exemplified as described below

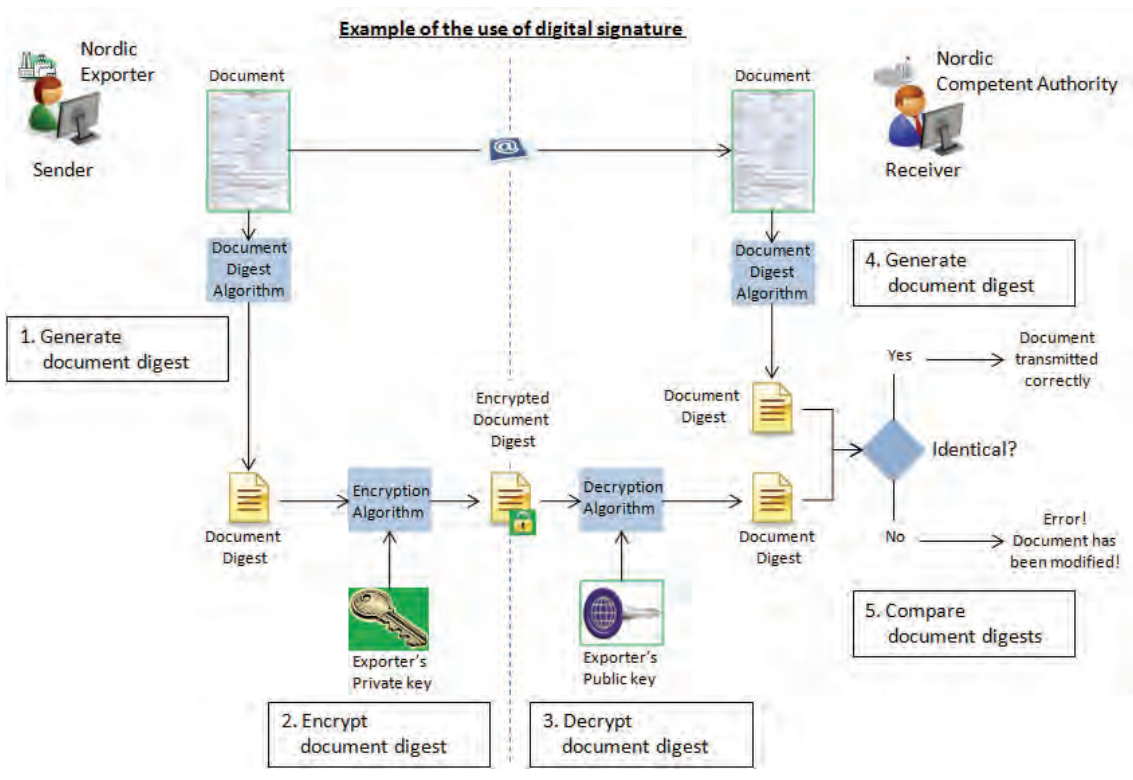

1. A document digest is generated. A document digest is a "summary" of the document that is going to be transmitted, it is always smaller than the document itself and even the slightest change in the document produces a different digest. The document digest is generated using a set of hashing algorithms. 
2. The document digest is encrypted using the sender's private key. The resulting encrypted document digest is the digital signature. The digital signature is attached to the document, and sent to the receiver.

3. Using the sender's public key, the receiver decrypts the digital signature to obtain the document digest generated by the sender.

4. The receiver uses the same document digest algorithm used by the sender to generate a document digest of the received document.

5. The receiver compares both document digests (the one sent by the sender as a digital signature, and the one generated by the receiver). If they are not exactly the same, the document has been tampered with by a third party.

The authenticity of the sender is ensured because only the sender's public key can decrypt the digital signature (which was encrypted by the sender's private key). Using public-key cryptography in this manner ensures integrity, but the document itself is sent unencrypted. In many cases the focus is on making sure that the integrity is guaranteed, however to add privacy to the document exchange one simply encrypt the document with the receiver's public key (who then later on decrypt the document by his or her private key) in addition to the above description.

The above example does guarantee, to a certain extent, the authenticity of the sender. Since only the sender's public key can decrypt the digital signature (encrypted with the sender's private key). However, the only thing this guarantees is that whoever sent the document has the private key corresponding to the public key we used to decrypt the digital signature. To ensure that the sender is the one he or she claims to be, it is common to use digital certificates. A digital certificate is a digital document that certifies that a certain public key is owned by a particular user.

This document is signed by a third party called the certificate authority (or CA). One of the more well-known certificate authorities is the company VeriSign which hold more than half of the certificate authority market.

A copy of the digital certificate is sent along with the document and when the receiver has decrypted the message he or she can check the digital certificate, thus ensuring the validity of the digital certificate and the sender.

\subsubsection{Recommendation for use of digital signatures in a Nordic TFS solution}

A correctly implemented solution with digital signatures provide a better and more secure way of ensuring the identity of the sender and the integrity of the information exchanged by different stakeholders involved in the notification and tracking procedures than the traditional handwritten signatures on paper based documents.

However a solution that aim to replace all exchange of documents with electronic documents with digital signatures within these procedures require 
all stakeholders (exporters, carriers, facilities, competent authorities etc) to both agree and acquire the necessary digital certificates and means to produce digital signatures. This can be even more complicated when it comes to the fact that documents that are required during transport have to be readable at any time during transport.

There are a number of tasks to overcome before a solution with digital signatures can replace all paper based documentation. Some of these are listed below

- EC-Regulation require agreement of all involved stakeholders (notifiers and involved competent authorities)

- Stakeholders must invest in (and maintain) digital certificates and other necessary equipment (e.g. card readers etc) to produce digital signatures

- Common ground must be reached by involved stakeholders on the type of digital signatures and technology as well as means to produce these digitally signed documents during transport

It is likely that the documents required during transport will remain paper based for some time to come, and with that the requirement of handwritten signatures (and sometimes stamps) on those original documents remain. It is also unlikely that a consensus can be reached with all involved stakeholders in a near future, due to costs and need of investigating the different solutions available.

Based on the unresolved issues and the number of stakeholders involved in a solution with digital signatures, this report recommends the Nordic countries not to implement digital signatures within the Nordic solution until an agreement has been reached by all involved stakeholders on when and how digital signatures will be used within these procedures.

The recommendation will instead be to focus on keeping certain key documentation in a paper based form with stamps and written signatures while replacing paper copies of documents with digital reporting and digital documentation without digital signatures until a common and stable solution for digital signatures have been developed.

As a security measure the solution instead propose an application procedure followed by approval by the competent authority before accepting new stakeholders. The stakeholders may then receive account and password information for use in the digital reporting within the Nordic TFS-system. The solution with account and password is quite similar to the solution used in the Terra system provided by the SenterNovem in Netherlands. 


\section{System requirements}

\subsection{General requirements}

\subsubsection{Requirements}

This chapter contain recommended requirements that a Nordic TFS-system should meet. The requirement descriptions are in some cases left rather vague. This is done intentionally in order to avoid building a system with features that are not approved by stakeholders and officials of the involved competent authorities. A more detailed study and a detailed IT-solution should be completed before starting the actual construction of the Nordic TFS-system.

Some terms and descriptions might be perceived as rather technical as focus in this chapter have been on describing the proposed IT-solution. The main target group for this chapter is a future project group with the assignment of detailing the requirements and also work out the details of the ITsolution for the digital reporting described in this report.

\subsubsection{Information model}

The information model provides an overview of the relation between different information objects involved in the digital reporting of notifications and shipments. Each of the grey boxes in the picture below represents an information object which contains several fields of information.

The main information objects are Notification and Shipment which basically contain the information given in the paper based notification document and the transport document.

The other objects (stakeholder, user, support data) are information objects which contain information that is used or needed by the IT-system to ensure faster registration and less human errors when registering notifications as well as ensuring that each user has access only to information and features that he or she is allowed to by the competent authorities. 


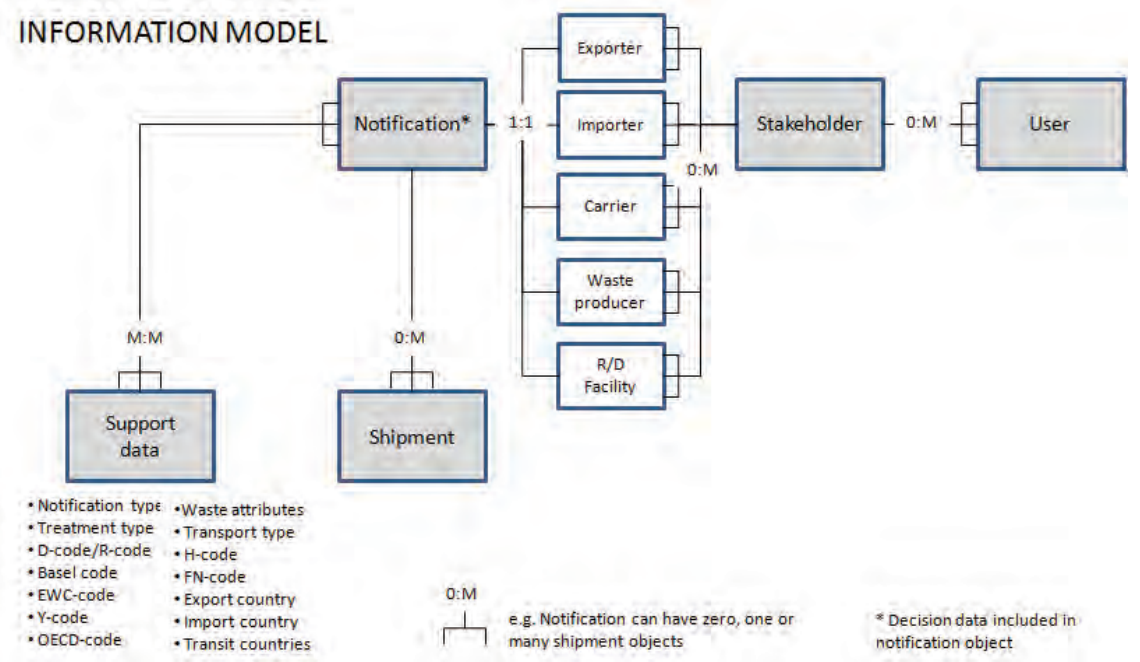

The Notification object contain all of the information of blocks 1-21 given in Annex 1A of EC-regulation 1013/2006 as well as information on decisions made by competent authorities regarding the number of shipments allowed, maximum amount of waste etc. Block 1, 2, 8, 9 and 10 which contain information on stakeholders can be completed manually or by selecting an existing stakeholder. All codes are provided to the user in drop down list boxes which contain valid codes for each of the fields. The notification object also has a status field which changes at certain points within the notification procedure (e.g. transmission of notification). This status can be used to monitor the progress of the notification procedure. Information on decisions made by the competent authorities are also kept within the Notification object, this is done with five sets of validity dates, one for dispatch, one for destination and up to three transit countries.

The Shipment object contains information on transport serial number, type, shipment date, date of receipt, date of recovery/disposal, estimated weight and actual weight. This includes the information within notification of shipment, receipt of waste and the recovery confirmation given by the exporter and the receiving R/D-facility. Each shipment object must belong to an existing notification object.

The Stakeholder object contains registration number, name, address and contact information as well as the type of stakeholder (e.g. exporter, carrier etc). The information is used when completing the notification and for sending automated acknowledgements by e-mail. A stakeholder can also have zero, one or multiple users that can access the Nordic TFS-system.

The User object contain name, type, expiration date and contact information for users of the Nordic TFS-system. The User object is used by the Nordic TFS-system to validate a user accessing the application and to determine which functions the user is allowed to use within the system. Each user must belong to a certain stakeholder. 
The Support data object is a collection of codes and texts that are used by the system to reduce spelling errors and making automatic checking easier while registering the notification object. The object contains code, type, language and description. The information is copied to the Notification object at the time of registration which means that a change in a code description within the support data object doesn't affect previously registered notification objects.

\subsubsection{Language}

The Nordic TFS-system should be designed and constructed in British English language with possible localized language support in Norwegian, Finnish, Danish and Swedish languages when registering notification and shipment objects. Information given in text fields etc can still be in the relevant local Nordic language.

The system should be able to show and print English, Norwegian, Finnish, Danish and Swedish variants of the Notification and Transport documents regardless ${ }^{69}$ of the language used when completing the documents. The desired language should either be selected by the user or stored with the information given in the stakeholder registration application.

\subsubsection{Access requirements}

The Nordic TFS-system should be an internet based application with access through a web browser and using Hypertext Transfer Protocol Secure (HTTPS) as a protocol.

The system does not offer offline support thus reducing complexity of the solution. Access to the system should only be given to registered valid users.

\subsubsection{Account and password requirements}

Each stakeholder including the competent authorities involved wishing to access the system must be registered as a relevant stakeholder within the system. Each account must belong to a certain registered stakeholder.

Each stakeholder may have one or more employees that should be able to access the system. The stakeholder is guarantees that the employee has the right to represent the company in the digital reporting activities involved within the Nordic TFS-system.

Each account and password is personal and activities carried out by an account are considered carried out by the person (and the company) registered to that account. Account and password information is sent by mail or

\footnotetext{
${ }^{69}$ Exception for text fields which have been completed in a local Nordic language. Language support is given on screen and document text and for code descriptions.
} 
e-mail and the password must be changed when accessing the system for the first time. Each account should have an expiration date assigned.

\subsubsection{Account-Role management requirements}

The system should be able to limit access to information and functions within the system based on the type of account used by a certain user. There are four types of account available, these are given below and carries certain rights within the system.

- Competent Authority official

- Exporter

- R/D Facility

- Other stakeholder (e.g. importer, carrier, non-Nordic C.A etc)

Competent Authority officials (approximately 15 in total) can register and edit any information for their respective country and can read all information within the Nordic TFS-system.

Exporters can register export notifications and notify shipments for their respective companies. They may also register receipt of waste and recovery confirmations if the receiving facility is a non-participant outside the Nordic countries. They can also view all notification and shipment information where their company is registered as the exporter.

R/D Facility accounts can register receipt of waste and processing statements. They are also allowed to see any notification and shipment information where their company is registered as the receiving facility.

Other stakeholders can view (but not register or edit) any notification and shipment information where their company/authority are involved. This might be as a Competent Authority (non-Nordic), carrier, importer or waste producer.

The charts below present an overview of what the different roles is allowed to do within the Nordic TFS-system. The charts show what an official of the competent authority usually access, but he or she can always register or edit any data for the country where the notification originates (e.g. a Norwegian official can register an export notification for Norway but not register an export notification for Finland). 

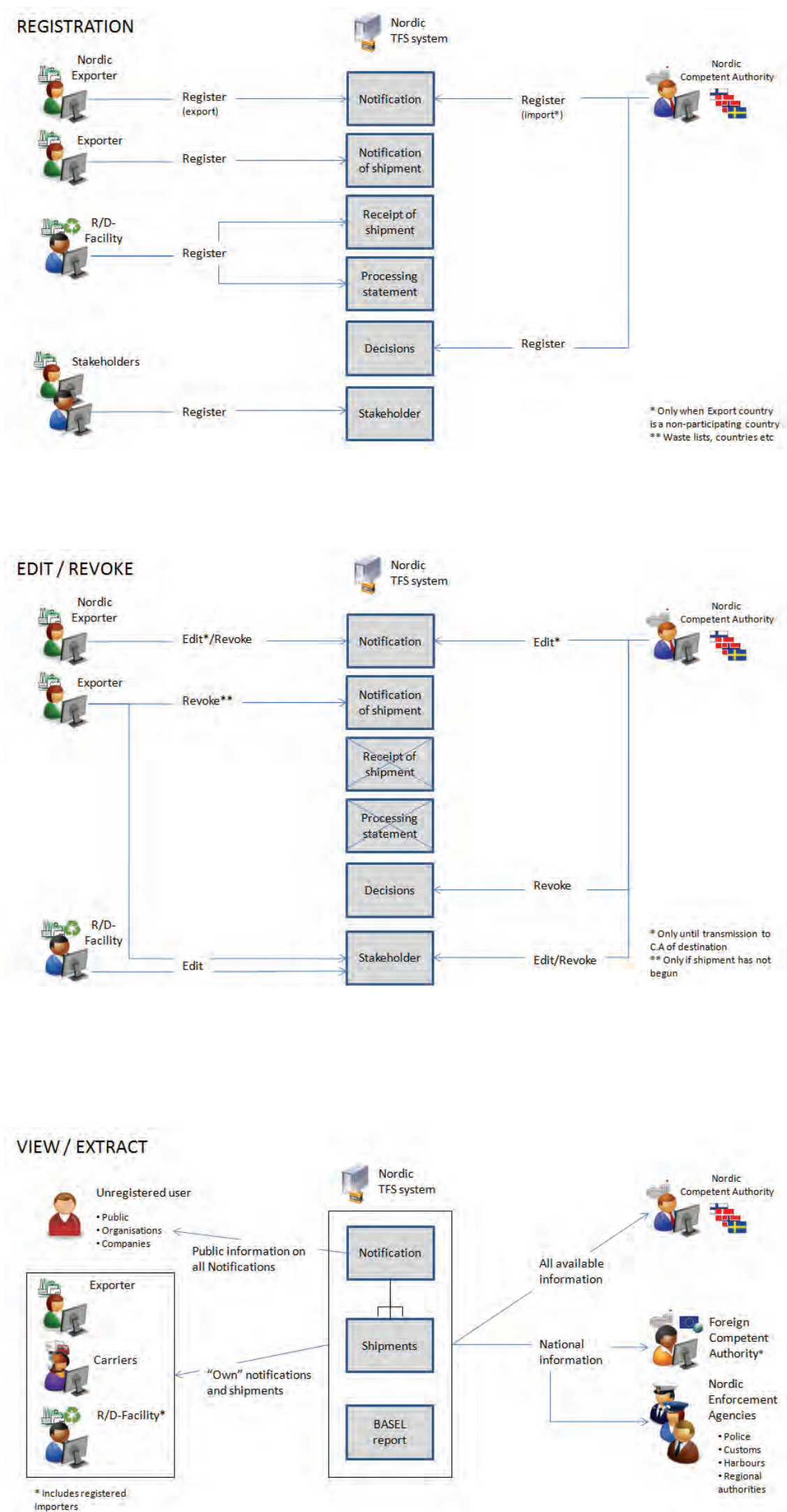


\subsubsection{Storage}

The information given in the Information model should be saved in a central database. The database should be able to use $\mathrm{SQL}^{70}$ and the database should have backup routines in place when implementing the system. Backup frequency should be monthly for total backup and daily for incremental backup. Estimated amount of data records and increase rates given below for each of the information objects.

- 1,200 Notification records annually

- 70,000 Shipment records annually

- 6,000 Support data records (no annual increase)

- 1,000 Stakeholder records (annual increase of 200)

- 800 User records

As long as the solution only deals with text-oriented information the above figures shouldn't pose a problem. However if scanned documents, maps or similar file types is to be included in the solution this might create storage issues, particularly if these are associated with the shipment records.

\subsubsection{Integrated e-mail services}

Some of the activities within the notification and tracking procedure require automated acknowledgements and information to be sent by e-mail to the relevant stakeholders and competent authorities. This requires the system to make use of e-mail from within the system. The sender of the e-mails would be the system itself and the receiver should be the e-mail address given for the appropriate stakeholder or competent authority.

This means that the e-mail addresses must be kept up to date by each of the participants and the system should also keep a copy of the e-mails sent to be able to prove that an e-mail were actually sent by the system.

The different e-mails used for acknowledgements and the like should have pre-formatted layout and content as well as contain both the appropriate unique notification number and the name of the document it is replacing (e.g. Acknowledgement) in the heading of the e-mail. The integration of email for transmissions, acknowledgements and information is designed to be a one-way communication and will not allow users to return those e-mails.

In the case of the Notification procedure there are also a suggested feature that when the export register his notification data there should be a link which open up a new e-mail with the pre-filled destination address of the relevant competent authority as well as putting the unique notification number in the subject (e.g. Inutavfall@naturvardsverket.se subject= SE 090245). This is done to ensure an easy way of getting the exporter to send digital versions of relevant documentation and to give the competent authorities a

\footnotetext{
${ }^{70}$ SQL- Structured Query Language.
} 
good way to discern these e-mail from other e-mails received to the competent authority.

\subsubsection{Integration requirements}

The integration of the Nordic TFS-system with the national TFS-systems currently used have to be detailed before deciding on the best way to integrate these systems. However because of the need to exchange notification data with national TFS-system and the possible future need to exchange information with other competent authorities and other systems, it is recommended to provide a standard interface for this exchange. This study recommend the use of XML ${ }^{71}$ and if possible to use the EUDIN-interface as a base for possible data exchange with other competent authorities.

\subsubsection{Viewing, printing and extraction of data requirements}

The system should be designed in a way that does require a minimum of interaction with the user and that keep data traffic back and forth to a minimum. The solution should be designed for $1024 \times 768$ pixel resolution but allow for (and take advantage of) the use of higher levels of resolution. The following pre-formatted reports should be available for viewing and printing (on standard A4-format)

- Notification document

- Movement document

- Overview of notifications

Each of the printed Notification and Movement documents should include a timestamp value of the time when the information was last changed. In addition to the above reports, it should be possible to extract the following information to Microsoft Excel (as Excel-files)

- Basel report (in the form of the template given on www.basel.int)

- Overview of notifications (based on screen contents)

The system should also provide means to publish public notification data to one or several WebPages containing public information of consented notifications as described in article 21 in the EC-regulation 1013/2006. These WebPages should not be a part of the actual system and should be publicly available without any registration requirements.

The system should provide means of making customized reports based on any information available in the system. This should make use of the SQL-language and be presented on screen with the normal extraction op-

\footnotetext{
${ }^{71}$ XML - eXtensible Markup Language.
} 
tions (e.g. Excel). This function would be limited to certain officials at the competent authorities that possess the needed skills of the SQL-language.

\subsubsection{Log requirements}

The system should log any changes done to the notification and shipment data after the notification have been registered. The log should contain the following information

- Date and timestamp when the change was made

- The account which executed the change

- Information changed (old value and new value)

The log should be presentable for officials and each change should be presented with date, change and account information.

\subsection{Notification procedure requirements}

\subsubsection{Notification requirements}

The following functions and requirements need to be fulfilled within the Nordic TFS-system to adhere to the solution described in chapter 2 of this report.

- Register export notification

- Register import ${ }^{72}$ notification

- Present company information (used in registration)

- Transmit or Acknowledge notification

- Present notifications per country (or all countries) as well as one of the following (stakeholder, type, notification number, official and status)

- Export/extract notification data (XML)

- Register decisions

- Revoke permit

- Revoke notification

- Print notification document

\subsubsection{Register export notification}

The registration form should be in the language chosen by or chosen for the current user with text and data lists in the chosen language. The type of account (competent authority or export) shall affect which fields that can be entered and which cannot.

\footnotetext{
${ }^{72}$ Includes transit notifications if desired.
} 
Data lists should be available with code and descriptive text being used for the following codes

- 125 Basel codes (e.g. A1010)

- 28 D- and R-codes (e.g. D 1 or R 1)

- 839 EWC-codes (e.g. 0103 99)

- 47 Y-codes (e.g. Y47)

- 36 OECD-codes (e.g. GC030)

- Export country (fixed and not editable to the country of the stakeholder, e.g. FI/DK/NO/SE)

- Transit countries (up to three transit countries allowed)

- Import country (with frequently used countries in top of list)

- 7 Waste attribute forms (block ${ }^{73} 7$ )

- 13 Waste attribute packages (block 13)

- 5 Means of transport (e.g. R for road transport)

- 14 H-codes (e.g. H4.1)

Block 1, 2, 8, 9 and 10 which contain information on exporter, importer, carrier, waste producer and R/D-facility should have a search function for registration number (or name). The function should copy information for the selected stakeholder to the appropriate block in the notification form.

For example, if the user enter a valid existing registration number for the importer the function return and fill the fields with information on Name, Address, Contact person, Telephone, Fax and e-mail.

If the account used for the registration is an exporter account, block 1 which contains information on the exporter is automatically filled with the appropriate information stored in the stakeholder register.

The notification form receives the next available unique notification number from the system, the notification is registered to the company (and individual) that initiated the registration but it is not considered received by the competent authority until the signed notification document arrives by mail to the receiving competent authority. Validity checks made by the Nordic TFS-system should include

- Required fields ${ }^{74}$

- Date format

- First and last date for transport (first date must be prior to last date)

- Pre-consented facility field is set by the system and only if the facility is registered as such

- Facility must be registered for recovery or disposal depending on the information given by the user in block 3

\footnotetext{
${ }^{73}$ Block refers to the relevant block of information given in the Appendix 1A within the ECregulation 1013/2006 Notification document.

${ }^{74}$ Code lists should include unlisted as an alternative if applicable and then make the field mandatory to ensure that the user have examined the available options.
} 
- Only D-codes are valid for disposal notifications and only R-codes are valid for recovery notifications

- If possible the transit countries available for the user to choose from should be limited to countries that can actually be transit countries when dealing with export from the user's country

The user can register the notification and edit the information therein but the signed and printed notification document must contain the same information given in the system. Each printed notification and movement document contain a timestamp value that can be compared to the timestamp value given within the Nordic TFS-system. If these values are the same then the printed and signed notification document contain the same information as the information given in the system.

The notification object also contains decision data (decision, validity dates, number of transports and weight allowed as well as the optional field of weight covered by the financial guarantee). Diary number references and responsible officers have also been included to provide additional functionality such as integration or reference to existing national TFS-systems and view for individual officers of the competent authorities. This information can only be registered (or edited) by the competent authorities involved.

\subsubsection{Register import notification}

Registration of import notifications which originates from a nonparticipating ${ }^{75}$ export country can only be done by a Nordic competent authority of destination. The registration of import notifications is quite similar to the registration of export notifications. The main differences being the following

- Registration done by competent authorities only

- Based upon a signed and stamped Notification document

- Involves only non-Nordic export countries

- Import country, not Export country is fixed (e.g. FI/DK/NO/SE) and not editable. Export country cannot be a Nordic country

\subsubsection{Transmit or Acknowledge notification}

When an officer of the Nordic competent authority of dispatch decides that the notification is complete he or she access the TFS-system and change the status field of the digital notification to "transmitted by dispatch". This triggers an automatic e-mail to the exporter containing informing of the receipt of a complete notification. The e-mail is sent by the Nordic TFS-system to the e-mail address given in block 1, exporter information and at the same

\footnotetext{
${ }^{75}$ A country which is a non-Nordic country and have one or more competent authorities and stakeholders that do not participate in the Nordic TFS-system.
} 
time export $^{76}$ a XML-file for import in the national TFS-system of the competent authority of destination.

The e-mail is designed for one-way communication and is pre-formatted with the text "Transmission of notification" followed by the unique notification number. The e-mail body should be a template text explaining what the acknowledgement means. The XML-file may differ depending on the receiving country's national TFS-system. The Swedish IT-system MODENA (used by the Swedish EPA) have a XML-description which, if used creates a notification object within the national TFS-system, this XML can be used as a template for other Nordic countries if desired.

Acknowledgement of notification by the competent authority of destination is handled in the same way except for the following

- No XML-file is created (as this is not necessary)

- E-mail is sent both to the exporter and the competent authority of dispatch

- Status used is "acknowledged by destination" instead of "transmitted by dispatch"

- E-mail heading is “Acknowledged notification” instead of "Transmission of notification"

\subsubsection{Present list of Notifications}

Every time a stakeholder accesses the system they should be presented with a list of notifications based on the account they are using. These views differ between the account types but use the same data stored in the Nordic TFSsystem.

- An Official of a Competent Authority is presented with a view of all valid or undecided notifications where the competent authority is involved as a competent authority of dispatch, transit or destination

- A stakeholder (e.g. Exporter) is presented with a view of all (valid, closed or undecided) notifications where the stakeholder is registered as exporter, importer, carrier, waste producer or R/D-facility

- Non-Nordic Competent Authority officials and national authorities officials is presented with a view of all valid notifications where the export, import or transit country is equal to the country of the authority which the user is employed by.

It should be possible to filter, sort or search the list so that notifications can be presented per country (or all countries) as well as one of the following (stakeholder, type, notification number, official and status).

Received export notifications which have not been transmitted within three days and received import notifications not acknowledged within three

\footnotetext{
${ }^{76}$ Only done if export is destined to Nordic (or participating) countries.
} 
days should be presented in a different colour so that officials of the competent authority may act before the three day limitation in EC-regulation $1013 / 2006$ is exceeded.

The presented list should be designed to print on standard size A4 paper and export to Microsoft Excel as well as XML-format should also be provided.

\subsubsection{Editing or revoking a Notification}

After a notification has been registered it can be altered by the exporter as well as by the Nordic competent authorities involved. This however is only possible if the signed original notification document is either not yet sent to the competent authority of dispatch or if the competent authorities involved agree to make the corresponding changes to the signed original notification document. The changes should be logged so that it is possible to review changes done by a certain user.

Only certain fields can be changed and the status of the notification can only be changed by an official of the relevant competent authority. All fields relating to the registration of decision information must also be done by an official of the appropriate competent authority.

An exporter (or a competent authority) can decide to revoke a notification, effectively ending the notification procedure. This however can only be done if there are no ongoing shipments related to the notification. Revoking a Notification is done by a change in the status field to "Revoked". Revoking of an already received signed notification still requires the appropriate fee to be paid in full to the competent authority of dispatch (and possible also the fee to the competent authority of destination).

An official of an involved competent authority can at any time decide to revoke a notification effectively ceasing the possibility to register any new shipments related to that notification. The revocation is done by a change in the status field to "Revoked". If an official revokes the notification the reason thereof should also be registered as well. Information about the revocation should be transmitted to the exporter as well as any other relevant competent authorities.

\subsubsection{Status changes for Notification data}

One of the most important information stored with the Notification is the status field. The status field contain information on the current status of the Notification document. A notification can have only one current status, but may have had a variety of status prior to the current one. Each notification can have (or had) one of the following statuses

- Created

- Registered 
- Transmitted by dispatch

- Acknowledged by destination

- Approved

- Rejected

- Expired

- Revoked

Which of these statuses a notification have is determined by the activities of the stakeholders and it is described in chapter 2 of this report. Certain status are set by the system itself when the user perform an action (such as register a notification), while other are invoked by changing the status field to the desired value (e.g. acknowledged by dispatch).

Presented below is the normal "flow" of statuses within an Export Notification

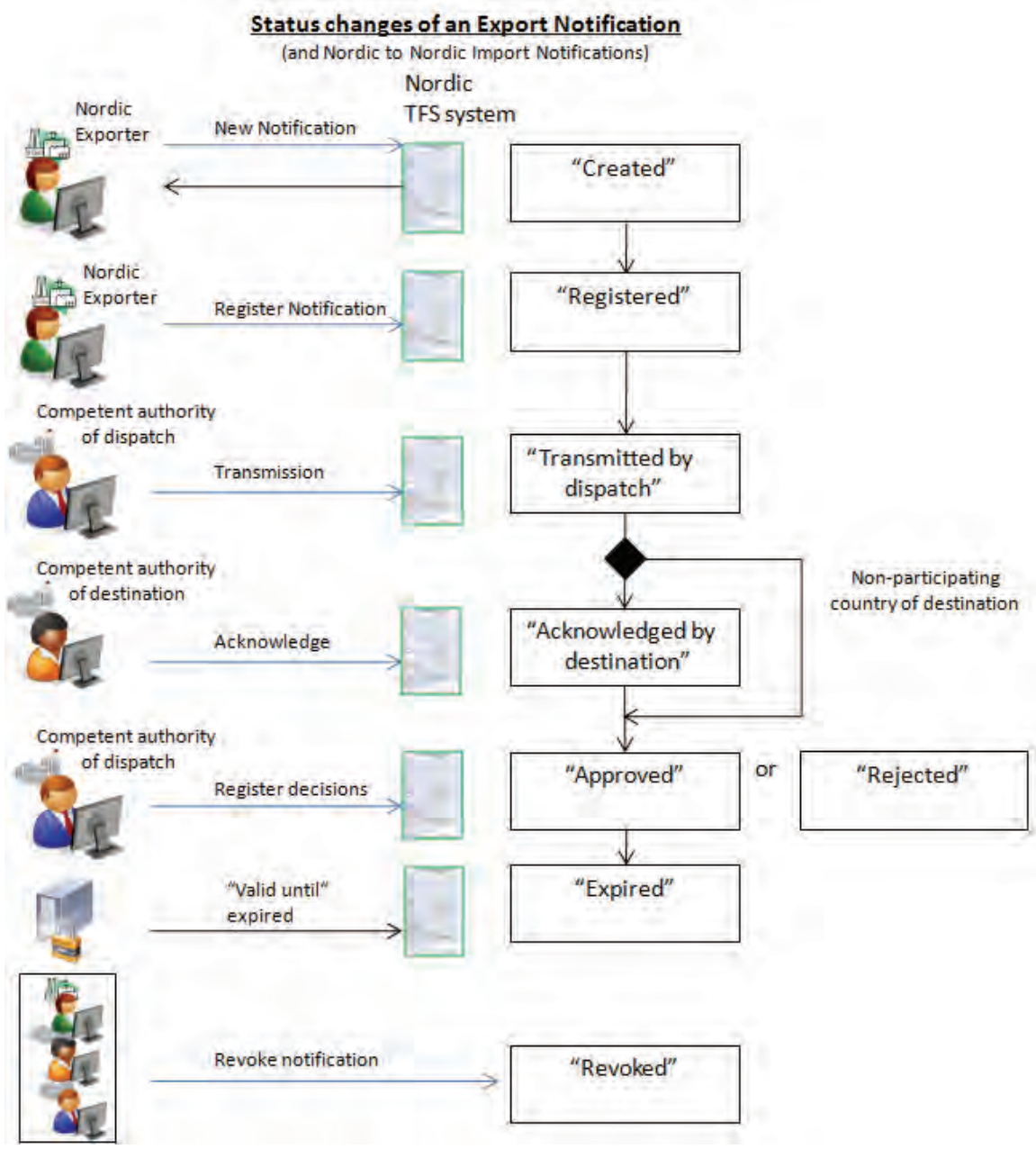

As described in the support procedures of chapter 2 in this report, the registration of import notifications from non-participating countries have to be registered by the Nordic competent authority of destination. This leads to a 
slightly different set of "normal" statuses for non-Nordic import notifications. This is illustrated in the flowchart below

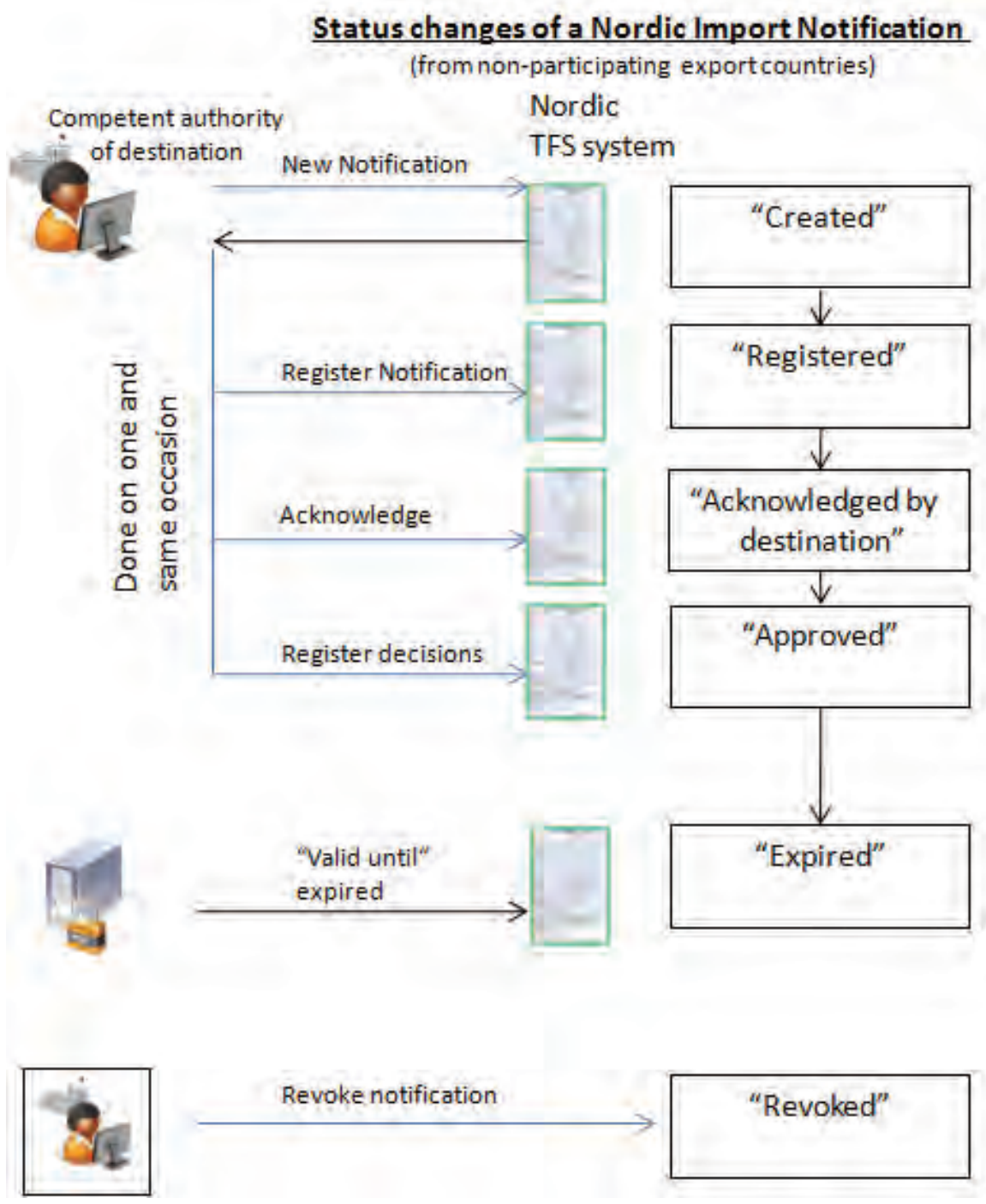

While it is possible for an official of the relevant competent authority of dispatch (or in some cases destination) to change the status value to almost any of the above statuses this should only be done to correct mistakes or similar actions. The table below show who is allowed to set a certain status and any special requirements for this.

\begin{tabular}{|l|c|c|c|c|}
\hline Status & Nordic TFS-system & C.A of dispatch & C.A of destination & Exporter \\
\hline Created & $\mathrm{X}$ & - & - & - \\
\hline Registered & $\mathrm{X}$ & $\mathrm{X}$ & $\mathrm{X}$ & - \\
\hline Transmitted by dispatch & - & $\mathrm{X}$ & - & - \\
\hline Acknowledged by destination & - & - & $X$ & - \\
\hline Approved & - & $\mathrm{X}$ & $\mathrm{X}$ & - \\
\hline Rejected & - & $\mathrm{X}$ & $\mathrm{X}$ & - \\
\hline Expired & $\mathrm{X}$ & - & - & - \\
\hline Revoked & - & $\mathrm{X}$ & $\mathrm{X}$ & $\mathrm{X}$ \\
\hline
\end{tabular}


An " $\mathrm{X}$ " in the table above marked with green colour represent a normal valid status change while the red marked " $X$ " represent an action which can be made on rare occasions (e.g. correcting an error etc).

The Nordic TFS-system should have a system function that at the beginning of each day search for notifications which have expired validity dates (within the decision data information) and have a status equal to "Approved". The notifications found by this function is then updated with the status "Expired" which in turn make it impossible to register any new shipments to any of these notifications.

\subsubsection{Printing Notification documents}

A registered notification should at any time be possible to print on standard A4-paper and it should be possible to decide in which language the notification document should be printed, default should be set to the language of the competent authority of dispatch. The printed notification document should look like the paper based documents that are used today by the competent authorities of the Nordic countries with the following changes

- The information should be printed from the system instead of handwritten (except for signatures and stamps)

- A timestamp showing the date and time of the last time the information was updated in the Nordic TFS-system should be visible on the printed paper document

Printed on the back of the notification document the explanatory text used for explaining the different waste codes etc should be in the same language as the chosen language for the front of the notification document. 
ANNEX IA

Notification document for transboundary movements/shipments of waste

EL

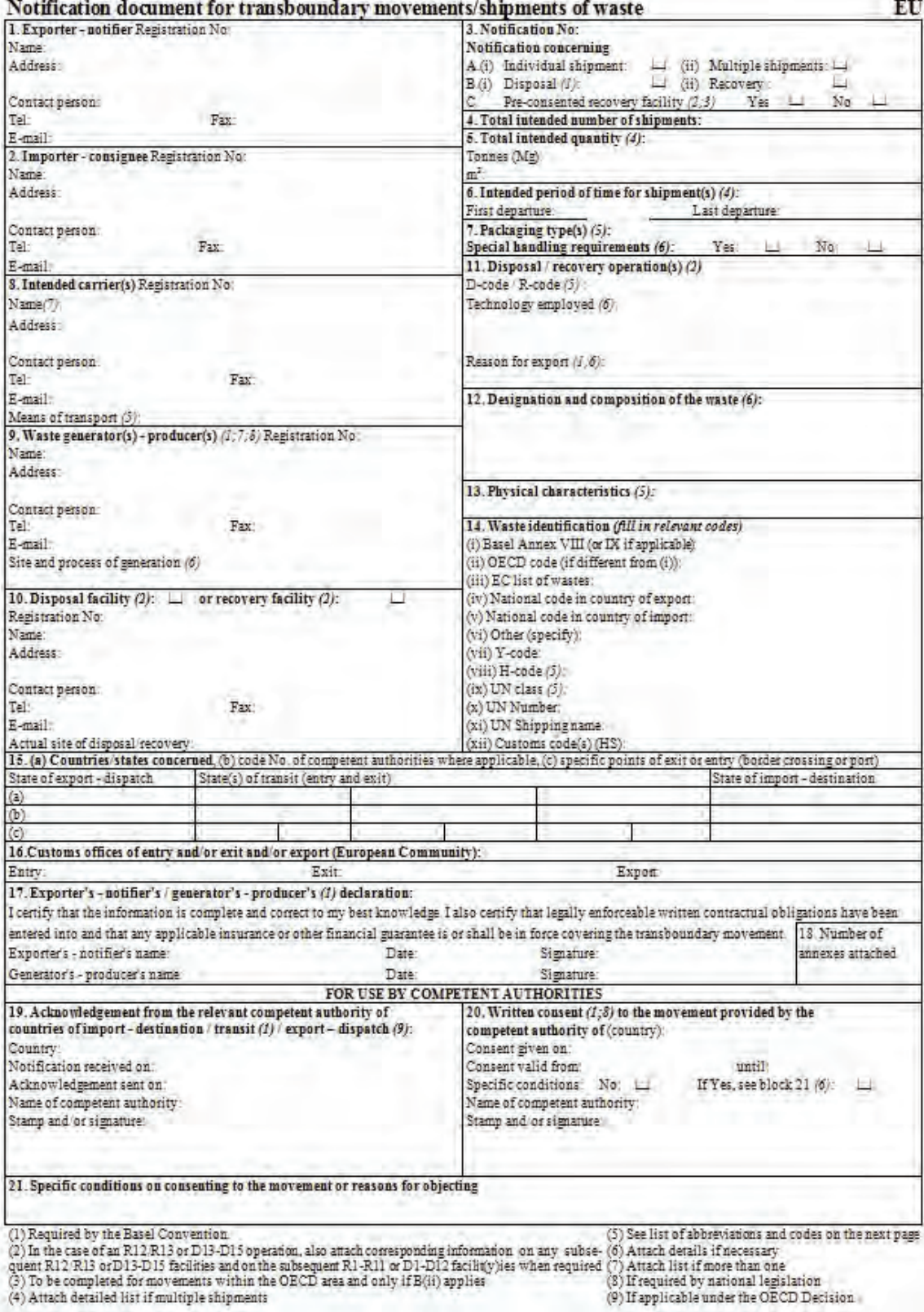

Front of Notification document in English (above). 
List of abbreviations and codes used in the notification document

\begin{tabular}{|c|c|c|c|c|}
\hline \multicolumn{5}{|c|}{ DISPOSAL OPERATIONS (block 11) } \\
\hline DI & \\
\hline D2 & \multirow{2}{*}{\multicolumn{4}{|c|}{$\begin{array}{l}\text { Land trestment (e. F, biodegradation of liquid or sludgy discards in soils, etc.) } \\
\text { Detpp injection (e.g. injection of pumpable discards into wwells, salt domes or naturally occuming repositories, etc.) }\end{array}$}} \\
\hline D3 & \multirow{2}{*}{\multicolumn{4}{|c|}{ Surfase impoundment (e.g. placement of liquid or sludge discards into pits, ponds or lagoons, etc.) }} \\
\hline D4 & & & & \\
\hline D5 & \multicolumn{4}{|c|}{$\begin{array}{l}\text { Specially engineered landfill (e. g. placemant into lined discrete calls which are capped and isolated from ona another and tha envi- } \\
\text { ronment, etc.) }\end{array}$} \\
\hline D6 & \multicolumn{4}{|c|}{ Release into a water body excapt 3ags/oceans } \\
\hline D7 & \multicolumn{4}{|c|}{ Release into saas ocesns including sea-bed insertion } \\
\hline D8 & \multicolumn{4}{|c|}{$\begin{array}{l}\text { Biological trestment not specified elsewwere in this list which results in final compounds or mixtures which are discardad by } \\
\text { means of any of the operations in this list }\end{array}$} \\
\hline D 9 & \multirow{2}{*}{\multicolumn{4}{|c|}{$\begin{array}{l}\text { Physico-chemical treatment not specified elsegvere in this list which results in final compounds or mixfures which are discardad } \\
\text { by mesns of any of the operations in this list (e.g. evsporstion, drying, calcination, etc.) } \\
\text { Incineration on land }\end{array}$}} \\
\hline Dio & & & & \\
\hline D11 & \multicolumn{4}{|c|}{$\begin{array}{l}\text { Incineration on land } \\
\text { Incineration at saa }\end{array}$} \\
\hline D12 & \multicolumn{4}{|c|}{ Pemanent storage (e.g., emplacement of containers in a mine, atc.) } \\
\hline D13 & \multicolumn{4}{|c|}{ Blending or mixing prior to submission to any of the operations in this list } \\
\hline DI4 & \multicolumn{4}{|c|}{$\begin{array}{l}\text { Blending or mixing prior to submission to any of the operations in this list } \\
\text { Repackaging prior to submission to any of the operstions in this list }\end{array}$} \\
\hline D15 & \multicolumn{4}{|c|}{$\begin{array}{l}\text { Repackaging prior to submission to any of the operstions in this list } \\
\text { Storagge pending any of the operations in this liat }\end{array}$} \\
\hline \multicolumn{5}{|c|}{ RECOVERY OPERATIONS (block 1I) } \\
\hline RI & \multicolumn{4}{|c|}{$\begin{array}{l}\text { Use as a fuel (other than in direct incineration) or other meani to generate energy (Base/OECD) - Use principally as a fuel or other } \\
\text { means to generate energy (EU) }\end{array}$} \\
\hline $\mathrm{R}_{2}$ & \multicolumn{4}{|l|}{ Solvent reclamation regeneration } \\
\hline R3 & \multicolumn{4}{|c|}{ Recycling reclamation of organic substances which are not used as solv } \\
\hline R4 & \multirow{2}{*}{\multicolumn{4}{|c|}{ Recycling reclamation of metals and metal compounds }} \\
\hline R5 & \multirow{2}{*}{\multicolumn{4}{|c|}{ Recycling inclamation of other inorganic materials }} \\
\hline R6 & Regeneration of acids or basea & & & \\
\hline RT & Recovery of components used for pollution & atemer & & \\
\hline R\& & Recovery of components from catslyats & & & \\
\hline Rg & Used oil re-refining or other reuses of prev & aly use & & \\
\hline R.10 & Land treatment resulting in benefit to agric & 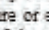 & gical in & rovement \\
\hline RII & Uass of residual materials obtainad from an & of the o & tions mun & bered R1-R.10 \\
\hline R 12 & Exchenge of wastes for submission to any & the ope & na numb: & red R1-RII \\
\hline R13 & Accumulation of material intended for any & eration & his list. & \\
\hline $\begin{array}{l}\text { PACT } \\
\text { 1. I }\end{array}$ & $\begin{array}{l}\text { KAGING TYPES (block } 7 \text { ) } \\
\text { Drim }\end{array}$ & H-C & $A N D$ & CLASS (block 14) \\
\hline & Wooden barrel & UN & H-rode & Characteristics \\
\hline & Jerrican & & & \\
\hline & & & 'HI & Explosive \\
\hline & Bag & & & Flammable liquids \\
\hline & Composite packaging & 4.1 & $\mathrm{H} 4,1$ & Flammable solids \\
\hline & Pressure receptacle & & $\mathrm{H} 4.2$ & Substances of wastes liable to spontaneous combustion \\
\hline 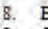 & Bull: & & $\mathrm{H} 4.3$ & Subatances of wastes which, in contact with water, emit \\
\hline & Other (specify) & & & flammable gasas \\
\hline AIEA & INS OF TRANSPORT (block 8) & & H5.1 & Oxidizing \\
\hline$R=R$ & Road & 5.2 & H5.2 & Organic peroxidas \\
\hline $\mathrm{I}=\mathrm{I}$ & Train/rail & 6.1 & H6.1 & Poisonous (acute) \\
\hline & & 6.2 & H6.2 & Infectious substancas \\
\hline$A=A$ & & 8 & $\mathrm{HB}$ & Corrosives \\
\hline & Inland waterways & & H10 & Liberation of toxic gases in contact with air or water \\
\hline PHYS & SICAL CHARACTERISTICS (block 13) & 9 & H11 & Toxic (delayed or chronic) \\
\hline & Powdery powder & 9 & $\mathrm{H} 12$ & Ecotoxic \\
\hline & & 9 & $\mathrm{H} 13$ & Cspable, by any means, after disposal of yielding another ma- \\
\hline & Viscous/paste & & & terial, e. g, leachate, which possasses any of the characteris- \\
\hline & Sludgy & & & tica listad shove \\
\hline & Liquid & & & \\
\hline & Gasaous & & & \\
\hline 7. $\mathrm{C}$ & Other (epecify) & & & \\
\hline
\end{tabular}

Further information, in particular felated to waste identification (block 14), i.e., on Basel Annexes VIII and IX codes, OECD codes and $\mathrm{Y}$ codes, can be fornd in a Gridsnce Instruction Mamual avsilable from the OECD and the Secretariat of the Bseal Convention.

Back of Notification document in English (above).

\subsubsection{Registration of all intended carriers}

It is possible to add a function for the registration of all intended carriers described in notification document (block "8 Intended carrier(s)"). If this is done, it is possible to add a system check so that Exporters only can choose one, two or three pre-registered carriers when registering a shipment (block 5a-5c) in the movement document.

This function however does not come without some disadvantages and it will require the exporters to register all intended carriers within the system (instead of annexing them in a document) and it will require the competent authorities to manually register this information when receiving non-Nordic import notifications. It will also require registration and editing of notification data by the competent authorities if the exporter gets the approval for 
using a carrier not previously registered when it comes to registering carriers for a certain movement. If this function is not implemented, control of actual carriers in comparison to intended carriers has to be made against the annexed information in case of multiple intended carriers.

\subsection{Tracking procedure requirements}

\subsubsection{Tracking procedure requirements}

The following functions and requirements need to be fulfilled within the Nordic TFS-system to adhere to the solution described in chapter 2 of this report.

- Present notifications

- Present shipments for a particular notification

- Register notification of shipment

- Register receipt of shipment

- Register processing statement

- Revoke shipment

- Print movement document

- Export overview or shipment to Excel or XML

- Present shipments per country (or all countries) as well as one of the following (stakeholder, type, notification number, official and status)

- Warning functions (e.g. no processing statement within one year of receipt of waste)

\subsubsection{Present notifications}

Within the tracking procedure there should be an overview of relevant notifications. The list should contain basic information about the notification such as

- Notification number

- Export country code

- Exporting company

- Import country code

- Receiving facility

- Validity dates (from - until)

- Quantity allowed

- Number of transports allowed 
For each of the notifications there should also be calculated fields for

- Dispatched quantity

- Dispatched transports

- Remaining quantity allowed

- Remaining transports allowed

The list contains notifications relevant to the stakeholder and is also used by the Exporter when registering a new notification of shipment for a selected notification.

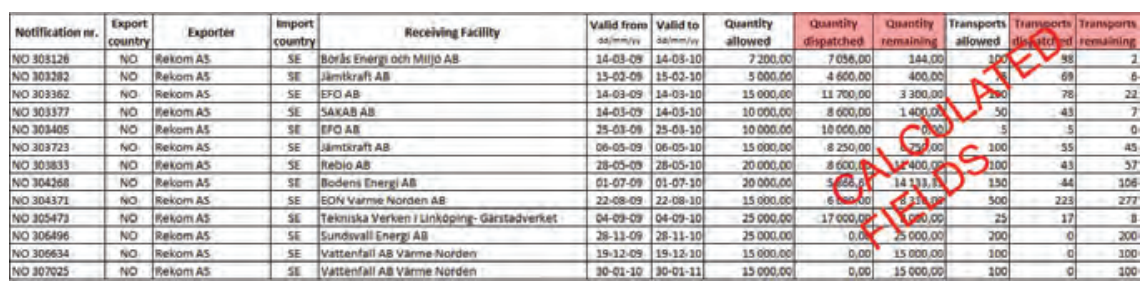

Example of an Export's list of notifications with calculated fields

For each of the notifications it should be possible to click and be shown a list of registered shipments belonging to the selected notification. The list should contain information on each of the registered shipments. It should be possible to select a shipment, receive a new screen and see all available information on the shipment. The list of registered shipments should contain the following fields

- Shipment number

- Actual shipment date

- Actual quantity

- Receipt date (if received)

- Received quantity (if received)

- Processing date (if recovered or disposed)

\subsubsection{Register notification of shipment}

The system should contain a function where an Exporter can register notification of shipment at least 3 working days prior to the actual shipment of waste. The exporter should be presented with a list of notifications ${ }^{77}$. It should only be possible to register notification of shipment for valid consented notifications which still have remaining transports and weight allowance.

If it is possible to register a notification of shipment for the selected notification, the exporter is presented with a web form where information on the following fields should be registered

\footnotetext{
${ }^{77}$ As described in "Present notifications" above.
} 
- Actual shipment date

- Actual quantity

- Number of packages

- Carrier information

- Means of transport

- Transfer dates (if any)

The actual shipment date can only contain dates which is equal to the current date +3 days (not including weekends). An exception to this limitation is made for Nordic receiving facilities that manage the registration procedure for a non-Nordic exporter. Actual quantity must be within the allowed quantity of the notification.

If a weight allowance limitation have been given for the financial guarantee in the decision data for the corresponding notification, the field "Actual quantity" may not exceed the amount given in the decision data reduced by the sum of notified but not yet treated waste for the relevant notification according to the following formula: "weight covered by financial guarantee" - "sum of all notified actual quantity for shipments with a actual shipment date but without a treatment date".

Carrier information given in the notification object is defaulted in the form but can be changed ${ }^{78}$ and up to three different carriers could be specified. If more than one carrier is used transfer dates between the different carriers have to be registered.

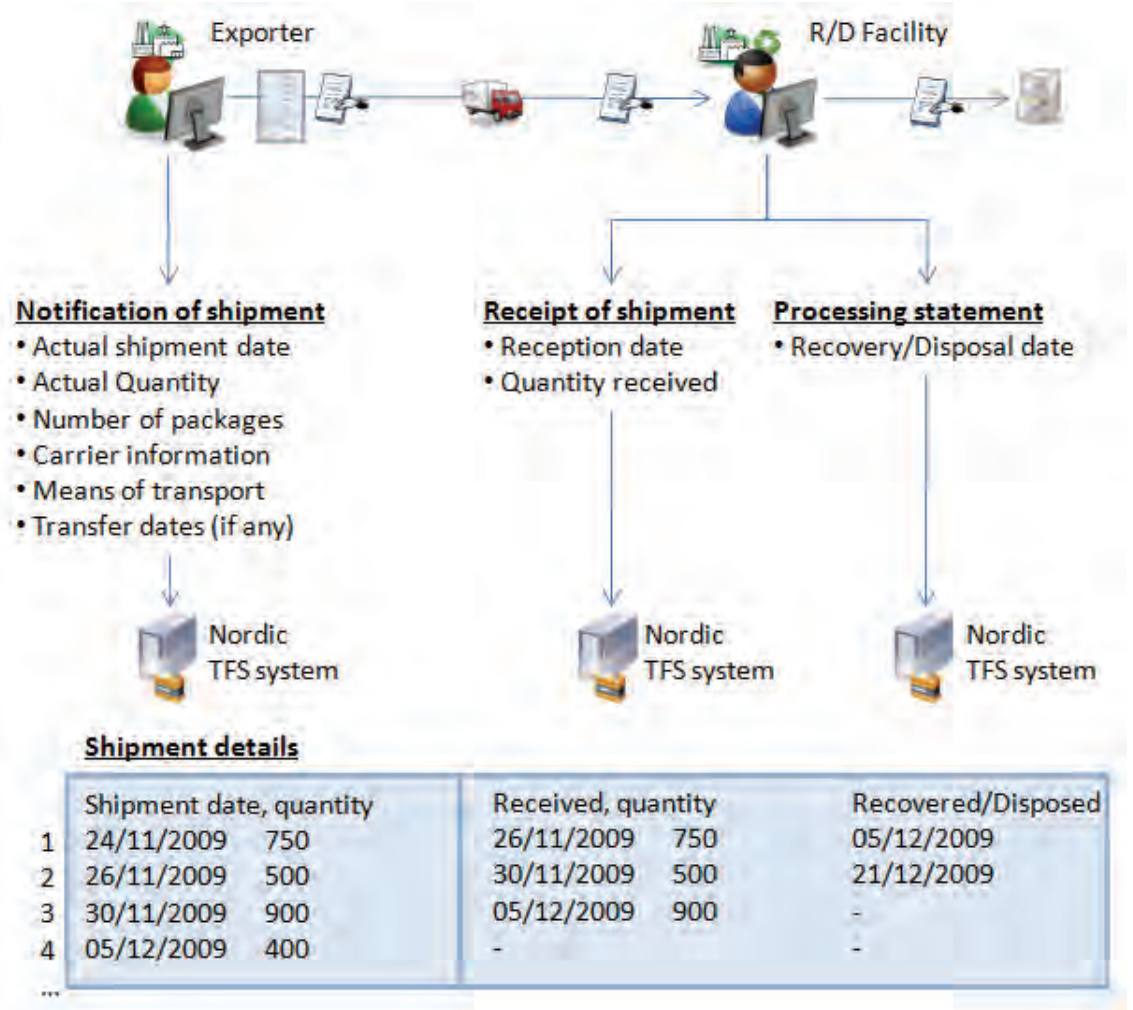

\footnotetext{
${ }^{78}$ If the function of registration of all intended carriers have been implemented this will have to be
} one of those previously registered carriers and the information may not be changed by the exporter. 


\subsubsection{Register receipt of shipment}

Registration of receipt of shipment can be done by the receiving facility (or by the Nordic Exporter in cases with non-participating non-Nordic facilities). The registration of a receipt of shipment can only be done for notifications with registered shipments and only for those shipments that have not yet been updated with information about reception date and quantity received.

The registration is done by selecting a notification and a notified shipment. Reception date and received quantity is registered for the relevant shipment and the Nordic TFS-system then send an automated e-mail to the Exporter with information about the reception of the shipment.

If the shipment is rejected by the facility for any reason, this should be immediately reported to the competent authorities involved. This information is also registered on the relevant shipment and the Nordic TFS-system send an automated alert e-mail to the involved Competent Authorities (and the Exporter) containing information that the shipment has been rejected.

\subsubsection{Register processing statement}

Registration of processing statement is done by the same stakeholders and in almost the same way as the registration for receipt of shipment described above. The difference is that it could only be done for shipments that have been registered as received and contain reception date and quantity received. The processing statement marks the end of the current shipment and the user register the date in which the waste was recovered or disposed.

This registration must be done within 30 days of treatment and no later than one calendar year after receiving the waste. Received shipments that have not been registered as recovered or disposed of within the one calendar year will be reported to the competent authorities by the Nordic TFS-system.

If there are no ongoing shipments related to the registered processing statement the system should ask the user about the intention of any further shipments related to this notification. The user should be offered the opportunity to close the notification if no further shipments will be registered to this notification.

\subsubsection{Revoke shipment}

A notified shipment for which the transportation has not yet begun (and is not registered as received) can be revoked by the Exporter. Revoked shipments remain registered with transport number, weight etc. but are not included in the calculated values for remaining weight purposes.

The transport number will not be re-used and the shipment has to be registered with a new transport number if the shipment will take place at a later date than originally intended. 


\subsubsection{Print movement document}

It should be possible to print movement documents at any time after the registration of a notification. The movement document should have the layout of the Annex 1B in EC-regulation 1013/2006 and should contain all information available for the relevant fields. The amount of information printed on the movement document depends on how far the notification and/or tracking procedures have gone.

Movement documents for registered but not yet decided notifications contain basic information from the notification object, this includes

- Notification number

- Exporter, importer, waste producer and facility information

- Waste characteristics and codes

Movement documents for registered and consented notifications also contain information on "Total number of shipments". When the Exporter have registered a notification of shipment for a valid consented notification, the movement document contain the additional information of

- Actual shipment date

- Actual Quantity

- Number of packages

- Carrier information (up to three carriers)

- Means of transport

- Transfer dates (if any)

If the movement document is printed for shipments that have been received, recovered or disposed of, the movement document also contain information on

- Reception date

- Quantity received

- Recovery/disposal date (if any)

The "original" movement document which should be signed by the Exporter and accompanying the carrier/carriers during transport is printed by the Exporter and after the Exporter have registered a shipment to the relevant notification. Other printed versions of the movement document are not considered valid movement documents (e.g. movement documents printed prior to notification of shipment with a handwritten transport number) but can be printed for other purposes (e.g. internal record keeping). 
ANNEX IB

Movement document for transboundary movements/shipments of waste

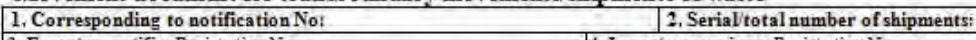

3. Expor

Addrass:

Tel:

2.Serial total number of shipments:

EU

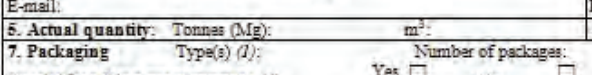

Special hand ling requirements: (2) Yes Number of packagas:

8.(a) $1^{\text {th Carrier (3): }}$

Registration No:

Name:

Addras:

Tel:

E-mail:

8.(b) $2^{\text {sa }}$ Camier

4. Importer - consignee Registration No:

ddress:

Contact person:

The.

\begin{tabular}{l|l} 
Registration No: & 8.(c) Last Camier \\
Registion
\end{tabular}

. Actual date of shipment.

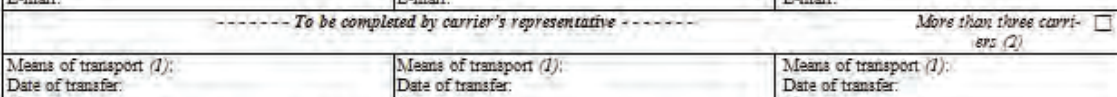

\begin{tabular}{l|l|l}
\hline Date of transfer. & Date of transfer: & Date of transfer \\
Signature: &
\end{tabular}

\begin{tabular}{l|l} 
Signathe: & Signature: \\
$\begin{array}{l}\text { 9. Waste generator(s) - producer(s) (4:5;.): } \\
\text { Regiatration No: }\end{array}$ & 12. Designation and composition of the waste (2):
\end{tabular}

Regiatration No:

Nadies:

Contact person:

Far:

E-mil:

10. Disposal facili

Registration No:

Name:

Contact person:

Tel:

E-mail:

Name:

No:

Fax:

disposal recovery (2)

11. Disposal/recorery operation(s)

D-coda / R-code (1)

15. Exporter's - notifier's / generator's - producer's (4) declaration :

I certify that the above information is complete and corret to $m y$ bast lnowladge. I also certify that legally enforceable written contractual obligation have been entered into, that any applicable insurance or other financial guarantes is in force covering the transboundary movemant and that all nec sary consents have ban received from the compatent authorities of the countrias concamed. Signature
Name

16. For use by any person involved in the transboundary movement in case additional information is required

17. Shipment received by importer - consignee (if not facility): Date: Name: $\quad$ Signanter

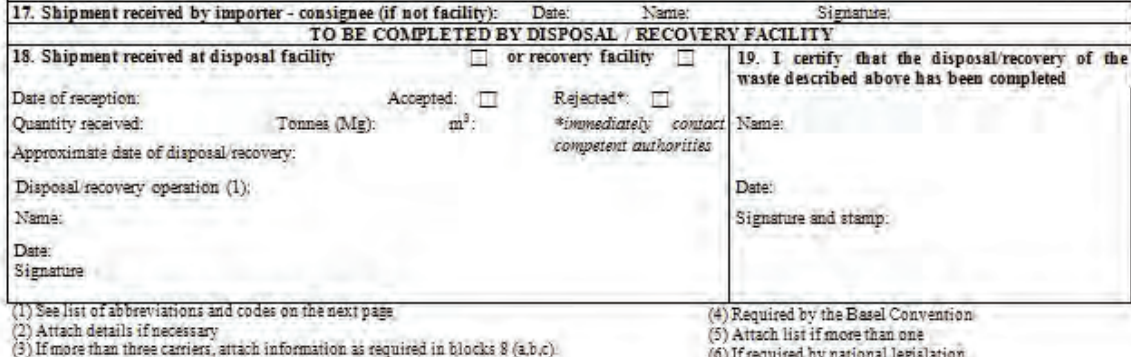

Front of Movement document (above). 


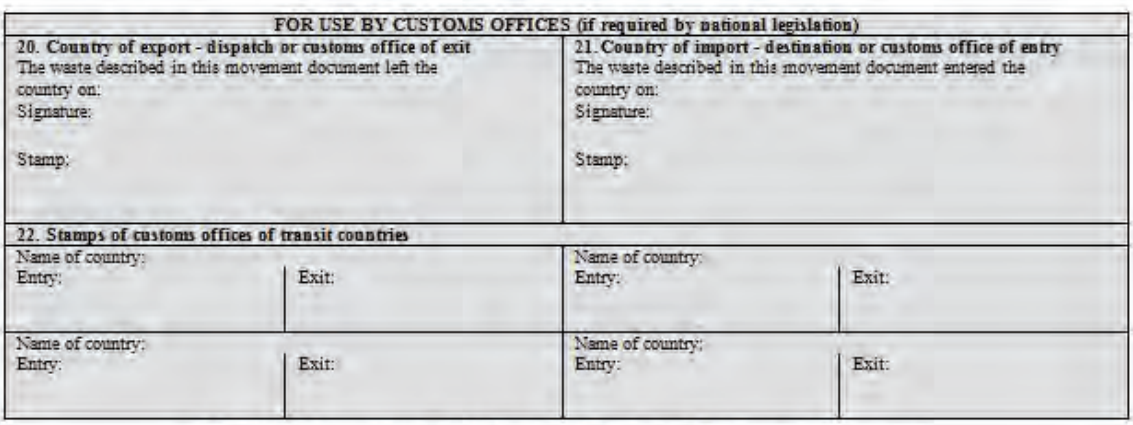

List of Abbreviations and Codes Used in the Movement Document

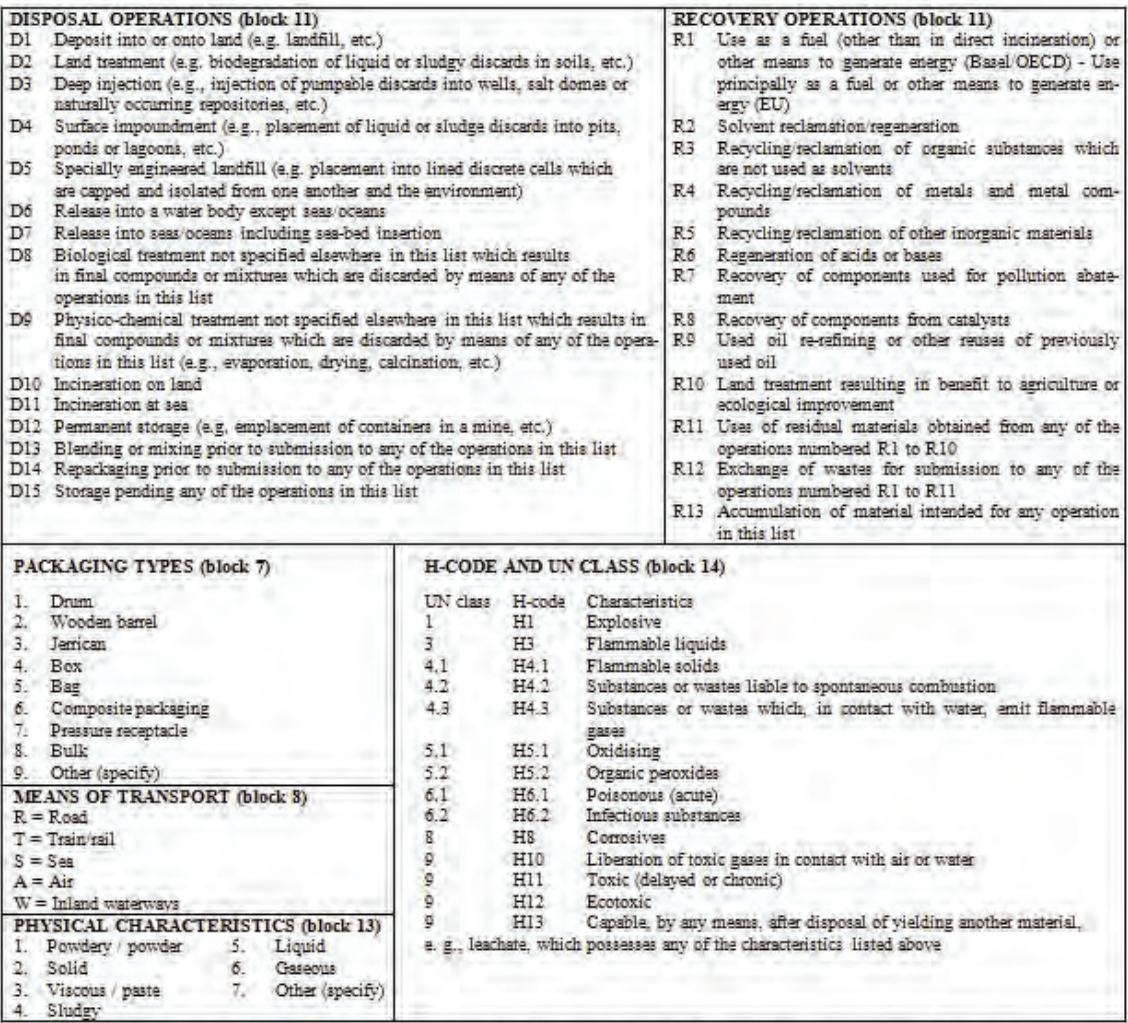

Further information, in particular related to waste identification (block 14), i.e. on Basel Anneres VIII and IX codes, OECD codes and Y-codes, can be found in a Guidance/Instruction Manual available from the OECD and the Secretariat of the Basel Convention.

Back of Movement document (above).

\subsubsection{Export overview or shipment to Excel or XML}

The Nordic TFS-system should provide a function which can export an overview (see "Present Notifications" above) or one particular shipment as a Microsoft Excel file or as a XML-file. This export should contain the same information as the relevant list of shipments. This function could be used by Exporters and other stakeholders for statistical, importing or other desired purposes but is not considered vital to the solution. 


\subsubsection{Present shipments per country}

It should be possible (but not essential) to be able to present shipments per country (or all countries) as well as one of the following (stakeholder, type, notification number, official and status). These views can be used for several purposes

- Finding shipments that have not been received for a certain amount of time after notifying the shipment

- All shipments related to a stakeholder (e.g. all shipments received by a Facility)

- All ongoing or notified shipments bound to or from a particular country (e.g. for use by customs, police etc.)

These views are presented on screen in the same way as lists of notifications etc. and should be able to be exported in the same way and format as the other lists (see Export to Excel or XML).

\subsubsection{Warning functions}

The Nordic TFS-system should include some warning functions to help officials of the competent authorities involved in monitoring the registered notification of shipments. Since the sheer number of notification of shipments (approximately 70,000 each year) compared to the number of officials managing the notification and tracking procedure (3-5 in each country) make it quite impossible to keep manual control of all registered shipments, it is suggested that the system include some warning functions to help monitoring the shipments. The following are suggested warning functions that would help to improve monitoring actions

- Rejected shipments

- Shipped but not received shipments

- Received but not recovered or disposed within one calendar year from reception date

- Ongoing shipments on expired notifications

Rejected shipments should be received by automated e-mail when a facility register a rejection in the same way as other automated e-mail described in this report.

Shipped but not received shipments should be a Query that an official can make at any time (but could be a weekly or monthly report) and should contain registered shipments which have not been registered as received within a certain amount of time.

Received but not recovered or disposed within one calendar year from reception date should also be Query that an official can make at any time, but could be a weekly or monthly routine check. 
Ongoing shipments on expired notifications could happen if the registration of a notification of shipment is made prior to the expiration date of the notification but no receipt of shipment has been registered before the notification expires. This could be implemented as an immediate response or as a weekly or even monthly routine.

\subsection{Support procedures requirements}

\subsubsection{Support procedure requirements}

The following functions and requirements need to be fulfilled within the Nordic TFS-system to adhere to the solution described in chapter 2 of this report.

- Present stakeholder list

- Register stakeholder

- Edit stakeholder information

- Copy stakeholder information to notification or movement object

- Adding or removing users

- Register non-Nordic import notifications

- Export Basel report

\subsubsection{Present stakeholder list}

The list should contain stakeholders for a given country and should present type and stakeholder information (e.g. Name, address etc). It should be possible to filter and/or sort the contents.

\subsubsection{Register stakeholder}

Registration as a stakeholder should be provided through a webpage without prior registration. The information is registered by the internet user and the following information can (or in some cases must*) be registered

- Country*

- Type of stakeholder*

- Registration number

- Name*

- Address

- Contact person

- Phone and Fax

- E-mail* 
And if the stakeholder is a R/D-facility the following information could be registered

- Recovery facility (yes/no)

- Disposal facility (yes/no)

- Site information

The information is stored along with the $\mathrm{IP}^{79}$-address used for registration of the information. Registration of additional user can also be done by providing the information described in "Adding or removing users" below.

Information is sent by automated e-mail to the competent authority which can then confirm the registration by checking the information and that the registered stakeholder has the right to act as a registered stakeholder of that type. If the stakeholder is approved an e-mail containing account and password information is sent out to the registered e-mail address and the user can start using the system. The user must change password the first time he or she access the Nordic TFS-system.

\subsubsection{Edit stakeholder information}

Any user registered to the stakeholder who has been given editing rights can change stakeholder information for the stakeholder to whom he or she is registered to as a user. All information can be changed except for the internal record number of the stakeholder. Mandatory fields must still be filled and valid.

The information changed does not affect already registered notifications and are only used for notifications registered after the change has been done and only as a way of registration help.

\subsubsection{Copy stakeholder information}

When registering a notification the system should contain a "copy stakeholder" function that based on the internal number, registration number or name collect and automatically complete the appropriate blocks of information given in the annex IA of the EC-regulation 1013/2006 Notification document.

These blocks (1, 2, 8, 9 and 10) contain information of the different stakeholders. Block 1 contains Exporter information and should be completed with stakeholder information related to the user which is currently doing the registration (except for users of competent authorities, where the block is left empty). All other blocks can be automatically completed by entering an existing registration number or name for the appropriate type of stakeholder. Information "copied” in this way can be altered in the notifica-

\footnotetext{
${ }^{79}$ An Internet Protocol (IP) address is a numerical label that is assigned to devices participating in a computer network utilizing the Internet Protocol.
} 
tion; however changes to company name, registration number and/or e-mail addresses have to be made by using the edit stakeholder information function.

\subsubsection{Adding or removing users}

If additional users are needed this can be achieved by accessing the stakeholder information page with an account which have editing rights to the relevant stakeholder. The names, e-mail and rights of these new accounts can then be registered and e-mails containing account and password information can be sent out.

Accounts with editing rights can also remove existing users, such changes are always logged and the user should take care not to remove the last account with editing rights as this will effectively hamper the possibilities of executing the digital reporting of the stakeholder.

\subsubsection{Register non-Nordic import notifications}

This registration is described above in " 3.2 Notification procedure requirements" and is done much in the same way as the normal Notification registration.

\subsubsection{Export Basel Report}

This function should based on a given country and a given year create a new Microsoft Excel-file containing the following two sheets

- Export < given year $>$

- Import < given year $>$

These sheets should contain the following columns

- Country of ...(export or import)

- Y-code

- Waste streams

- Annex VIII

- UN class

- H-code

- Characteristics

- Amount ... (exported or imported) in metric tons

- Country of Transit

- Country of ... (destination or origin)

- D-code

- R-code 
The amount information for export should be based on a calculated sum of the "Actual quantity" field for all registered notified (not revoked) shipments for the given country and year (using "Date of shipment" for determination purposes). The information is grouped by all of the other columns given so that the total amount is given for a waste with the same Y-code, Dcode etc.

The amount information for import is calculated in a similar way but uses the "Quantity received" field for the given country and year. And it uses the "Date of reception" instead of "Date of shipment". The sheet can thereafter be edited in any way desired before making the official Basel report available. An example of the Excel file is given below

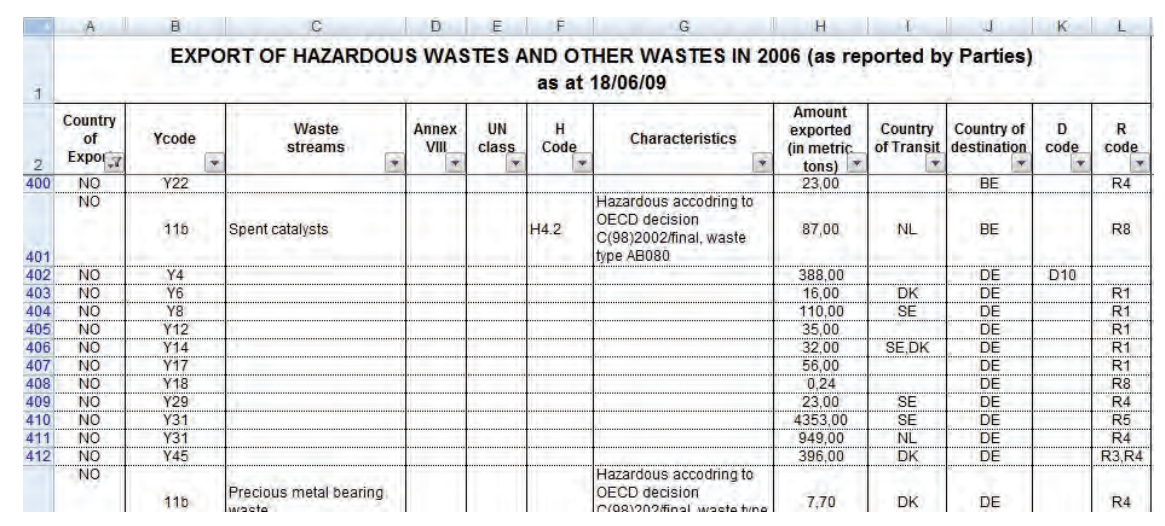





\section{References}

José, M. \& Ariño, N. (2007): Problems with interoperability in the context of transfrontier hazardous waste management SEEMSEED project. Insituto Tecnológico del Mueble, Madera, Embalaje y Afines: 7-11.

Vavalo, M. \& Minguet, R. (2005): Presentation SEEMSEED. FCV, Brussels.

Fundació Fòrum Ambiental \& Atos Origin (2006): Libro Blanco de Tecnologias de la Informacion aplicadas al sector Residous Industriales. Barcelona Atos Origin.

ATOS Press release 2006-05-02 http://www.atosorigin.com/enus/Newsroom/en-us/Press_Releases/ 2006/2006_05_02_01.htm.

Fundació fòrum ambiental. (2008): Filosofía y Objetivos

http://www.eterproject.org/.

IREALP Newsletter n.11-18 dicembre 2008: http://www.irealp.it

Matonti F. \& Allevi, I. (2008): Presentation IREALP. Istituto di Ricerca per l'Ecologia e l'Economia Applicate alle Aree Alpine.

Allevi, I, Caffi, C, Gelmini, A, Grimaldi, L, Matonti, F, Pedrana, M.G., Scuratti, M. \& Soldavini, G. (2008): Stazioni GNSS permanenti a supporto del monitoraggio di veicoli e persone. IREALP

Ternoy, M. (2008): Mise en oeuvre du règlement 1013-2006. Ministère de l'Écologie, de l'Energie, du Développement durable et de la Mer Presentation, Le Havre Séminaire 2008.

European Commission. (2004): Detailed Twinning "light” Project Fiche 2004/16762.07.01.

Glasel, C. (2009): Experiences with notification of shipment of waste. BMLFUW.
Celarc, S., Zupančič, I.E. \& Vihtelič, A. (2008): ARSO Userguide 1.3; 8-9.

Lebensministerium. (2006): Federal Waste Management Plan 2006. Federal Ministry of Agriculture and Forestry, Environment and Water Management; 124129.

Environment Canada. (2008): Evaluation of Enhanced Security for the transboundary Movement of Hazardous Waste: Lessons Learned available at http://ec.gc.ca/doc/ae-ve/200809/602/p3_eng.htm.

Ching-Shi Yang \& Soon-Ching Ho. (2007): e-Revolution and Mobilization of Waste Management in Taiwan, extended abstract \#333. EPA, Taiwan.

EPA. (2005): Taiwan's Waste Import/Export Control Measures. Environmental Protection Administration, Taiwan; 2-5.

Technical Adaptation Committee. (2004): EUDIN project description. TAC, Brussels.

Flor, E. (2002): First Steps Towards an International Standard in Waste Data Interchange. Condat AG; page 3.

Wuttke, J. (2002): Experiences with Electronic Data Interchange for Waste Management in Germany. FEA, Berlin.

SenterNovem. (2009): Gebruikersinstructie EM, SenterNovem; 5-8.

VeriSign, Inc, (2004): Digital ID A Brief Overview. VeriSign WebPage.

Secretariat of the Basel Convention, (2007): Part II Annual Reporting (Section A). www.basel.int National reporting. 



\section{Sammanfattning}

\subsection{Digital rapportering för gränsöverskridande transporter av avfall}

Rapporten innehåller en omvärldsanalys och ett förslag till lösning för att erbjuda de Nordiska länderna ett sätt att hantera processerna kring anmälan och rapportering av transportdokument genom digital rapportering istället för dagens pappersbaserade processer. Omvärldsanalysen omfattar alla 27 EU-medlemsländer och tre ytterligare länder.

Såvitt denna rapport har kunnat avgöra har inga av de undersökta länderna en digital lösning för alla TFS-processer och endast tre av länderna har en nationell eller regional lösning när det gäller digital rapportering av transportdokument. Däremot har flera av länderna implementerat eller är på gång att implementera digital rapportering som ett koncept för andra typer av processer (ex. nationell rapportering av avfall).

Huvuddelen av the undersökta länderna använder fortfarande en pappersbaserad process och förväntas göra detta även fortsättningsvis baserat på det låga antal pågående projekt som har som mål att erbjuda digital rapportering inom TFS-processerna.

Digital rapportering för TFS-processerna kan minska administrativa kostnader, öka kvalitén samt snabba upp informationsutbytet mellan the inblandade intressenterna samtidigt som man sparar värdefull tid och pengar som kan användas till övervakning och kontroll istället för till administrativt arbete. Lösningen som beskrivs i rapporten föreslår ett Nordiskt TFS-system som täcker både processen för anmälan och processen för rapportering av transportdokument, och även om rapporten förslår en initial begränsning av lösningen till de Nordiska länderna så är systemet designat så att det enkelt går att lägga till ytterligare deltagande länder. Huvudkomponenterna i lösningen täcker följande aktiviteter

- Registrering av intressenter (exportörer, anläggningar m.fl.)

- Digital registrering av export anmälan

- Digital registrering av icke-nordisk import anmälan

- Export/Import av data från Anmälan via XML till Nationella TFSsystems

- Automatisk bekräftelse av anmälan via e-post

- Registrering av beslutsdata

- Digital rapportering av transportdokument

- Automatisering av den årliga rapporteringen till Basel 
Lösningen är baserad på antagandet att inte alla inblandade länder kommer delta i lösningen och att vissa centrala dokument (t.ex. original anmälan, transpordokumentet och bankgarantin m.fl.) behöver finnas kvar i pappersform men att man ersätter kopior av dessa med elektroniska kopior, digital rapportering och e-post.

Detta sätt att hantera lösningen ger möjlighet till ett gradvist införande och gör anslutandet av ytterligare länder relativt enkelt, samtidigt som man tillgodogör sig många av fördelarna utan att inblandade intressenter för den skull behöva göra stora investeringar i IT-infrastruktur.

\subsection{Rekommendation}

Baserat på vad som framkommit i rapporten rekommenderar författaren de ansvariga myndigheterna i de Nordiska länderna (Danmark, Norge, Finland och Sverige) att designa och bygga ett Nordiskt TFS-system för digital rapportering med den funktionalitet och funktioner som finns beskriven för lösningen i kapitel 2 och kapitel 3.

Detta kan göras som ett sammanhållet projekt med design, detaljerade krav, utveckling, test och implementering eller så kan det delas upp i två projekt där det första levererar en komplett systemlösning inklusive specifikationer m.m. följt av ett andra projekt som konstruerar, testar och implementerar det Nordiska TFS-systemet.

Projekten bör vara gemensamma med representanter från de Nordiska ländernas myndigheter, representanter från företagen och IT-företag som specialiserat sig på design och konstruktion av internet applikationer.

Finansiering och ägarskap av det Nordiska TFS-system kan lösas på flera olika sätt, där finansiering och ägande antingen sker gemensamt med en engångsinsats följt av ett gemensamt årligt underhållsansvar alternativt skulle myndigheterna kunna behålla ägandet av informationen och istället betala årliga licensavgifter för användandet av ett TFS-system som ägs och underhålls av ett privat företag.

Rekommendationen är att bygga och implementera det Nordiska TFSsystemet som en helhet och där systemet omfattar både processerna för anmälan och transportdokument i linje med de krav som beskrivs i kapitel 2 och kapitel 3 i rapporten. Om detta bedöms som för dyrt eller tidskrävande rekommenderas ett alternativ där systemet täcker digital rapportering av transportdokument samt funktionalitet för att registrera beslutdata.

Ytterligare expansion av deltagande länder bör göras efter systemet har byggts och testats klart av de Nordiska länderna och bör koncentreras till de icke Nordiska länder ${ }^{80}$ som har ett stort antal årliga anmälningar för transporter till eller från ett Nordiskt land för att maximera nyttan med systemet.

${ }^{80}$ Se Annex I, II, III och IV för avfallsflödet till och från de Nordiska länderna. 


\section{Annex I}

\section{TFS information for Sweden}

\begin{tabular}{|c|c|c|c|c|}
\hline \multirow[b]{2}{*}{ Competent authority: } & \multicolumn{4}{|c|}{ The Environmental Protection Agency (SEPA) } \\
\hline & 1 on National level & TFS experts: & 3 & National \\
\hline Membership: & EU (1995), Schengen, OECD & Decisions on internet: & No & \\
\hline Notifications/year: & 600 & Internal TFS system: & Yes & \\
\hline Movement documents: & - & External TFS system: & No & \\
\hline
\end{tabular}

SEPA TFS webpage: http://www.naturvardsverket.se/sv/Produkter-ochavfall/Avfall/Hantering-och-behandling-av-avfall/Gransoverskridandetransporter-av-avfall/

The Swedish Environmental Protection Agency (SEPA) has a webpage with information on

- Regulations (e.g. 1013/2006)

- Guides (e.g. completing applications)

- Lists of recovery facilities

The Swedish SEPA uses a case management system called MODENA for the registration of single and general notifications. The MODENA system was implemented in early 2010 and is based upon the iipax system software. SEPA is involved in a Nordic cooperation together with Norway, Finland and Denmark. The Nordic countries is looking at the different digital solutions available and are also looking at the possibility of developing a solution for the Nordic countries, whereas this pre-study is part of that work.

The number of notifications managed by the Swedish SEPA is evenly divided between import and export and $63 \%$ of the import notifications come from other Nordic countries (with Norway being the largest exporter). The Swedish export notifications are mainly directed to Germany and the Nordic countries ( $49 \%$ of the notifications). 


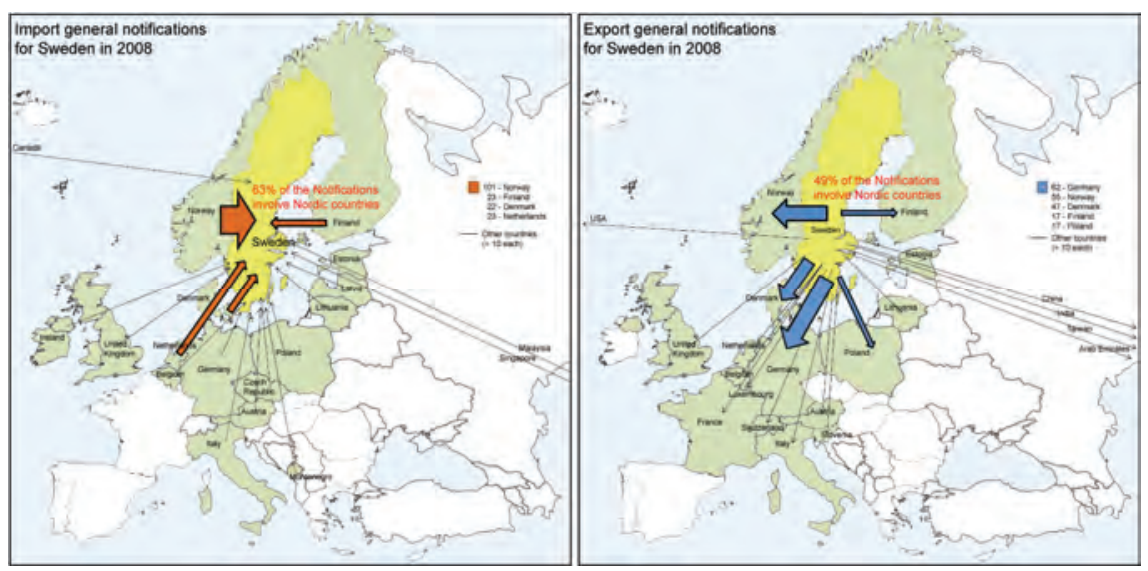




\section{Annex II}

TFS information for Norway

\begin{tabular}{lllll} 
& \multicolumn{5}{c}{ Norwegian Climate and Pollution Agency (KLIF) } \\
\cline { 2 - 5 } Competent authority: & $\mathbf{1}$ on National level & TFS experts: & 5 & National \\
\hline Membership: & OECD & Decisions on internet: & No & \\
Notifications/year: & $\mathbf{3 0 0}$ & Internal TFS system: & Yes \\
Movement documents: & - & External TFS system: & No & \\
\hline
\end{tabular}

TFS Webpage

(Norwegian Climate and Pollution Agency): http://www.klif.no/no/Tema/ Avfall/Eksport-og-import-av-avfall/

(State of the Environment Norway) http://www.environment.no/Tema/ Avfall/Import-og-eksport-av-avfall/

\section{Description:}

The Norwegian Climate and Pollution Agency (KLIF) has a webpage with information on

- Regulations (e.g. 1013/2006)

- News (e.g. new regulations)

- Lists of waste codes

The Norwegian Climate and Pollution Agency uses a case management system called ePhorte and has a database called Miljødata for the registration of single and general notifications and it contains data from 2002 until today. The Climate and Pollution Agency is involved in a Nordic cooperation together with Sweden, Finland and Denmark. The Nordic countries is looking at the different digital solutions available and are also looking at the possibility of developing a solution for the Nordic countries, whereas this pre-study is part of that work.

The number of notifications managed by the Norwegian Climate and Pollution Agency is approximately two-thirds export and one third import notifications. 73\% of the export notifications involve Nordic countries (with more than half directed to Sweden) and $81 \%$ of the import notifications come from other Nordic countries (with Sweden and Denmark as the largest exporters). 


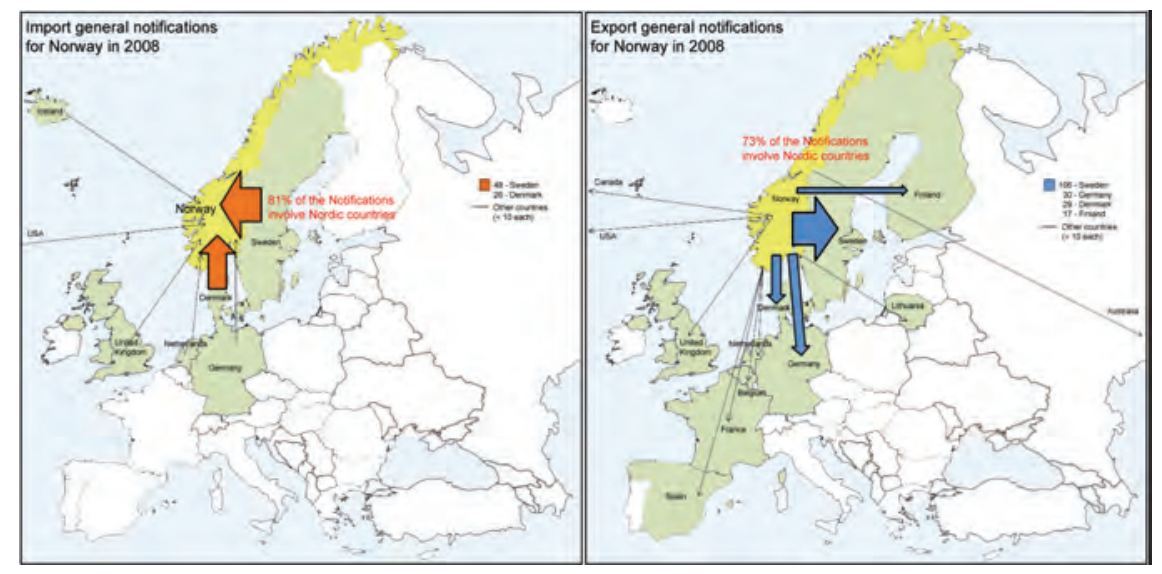




\section{Annex III}

\section{TFS information for Finland}

\begin{tabular}{|c|c|c|c|c|}
\hline \multirow[b]{2}{*}{ Competent authority: } & \multicolumn{4}{|c|}{ The Finnish Environment Institute (SYKE) } \\
\hline & 1 on National level & TFS experts: & 4 & National \\
\hline Membership: & EU (1995), Schengen, OECD & Decisions on internet: & Yes & \\
\hline Notifications/year: & 138 & Internal TFS system: & Yes & \\
\hline Movement documents: & 3,552 transports $(2008)$ & External TFS system: & No & \\
\hline
\end{tabular}

\section{TFS Webpage}

(The Finnish Environment Institute): http://www.ymparisto.fi/default.asp? node $=20999 \&$ lan $=\mathrm{fi}$

(Valid notifications): http://www.ymparisto.fi/default.asp?node=21554\&lan=en

\section{Description:}

The Finnish Environment Institute (SYKE) has a webpage with information on

- Regulations (e.g. 1013/2006)

- Authorization procedures

- Valid notifications presented monthly (Pdf file)

- Valid recovery and disposal permits

- Multi-language support (English, Swedish, Finnish)

The Finnish SYKE uses an access database called BASEL for registration of single and general notifications. The system has been active since 1995 and contains notification data from 1993 until today. SYKE also uses a CMSsystem for environmental data collection called VAHTI.

SYKE is involved in a Nordic cooperation together with Sweden, Norway and Denmark. The Nordic countries is looking at the different digital solutions available and are also looking at the possibility of developing a solution for the Nordic countries, whereas this pre-study is part of that work.

The number of notifications managed by the Finnish SYKE is evenly divided between import and export and $44 \%$ of the import notifications come from other Nordic countries, with Sweden being the largest exporter. The Finnish export notifications are mainly directed to Sweden (38\% of the notifications) and Germany. 


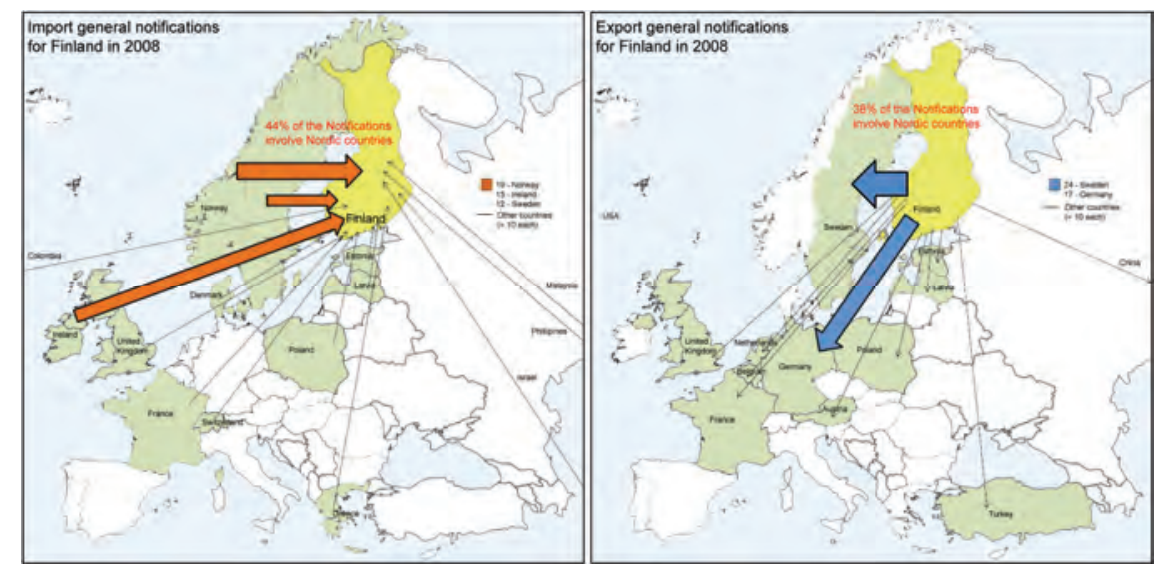




\section{Annex IV.}

\section{TFS information for Denmark}

\begin{tabular}{|c|c|c|c|c|}
\hline \multirow[b]{2}{*}{ Competent authority: } & \multicolumn{4}{|c|}{ Danish Environmental Protection Agency (EPA) } \\
\hline & 1 on National level & TFS experts: & $3-4$ & National \\
\hline Membership: & EU (1973), Schengen, OECD & Decisions on internet: & No & \\
\hline Notifications/year: & 400 & Internal TFS system: & Yes & \\
\hline Movement documents: & - & External TFS system: & No & \\
\hline
\end{tabular}

TFS Webpage (English and Danish version):

http://www.mst.dk/English/Soil+and+Waste/Shipment_of_waste/

http://www.mst.dk/Affald/Import_og_Eksport_af_affald_Shipments_of_waste/

\section{Description:}

The Danish Environmental Protection Agency (EPA) has a webpage with information on

- Regulations (e.g. 1013/2006)

- Guides (e.g. completing applications)

- Waste lists

- Examples

- Links to useful information

The Danish EPA uses an access database called Affaldstransportdatabase for registration of single and general notifications. EPA also uses a CMS system called Captia for general case management.

EPA is involved in a Nordic cooperation together with Sweden, Norway and Finland. The Nordic countries is looking at the different digital solutions available and are also looking at the possibility of developing a solution for the Nordic countries, whereas this pre-study is part of that work. 



\section{Annex V.}

\section{Other examined countries WebPages on transboundary movements of waste}

Austria

http://www.umweltnet.at/article/archive/7510

Belgium

http://www.bruxellesenvironnement.be/Templates/Professionnels/Informer.a spx?id=1462\&langtype $=2060$

Bulgaria

http://www.moew.government.bg/waste/transboundary.html

\section{Canada}

http://www.ec.gc.ca/drgd-wrmd/default.asp?lang=En\&n=FDC36D83-1

Czech Republic

http://www.mzp.cz/cz/preshranicni_preprava_odpadu

\section{Estonia}

http://www.envir.ee/967899

France

http://www.ecologie.gouv.fr/Bordereau-de-suivi-des-dechets,4534.html

Germany

(See the 16 Federal States, below)

Hungary

http://www.orszagoszoldhatosag.gov.hu/index.php?akt_menu=247

Ireland

http://www.dublincity.ie/waterwasteenvironment/waste/wastecollectors/national_tfs_office/pages/nationaltfsoffice.ASPX

Italy

http://www.minambiente.it/opencms/opencms/home_it/menu.html?menuIte $\mathrm{m}=/ \mathrm{menu} / \mathrm{menu}$ _informazioni/Rifiuti_e_bonifiche.html\&menu=/menu/menu 
_informazioni/argomenti.html//menu/menu_informazioni/Rifiuti_e_bonifich e.html

http://www.ors.regione.lombardia.it/cm/pagina.jhtml?param1_1=N1201947 add0e902cfc8

\section{Luxembourg}

http://www.environnement.public.lu/guichet_virtuel/GV_dechets/GV_transf ert/index.html

Malta

http://www.mepa.org.mt/waste-tfs

Netherlands

http://www.senternovem.nl/uitvoeringafvalbeheer/Afval_over_de_grens/ind ex.asp

Poland

http://www.gios.gov.pl/index7.php?temat=197

Romania

http://www.mmediu.ro/departament_mediu/gestiune_deseuri/transport.htm

Slovakia

http://www.enviro.gov.sk/servlets/page/868?c_id=2908

\section{Slovenia}

http://www.arso.gov.si/varstvo\%20okolja/odpadki/po\%C5\%A1iljke\%20pre ko\%20meja/

Spain

http://www.mma.es/portal/secciones/calidad_contaminacion/residuos/proced imiento_control/index.htm

\section{Taiwan}

http://waste.epa.gov.tw/prog/indexFrame.asp?Func=eng

http://waste.epa.gov.tw/export/main.asp

\section{United Kingdom}

http://www.environment-agency.gov.uk/business/topics/waste/32196.aspx http://www.sepa.org.uk/waste/waste_regulation/transfrontier_shipment.aspx http://www.ni-environment.gov.uk/waste-

home/regulation/transfrontier_shipment_of_waste.htm 
Federal states of Germany

Baden-Württemberg

http://www.um.baden-wuerttemberg.de/servlet/is/1538/

http://www.saa.de/

\section{Bayern}

http://www.lfu.bayern.de/index.htm

http://www.gsb-mbh.de/

Berlin

http://www.stadtentwicklung.berlin.de/

\section{Brandenburg}

http://www.mugv.brandenburg.de/sixcms/list.php/mugv_portal http://www.sbb-mbh.de/

\section{Bremen}

http://www.bauumwelt.bremen.de/de/detail.php?gsid=bremen02.c.1602.de

\section{Hamburg}

http://www.hamburg.de/abfall/

Hessen

http://www.hmulv.hessen.de/

Mecklenburg-Vorpommern

http://www.regierung-

mv.de/cms2/Regierungsportal_prod/Regierungsportal/de/lm/

http://www.lung.mv-regierung.de/

\section{Niedersachsen}

http://www.mu.niedersachsen.de/master/C599_L20_D0.html

http://www.gewerbeaufsicht.niedersachsen.de/master/C7017070_N5954474

_L20_D0_I1717444.htmhttp://www.ngs-mbh.de/

Nordrhein-Westfalen

http://www.umwelt.nrw.de/

http://www.lanuv.nrw.de/

http://www.bezreg-duesseldorf.nrw.de/BezRegDdorf/hierarchie/fehler.php

Rheinland-Pfalz

http://www.mufv.rlp.de/

http://www.sam-rlp.de/ 


\section{Saarland}

http://www.saarland.de/ministerium_umwelt_energie_verkehr.htm

\section{Sachsen}

http://www.umwelt.sachsen.de/umwelt/index.html

http://www.smul.sachsen.de/lfulg/

Sachsen-Anhalt

http://www.sachsen-anhalt.de/LPSA/index.php?id=1743

\section{Schleswig-Holstein}

http://www.schleswig-holstein.de/

http://www.goes-sh.de/

\section{Thüringen}

http://www.thueringen.de/de/tmlfun/content.asp

Note: No specific pages for transboundary movements of waste were found for the following countries:

Iceland, Cyprus, Latvia, Lithuania, Portugal, Greece 